
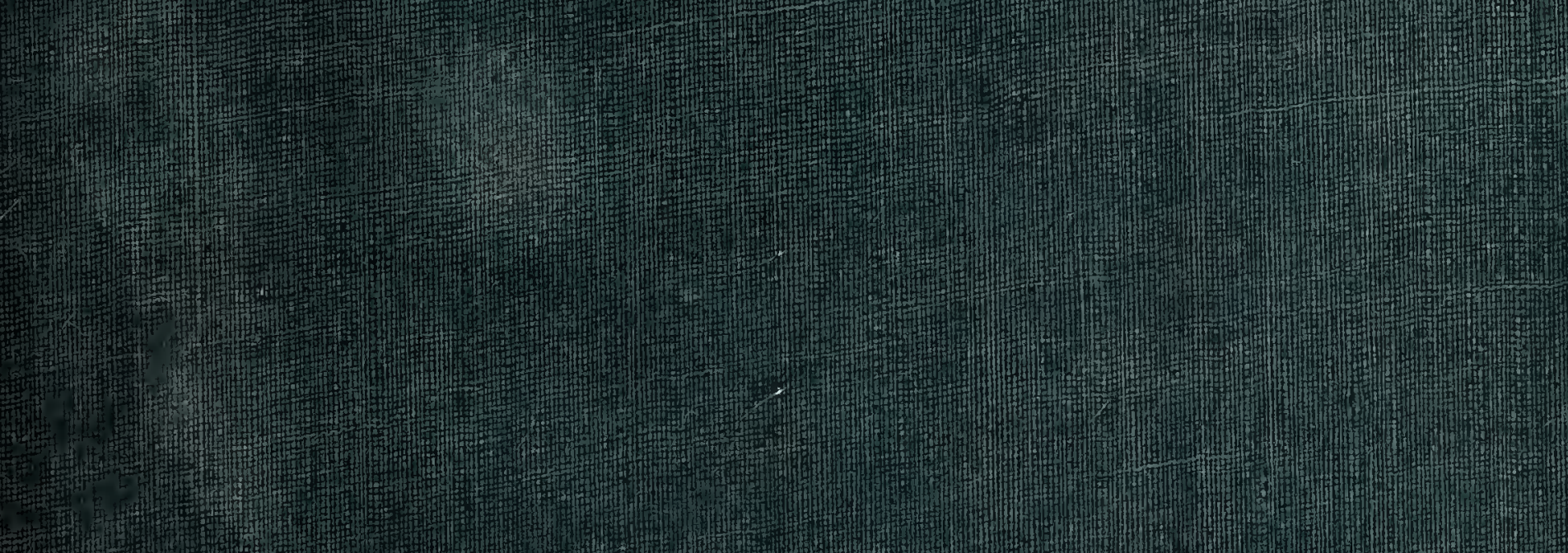


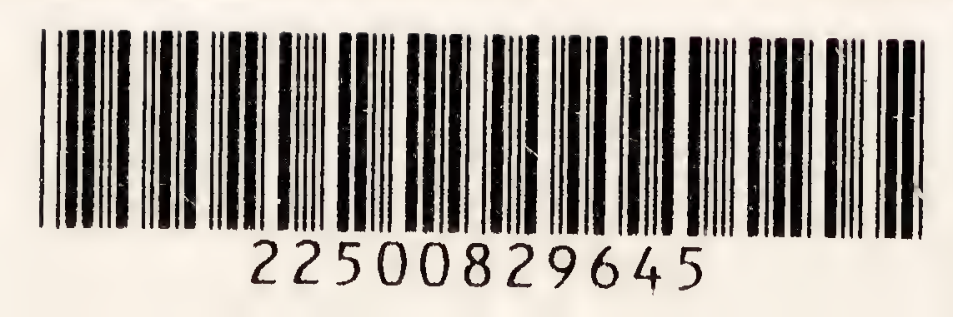


Di. स\%

Med

K4431

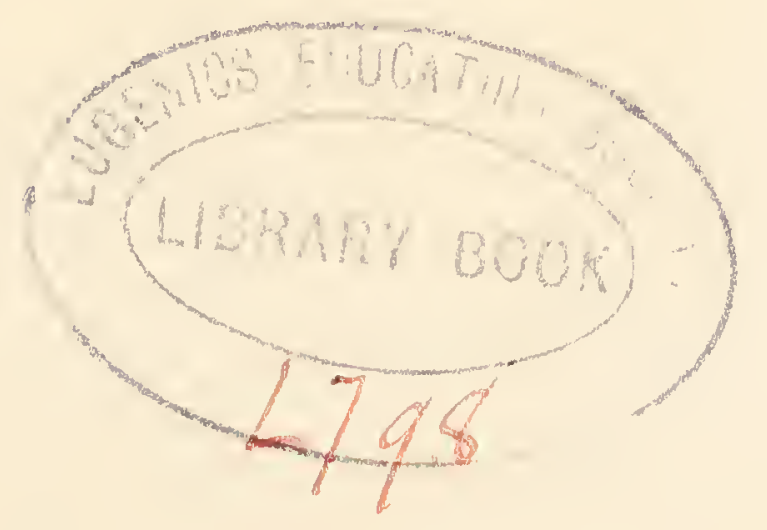


Digitized by the Internet Archive in 2017 with funding from Wellcome Library 
A MANUAL OF MENDELISM 


\section{THE FIRST PRINCIPLES OF HEREDITY}

\section{BY}

S. HERBERT, M.D., M.R.C.S., I.R.C.P.

LARGE CROWN 8Vo. BOUND IN Cloth

$$
\begin{gathered}
\text { Price 5/- NET } \\
\text { (By post, 5/5) }
\end{gathered}
$$

"Dr. Herbert's book can be recommended as a trustworthy 'first aid ' in the study of a difficult subject. His style is lucid and concise, and he has provided a glossary which will be of service to many." -A then aum.

" ' First Principles of Heredity ' gives a popularly written yet scientific account of all that the average educated reader may desire to know about heredity and kindred subjects, without assuming any knowledge of the subject on the reader's part."-Public Opinion.

A. AND C. BLACK LTD., 4, 5 AND 6 SOHO SQ., LONDON, W.

\section{AGENTS}

AMERICA

AUSTRALASLA

CANADA

INDIA
THE MACMILI.AN COMPANY

64 \& 66 FIFTH AVENUE, NEW YORK

THE OXFORD UNIVERSITY PRESS

205 FLINDERS LANE, MELBOURNE

THE MACMILLAN COMPANY OF CANADA LTD

ST. MARTIN'S HOUSE, 70 BOND STREET; TURONTC

MACMILLAN BUILDING, BOMBAY

309 BOW BAZAAR STREET, CALCUTTA 


\section{A MANUAL}

OF

\section{E N D E L I S M}

BY

JAMES WILSON, M.A., B.Sc.

PROFESSOR OF AGRICULTURE IN THE ROYAL COILEGE OF SCIENCE FOR IRELAND, DUBLIN

AUTHOR OF "THE EVOLUTION OF BRITISH CATTLE"

" THE PRINCIPIES OF STOCKBREEDING" ETC.

A. \& C. BLACK, LTD.

$4,5 \& 6$ SOHO SQUARE, LONDON, W.

1916 


$$
5301082
$$

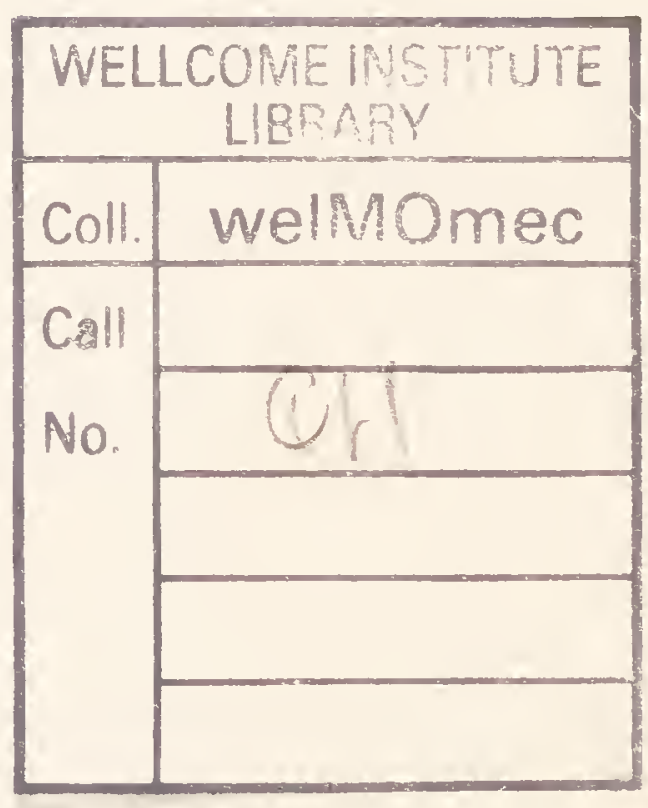


TO

The Late James BRODie, M.A.

MATHEMATICAL MASTER IN

FORFAR ACADEMY

"Aye be true to the line" 


\section{NOTE}

The author of this volume is deeply indebted to a former pupil, Mr. Edmond Sheehy, A.R.C.Sc.I., for having read the proof-sheets and made many valuable suggestions 


\section{CON'TE N'T}

CHAP.

PAGE

I. Mendelo's Experiments 1

II. Mendel's Law 12

III. Observations and Deductions 22

IV. Inseparable Effects $\quad \mathbf{3 0}$

V. Suppressed Effects 42

VI. 'The Absence of Dominance 58

VII. Polygamous Factors 70

$\begin{array}{lr}\text { VIII. Coupling } & 90\end{array}$

IX. Similar Effects 111

$\begin{array}{ll}\text { X. Quantity } & 119\end{array}$

XI. Economic 145

$\begin{array}{ll}\text { INDEX } & 151\end{array}$ 



\section{A MANUAL OF MENDELISM}

\section{I \\ MENDEL'S EXPERIMENTS}

Gregor Mendel, who was abbot of Brünn in the middle of the nineteenth century, was a botanist of unusual accomplishments whose interests lay chiefly in hybridization. In this subject, many botanists had already been at work, but their operations had been accompanied by a serious defect. Hybrids had been bred and observed and some had even been bred from again; but, so far, no hybrids' descendants had been systematically counted and classified, and, in consequence, the knowledge of their reproductive behaviour was neither full nor exact. It was generally believed they did not breed true but threw progeny of different kinds; yet this belief rested upon haphazard observation and, as a useful predictive weapon, was of little or no value. So far, nobody had arranged the progeny of any hybrid in differing kinds and counted either the number of kinds or the individuals in each; and, realizing that, till this were done, the law which governs the reproductive behaviour of hybrids was unlikely to be discovered, Mendel undertook to do what earlier investigators had either overlooked or neglected. Accordingly, he 
decided to breed a number of hybrids and follow their descendants through as many generations as might be necessary, and, to make sure that his materials were suited to his purpose, he laid down the following as the conditions which the plants to be made use of should fulfil :

(a) The parents should differ from each other in clear and well-defined characters.

(b) They should breed true.

(c) They and their descendants should be naturally protected or readily protectable from strange pollen during the flowering season.

(d) Their descendants should not suffer seriously from infertility.

In Mendel's opinion, the plant which fulfilled these conditions best and was, at the same time, easily cultivated was the ordinary edible pea. The seeds of 34 varieties were purchased and two generations grown to discover whether they bred true * before any experiments were begun. Of the 34 varieties 22 were retained, and, for the first series of experiments, 14 were chosen which could be arranged as 7 pairs, in all of which one of each pair differed from the other in one well-defined character. The following table gives the characters in which the members of each pair differed:

In one member

1. The seed-coat was round.

2. The seed had yellow "albumen."

3. The seed-coat was coloured.

4. The pods were plain.

5. The unripe pods were green.

6. The flowers were axial.

7. The stems were 6 to $7 \mathrm{ft}$. long.
In the other

The seed-coat was wrinkled.

The seed had green "albumen." The seed-coat was white.

The pods were constricted.

The unripe pods were yellow.

The flowers were terminal.

The stems were $\frac{3}{4}$ to $1 \frac{1}{2} \mathrm{ft}$. long.

* This treatment was continued till the end of the experiments. 


\section{MENDEL'S EXPERIMENTS}

The two members of each of these seven pairs were then crossed with each other : reciprocal crosses being made in all cases. That is to say: plants having round seeds were crossed with others having wrinkled, sometimes the one kind being the male parent, sometimes the other ; and so on for the remaining pairs.

When grown, the hybrids were found to be like one of their parents only. Those between parents having round seeds and others having wrinkled had round seeds only; those between parents having long stems and others having short had long stems only; and so on. The differing character borne by the second parent had, in all cases, disappeared. By way of designation, Mendel called the parental character transmitted to the hybrid the dominant, that which had disappeared the recessive. Thus, in pea seeds, the round character is the dominant while the wrinkled is the recessive; in stems, the long character is the dominant while the short is the recessive. The following table, in which the characters found to be dominant are printed in capitals and placed in the first column, gives the number of parent plants crossed and the number of successful fertilizations in each of the seven pairs :

$\begin{array}{lc}\text { Plants } & \begin{array}{c}\text { Successful } \\ \text { fertili- } \\ \text { crossed } \\ \text { zations }\end{array}\end{array}$

1. ROUND seeds

$\mathrm{x}$ wrinkled

15

60

2. YELLOW albumen

$\mathrm{x}$ green

10

3. COLOURED seed-coat $x$ white

10

58

4. PLAIN pods

$\mathrm{x}$ constricted 10

35

5. GREEN unripe pods

$\mathrm{x}$ yellow

40

6. AXIAL flowers

$\mathrm{x}$ terminal

5

7. LONG stems

$\mathrm{x}$ short

10

23

34

10 37 
Having bred the hybrids, the next part of Mendel's work, which was that overlooked by earlier observers, was to breed them on to another generation and examine their progeny. Accordingly, seeds of all the seven kinds were sown, and their progeny, when arranged and counted, were found to consist, in every case, of both the original parent kinds again, but in the proportion of three dominants to one recessive. The following table gives the actual figures and their proportions:

Hybrids

1. Round seeds

2. Yellow albumen

3. Coloured seed-coat

4. Plain pods

5. Green unripe pods

6. Axial flowers

7. Long stems
Their Progeny

$\begin{array}{lrlrrr}\text { Round } & 5474 & \text { Wrinkled } & 1850 & 2 \cdot 96: 1 \\ \text { Yellow } & 6022 & \text { Green } & 2001 & 3 \cdot 01: 1 \\ \text { Coloured } & 705 & \text { White } & 224 & 3 \cdot 15: 1 \\ \text { Plain } & 882 & \text { Constricted } & 299 & 2 \cdot 95: 1 \\ \text { Green } & 428 & \text { Yellow } & 152 & 2 \cdot 82: 1 \\ \text { Axial } & 651 & \text { Terminal } & 207 & 3 \cdot 14: 1 \\ \text { Long } & 787 & \text { Short } & 277 & 2 \cdot 84: 1\end{array}$

This result raised the question: Are these hybrids' progeny hybrids again like their parents or truebreeding individuals like their grandparents? To settle it, they, in their turn, were also bred from, and, judged by their progeny, one only in every three dominants bred true while all the recessives did so. The dominants which did not breed true threw dominants and recessives in the proportion $3: 1$, just as their hybrid parents had done, and, by doing so, showed themselves to be hybrids of the same kind. The following table gives the actual numbers of dominants and recessives among the hybrids' progeny which did or did not breed true : 


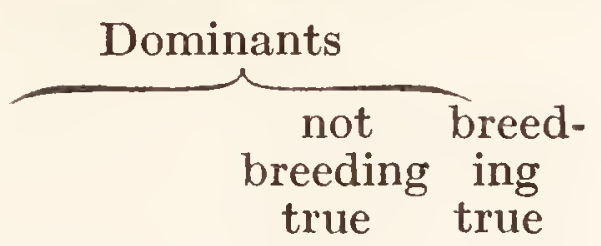

1. Round seed

2. Yellow albumen 353

3. Coloured seed-coat 64 .

4. Plain pods

5. Green unripe pods

6. Axial flowers

7. Long stems
71

60

67

72
Recessives

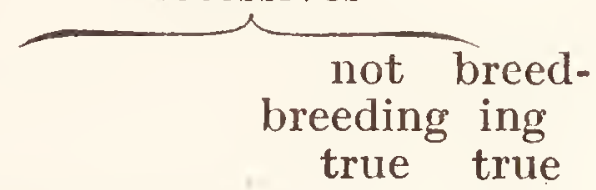

Wrinkled seed 0 all

Green albumen 0 all

White seed-coat 0 all

Constricted pods 0 all

Yellow unripe pods 0 all

Terminal flowers 0 all

Short stems $\quad 0$ all

It will be noticed that the true-breeding dominants are to all the dominants in the proportion $1: 3$; and the recessives, every one of which breeds true, are also to all the dominants in the same proportion. Thus in each of the two groups into which a set of hybrids' progeny divides there are equal numbers of truebreeding individuals.

Among the foregoing results, three are to be noted, namely :

(a) In each of the seven cases, the hybrids' progeny consist of two groups.

(b) These two groups are to each other numerically in the ratio $3: 1$.

(c) The two groups in each pair contain equal numbers of individuals which breed true.

In addition to these experiments, Mendel carried out others in which the original parents differed in two pairs of characters in one set and in three pairs in another. In that in which the parents differed in two pairs, one parent had round seeds with yellow albumen while the other had wrinkled seeds with green albumen. Thus one parent carried two of the dominants dealt with in 
the first series of experiments while the other carried the two corresponding recessives, and, as is to have been expected, the hybrids bore the two dominant characters only-the recessives both disappearing; but, when they in their turn were bred from, their progeny consisted of four groups bearing the characters given in the following table and standing to each other numerically in the ratio $9: 3: 3: 1$, thus :

\begin{tabular}{|c|c|c|c|}
\hline $\begin{array}{l}\text { Round } \\
\text { with } \\
\text { yellow } \\
\text { albumen }\end{array}$ & $\begin{array}{l}\text { Round } \\
\text { with } \\
\text { green } \\
\text { albumen }\end{array}$ & $\begin{array}{l}\text { Wrinkled } \\
\text { with } \\
\text { yellow } \\
\text { albumen }\end{array}$ & $\begin{array}{l}\text { Wrinkled } \\
\text { with } \\
\text { green } \\
\text { albumen }\end{array}$ \\
\hline 315 & 108 & 101 & 32 \\
\hline 9 & 3 & 3 & 1 \\
\hline
\end{tabular}

This again raised the question: Were the hybrids' progeny hybrid or pure? To answer it, their seeds were sown, and, from the generation so produced, just as in the first series of experiments, some were found to be hybrid while others bred true. And not only so; for it was also found, although there were now four groups of hybrids' progeny, that each group again contained equal numbers of true-breeding individuals. The following table gives the number bred from and the number which bred true:

Round Round Wrinkled Wrinkled

$\begin{array}{cccc}\text { with } & \text { with } & \text { with } & \text { with } \\ \text { yellow } & \text { green } & \text { yellow } & \text { green } \\ \text { albumen } & \text { albumen albumen } & \text { albumen }\end{array}$

$\begin{array}{lrrrr}\text { Bred from : } & 301 & 102 & 96 & 30 \\ \text { Breeding true : } & 38 & 35 & 28 & 30\end{array}$

In this experiment, three results similar to those in the first series are to be noted, namely: 
(a) The hybrids' progeny consist of four groups.

(b) These four groups are to each other numerically in the ratio $9: 3: 3: 1$.

(c) Each group contains equal numbers of truebreeding individuals.

But it has to be observed, in addition, that, since the dominant and recessive characters which form a pair cannot both appear upon the same plant, the characters borne by the four groups of hybrids' progeny represent all the possible combinations of the four parental characters taken two at a time. The following scheme, in which the continuous lines show the possible combinations and the dotted lines the impossible, will make this clear :

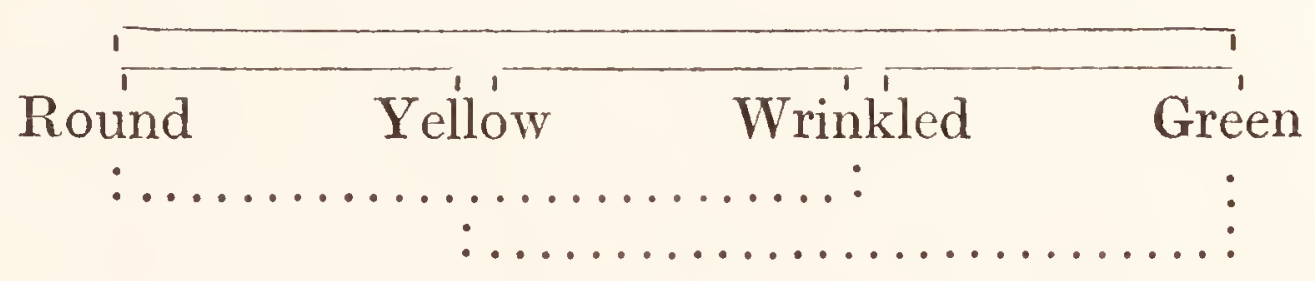

In the experiment in which the original parents differed in three pairs of characters, one had round seed with yellow albumen and coloured seed-coat while the other had wrinkled seed with green albumen and white seed-coat. Thus one carried three of the dominants dealt with in the first series while the other carried the three corresponding recessives. The result of the cross was 687 hybrid seeds, all of which were round with yellow albumen and coloured seed-coats. From these 687 seeds, 639 plants were grown which were found to consist of eight different kinds bearing the characters given in the following table and standing to each other numerically in the proportion $27: 9: 9: 9: 3: 3: 3: 1$. The first character named in the table refers to shape 
of seed, the second to colour of albumen, the third to colour of seed-coat.

Round Round Round Wrnkld. Round Wrnkld. Wrnkld. Wrnkld. yellow yellow green yellow green yellow green green clrd. white clrd. clrd. white white clrd. white

$\begin{array}{llllllll}269 & 98 & 86 & 88 & 27 & 34 & 30 & 7\end{array}$

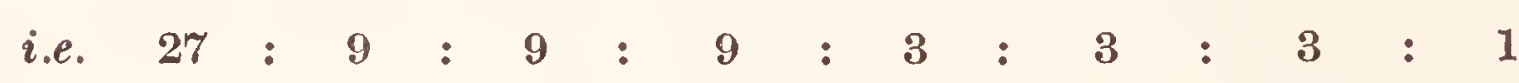

But this result again raised the question: How many of the hybrids' progeny were hybrids and how many bred true? To answer it, the 639 plants were all bred from, and, although they now consisted of eight groups, it was again found that each group contained equal numbers of true-breeding individuals. The following are the actual numbers in each group which bred true :

Round Round Round Wrnkld. Round Wrnkld. Wrnkld. Wrnkld. yellow yellow green yellow green yellow green green clrd. white clrd. clrd. white white clrd. white
8
14
9
8
1110
10
r

As in the previous experiment, four results are again to be noted, namely :

(a) The hybrids' progeny consist of eight groups.

(b) These eight groups are numerically to each other in the ratio $27: 9: 9: 9: 3: 3: 3: 1$.

(c) Each group contains equal numbers of truebreeding individuals.

(d) Since the dominant and the recessive members of a pair of characters cannot appear together on the same plant, the characters borne by the eight groups of hybrids' progeny represent every possible combination of the six parental characters taken three at a time. 
This is shown in the following diagram in which the impossible combinations are omitted because, otherwise, the diagram would be overcrowded.

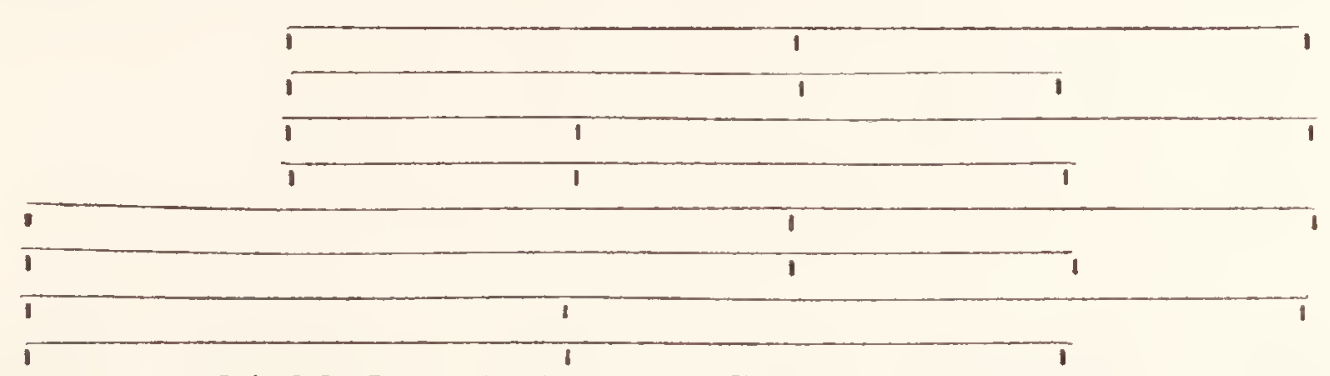

Round. Wrinkled. Yellow. Green. Coloured. White.

Having described so much of his experimental work in detail, Mendel proceeds : "Still further experiments were made with a smaller number of plants in which the remaining characters (shape of pod, length of stem, and so on) were united into two-pair and three-pair hybrids ; and all with similar results. There can be no doubt, therefore, as regards the whole of the characters concerned in the experiments, that it is valid to say that the progeny of the hybrids in which several essentially different characters are combined are ranged in a series which is developed by combining the ratios for each pair of characters.* Thus it is shown at the same time that the behaviour of every two differentiating characters is independent of the remaining differences in the original parents."

The purport of this statement is, as regards Mendel's seven pairs of characters whose ratios in the hybrids' progeny are in every case $3: 1$, that the progeny of hybrids whose parents differed in two of these pairs are ranged in a series developed by combining the separate

* Stellen sie Glieder einer Combinationsreihe vor, in welchem die Entwicklungsreihen für je zwei differirende Merkmale verbunden sind. 
ratios for the two pairs, thus (putting initial letters for the characters) :

$$
\begin{aligned}
& 3 \mathrm{R}+1 \mathrm{w} \\
& 3 \mathrm{Y}+1 \mathrm{~g}
\end{aligned}
$$

$9 \mathrm{RY}+3 \mathrm{Rg}+3 \mathrm{wY}+1 \mathrm{wg} ;$

that the progeny of hybrids whose parents differed in three pairs are ranged in a series which is developed by combining the ratios for the three pairs, thus (putting $\mathrm{C}$ for coloured and $\mathrm{c}$ for white) :

$9 \mathrm{RY}+3 \mathrm{Rg}+3 \mathrm{wY}+1 \mathrm{wg}$

$3 \mathrm{C}+1 \mathrm{c}$

$27 \mathrm{RYC}+9 \mathrm{RgC}+9 \mathrm{wYC}+3 \mathrm{wgC}+9 \mathrm{RYc}+$ $3 \mathrm{Rgc}+3 \mathrm{wYc}+1 \mathrm{wgc}$;

and so on.

This statement might be simplified still farther, thus : The result of the first pair of characters is to divide the hybrids' progeny into two groups in which the dominant group is to the recessive in the ratio $3: 1$. The result of the second pair is to subdivide each of these two groups again in the ratio $3: 1$, and, if the number in the smallest group is to be represented by the figure 1 as unit, the numbers in the other groups must be trebled; and so on, for any number of pairs, thus :

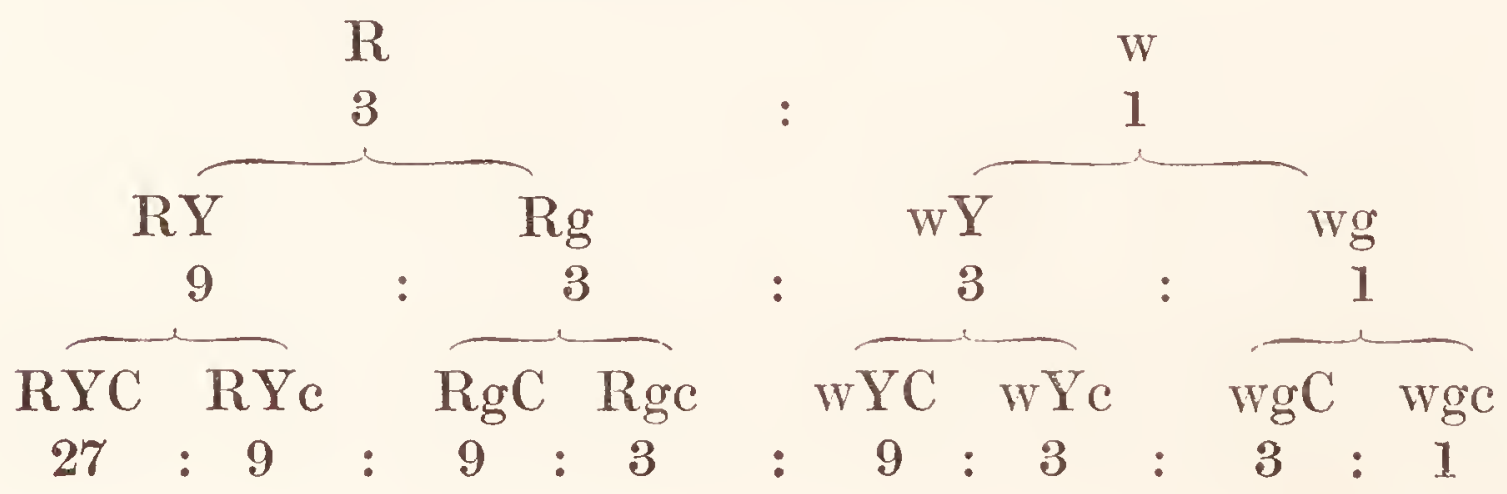




\section{MENDEL'S EXPERIMENTS}

Then, as Mendel points out, the distribution of each pair of characters must be independent of that of all the others, for, if not, these combinations would not occur and the series $3: 1 ; 9: 3: 3: 1$; and so on, would not be formed. 


\section{II}

\section{MENDEL'S LAW}

THE first result of Mendel's experiments was to reveal the extraordinary regularity with which hybrids breed, as manifested by the following observations :

(1) The number of groups or kinds in the hybrids' progeny is doubled with every additional pair of characters in which the original parents differ.

(2) The numbers of individuals in the several groups can be arranged in the series $(3+1)^{n}$ where $n$ stands for the number of pairs of characters in which the original parents differed.

(3) The character's borne by the several groups represent all the possible combinations in which the parental differentiating characters can be combined, consistent with the action of dominance.

(4) Each group in a set of hybrids' progeny contains equal numbers of constant or true-breeding individuals.

It now became Mendel's task to discover the law by which this regularity is determined and to formulate it in words; and this he did in the following statement:

"The results to which the foregoing experiments led were the cause of further experiments so designed that conclusions might be drawn from them as to the nature 
of the egg cells and pollen cells of the hybrids. An important starting-point is furnished by the pea in the fact that, among the descendants of the hybrids, constant forms appear, and these in all combinations of the mated characters. According to experience, we find it everywhere the rule that constant descendants can be produced only when the egg cells and the fertilizing pollen are of like kinds : that is when both are furnished with the materials * to produce individuals completely alike, as happens in the normal fertilization of pure kinds. We are therefore forced to the conclusion that, in the production of constant forms among the hybrids, completely similar factors co-operate. Since the various constant forms are produced not only on a single plant, but even in a single flower of that plant, the conclusion seems sound that, in the ovaries of the hybrids as many kinds of egg cells and in the anthers as many kinds of pollen cells are formed as there are constant combination forms possible; and these egg and pollen cells correspond in their inherent constitution $\dagger$ with the separate forms. Indeed it could be shown theoretically that this hypothesis would explain completely the behaviour of the hybrids in the different generations if it could be granted at the same time that the various kinds of egg and pollen cells are formed in the hybrids in equal numbers on the average."

Mendel's statement may be simplified by being resolved into the following four propositions, the first three of which are mere statements of fact with deductions which are obvious, while, in the last, the law he was in search of is inferred:

* Anlage. $\dagger$ Ihrer innern Beschaffenheit nach. 


\section{A MANUAL OF MENDELISM}

(1) Pure species produce constant or true-breeding forms, and must therefore be furnished with the materials for doing so.

(2) Hybrids also produce pure-breeding forms, and also must be furnished with the materials for doing so.

(3) Hybrids produce true-breeding forms in all the combinations in which the characters carried by their parents can be combined, and therefore must be furnished with the materials to produce all these truebreeding forms.

(4) Hybrids produce equal numbers of these truebreeding forms, and therefore must be furnished with equal numbers of the materials for the production of their characters.

Since the characters distributed among the truebreeding forms are the same as those in which their grandparents differed, Mendel's hypothesis might be rendered: Hybrids must be furnished with equal numbers of the materials for the production of the differentiating characters carried $(a)$ by their true-breeding progeny or $(b)$ by their parents.

As yet, however, this last statement is no more than a theory, a hypothesis, which must be tested and proved before being raised to a higher level. Mendel remarked that it might be proved "theoretically," that is without further experiment, but did not stop to do so ; and, before proceeding to his experimental proof, it will be well to consider how this may be done.

Consider first the case in which the parents differ in one pair of characters : in one having round seed while the other has wrinkled. The hypothesis is that, in their hybrids, the ovaries, on the one hand, and the anthers, on the other, contain equal numbers of the 
materials for the production of both roundness and wrinkledness. If the materials be represented by their initial letters, with capitals for dominants and small letters for recessives, then the following diagram should represent the distribution of the materials in the hybrids :

In the ovaries

In the anthers
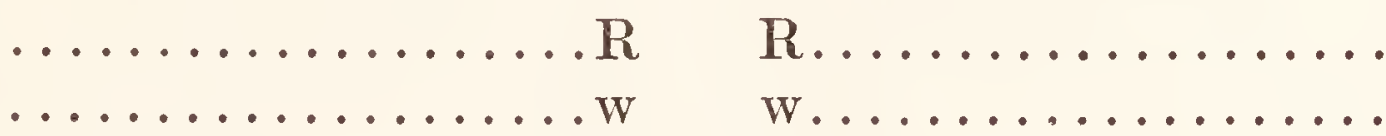

w.................

Since the materials in the ovaries unite with those in the anthers and since there are two kinds of materials in both ovaries and anthers, the chances of the four combinations $\mathrm{RR}, \mathrm{Rw}, \mathrm{wR}$, and ww being formed are equal. A further diagram will make this clearer :
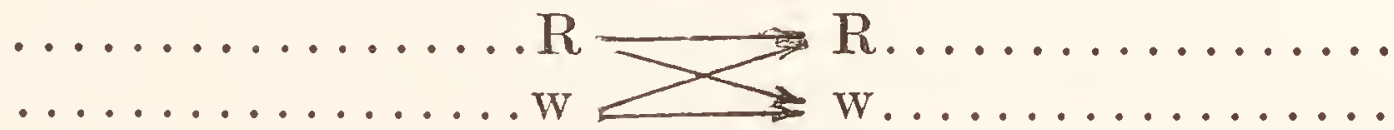

The combinations $R w$ and $w R$ being the same, the chances are $1: 2: 1$ that the combinations $\mathrm{RR}, \mathrm{Rw}$, and ww should be formed. But, as all the progeny receiving the materials $\mathrm{RR}$ and $\mathrm{Rw}$ should be round while those receiving the materials ww should be wrinkled, the chances are that three round seeds should be produced for one wrinkled; and, as the progeny receiving the materials RR should be pure and should breed true while those receiving the materials $\mathrm{Rw}$ should be hybrid, the chances are that one only in every three round seeds should breed true.

Thus expectation is in complete agreement with the results obtained. The hypothesis is consistent with the observed phenomena.

Consider next the case in which the parents differ in 
two pairs of characters : one in having round seed with yellow albumen while the other has wrinkled seed with green. The materials offered should be:

In the ovaries

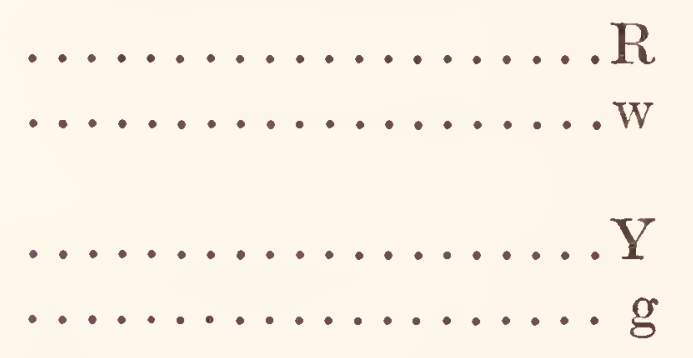

In the anthers

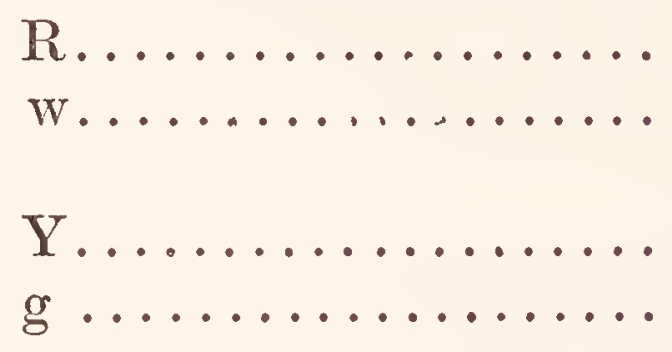

The materials $\mathrm{R}$ and $\mathrm{w}$ in the ovaries have equal chances of combining with $\mathbf{R}$ or $\mathrm{w}$ in the anthers, and equal numbers of the combinations $\mathbf{R R}, \mathbf{R w}, w \mathbf{R}$, and ww should be formed. At the same time the materials $Y$ and $g$ should form equal numbers of the combinations $\mathrm{YY}, \mathrm{Yg}, \mathrm{gY}$, gg. But, since the materials are distributed concurrently and independently, the combinations formed by one pair should be distributed equally among those formed by the other. For instance, among the seeds carrying the materials RR, equal numbers should be found carrying the materials YY, $\mathrm{Yg}, \mathrm{gY}$, and $\mathrm{gg}$, and so on for the other combinations in which $\mathbf{R}$ and $\mathrm{w}$ are concerned. This will be made clearer by the diagram on page $\mathbf{1 \%}$, in which the distribution of the $\mathbf{R}$ and $w$ materials is shown horizontally and that of the $\mathrm{Y}$ and $\mathrm{g}$ materials perpendicularly.

If this diagram be examined, the action of dominance being kept in mind, it will be seen that there should be nine round seeds with yellow albumen, three round with green, three wrinkled with yellow, and one wrinkled with green. It will also be seen that there should be one seed pure as to both parental characters in each of the four kinds. These pure seeds are indicated at the 
four corners of the diagram. Thus, again, Mendel's hypothesis is consistent with the observed phenomena.

\begin{tabular}{lll|l} 
RR & Rw & wR & ww \\
YY & YY & YY & YY \\
& & & \\
RR & Rw & wR & ww \\
Yg & Yg & Yg & Yg \\
RR & Rw & wR & ww \\
gY & gY & gY & gY \\
\hline RR & Rw & wR & ww \\
g g & g g & g g & g g
\end{tabular}

The case in which the original parents differed in three pairs of characters could be dealt with in a similar manner, but the diagram becomes too complicated to be useful.

Mendel's experimental proof is as follows: As the hypothesis had reference to the hybrids' constitutions, that is to the materials they carried, it was necessary that hybrids should be employed in the experimental proof, and, as their constitutions were hypothetical, it was also necessary that they should be mated with true-breeding plants whose constitutions were known. Hybrids, therefore, similar to those produced by the experimental parents differing in two pairs of characters were chosen and mated first with one and then with the other of their true-breeding parent kinds. That is to say: hybrids between parents having round seeds and yellow albumen and others having wrinkled seeds with green albumen were mated first with the one and then with the other parental kind.

The following scheme should represent the materials 
carried by the pure kind having wrinkled seeds with green albumen and those carried by the hybrids :

By the pure kind

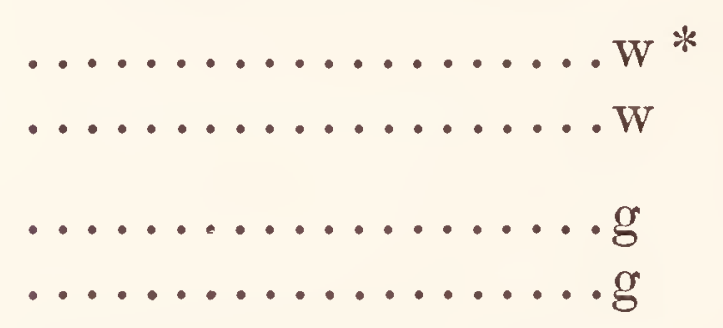

By the hybrids

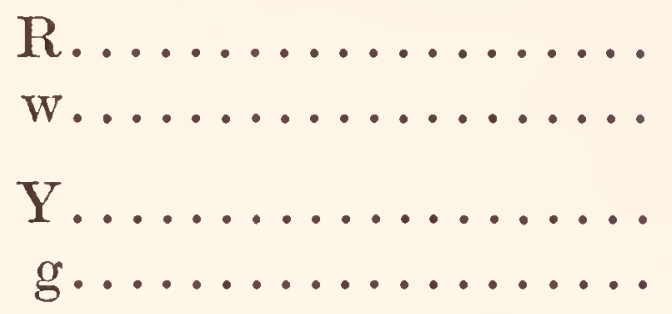

If the hybrids contain equal numbers of these two pairs of materials, then equal numbers of the combinations $\mathrm{Rw}$ and $\mathrm{ww}$, and $\mathrm{Yg}$ and $\mathrm{gg}$ should be produced. But, as the two sets of materials are distributed independently and simultaneously, the combinations formed by one set should be distributed equally among those formed by the other, thus :

$\begin{array}{llll}R w & R w & w w & w w \\ Y g & g g & Y g & g g\end{array}$

Round with Round with Wrinkled with Wrinkled with

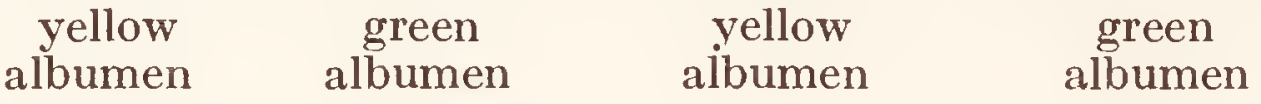

$1:: \begin{array}{llll}1 & : & 1 & :\end{array}$

The actual numbers found of each of these kinds of seeds were :

With the hybrid as pollen-bearer $\}$

With the pure parent as pollen-bearer

\section{Round with Round with yellow albumen

green
albumen

24

31
25

26

$$
\begin{aligned}
& \text { Wrinkled } \\
& \text { with yellow } \\
& \text { albumen }
\end{aligned}
$$

22

27
Wrinkled with green albumen

27

26

* For ease and accuracy in manipulation it is well to represent the pure kind as containing the same number of lines of materials as the hybrid. 
In the experiment in which the hybrids were mated with the other pure parent, the following diagram should represent the materials offered by the pure kind having round seeds with yellow albumen on the one hand and by the hybrids on the other :

By the pure kind

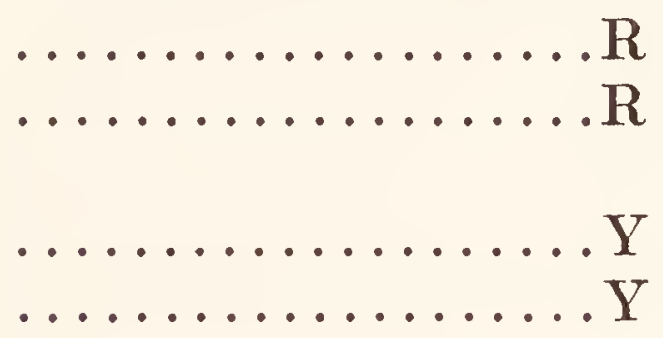

By the hybrid

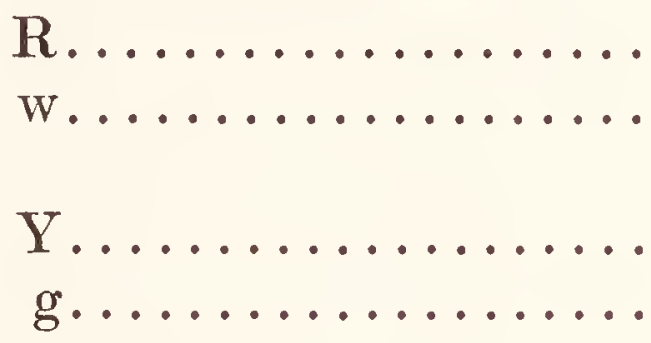

If the hybrids contain equal numbers of each of these two pairs of materials, then equal numbers of the combinations $\mathrm{RR}$ and $\mathrm{Rw}$ on the one hand, and $\mathrm{YY}$ and $\mathrm{Yg}$ on the other should be formed. But, as the two sets of materials are distributed independently and simultaneously, the combinations made by one pair should be distributed equally among those made by the other, and equal numbers of the four following combinations should be formed:

$\begin{array}{llll}R R & R R & R w & R w \\ Y Y & Y g & Y Y & Y g\end{array}$

Pure round Pure round Impure round Impure round and pure and impure and pure and impure yellow yellow yellow yellow $1: 1: 1: 11$

As, in this case, the pure parent which was crossed with the hybrid carried dominant characters, the progeny carried the dominant characters only and had to be bred on to another generation to determine which 
were or were not pure in each of the two pairs of characters. The result was as follows :

\section{Pure round Pure round and pure yellow}

With the hybrid) as pollen-bearer 25 With the pure, parent as pollen- 20

In Mendel's final experiment, the hybrids between parents differing in one pair of characters were mated with the hybrids between parents differing in another pair. One hybrid was got by mating parents having violet-red flowers and short stems with others having white flowers and short stems, while the other was got by mating parents having white flowers and long stems with others having white flowers and short stems. If Mendel's theory be true, then the materials offered by the two kinds of hybrids, putting $\mathrm{V}=$ violet-red, $\mathrm{w}=$ white, $\mathrm{L}=$ long, and $\mathrm{s}=$ short, should have been :

By one hybrid

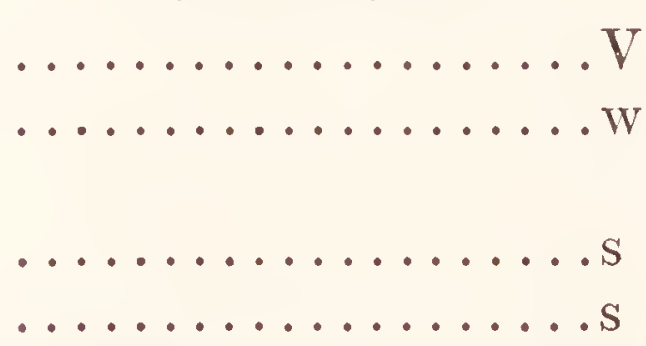

By the other

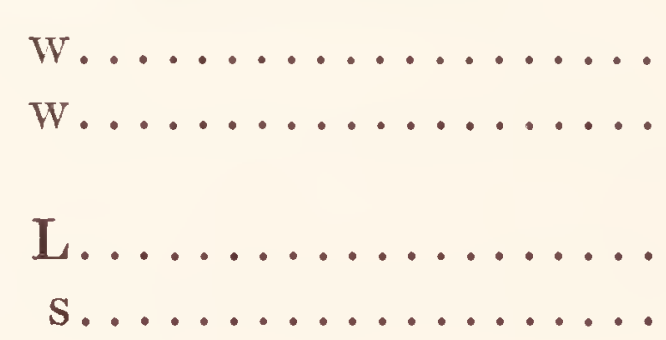

And this mating should have produced equal numbers of the combinations $V_{w}$ and $\mathrm{ww}$ on the one hand and of Ls and ss on the other; but, as the two pairs of materials are distributed independently and simultaneously, there should have resulted equal numbers of 
the four following combinations bearing the characters written down below :

\begin{tabular}{|c|c|c|c|}
\hline$V_{w}$ & $V w$ & ww & ww \\
\hline $\mathrm{L}$ s & S S & L s & S S \\
\hline $\begin{array}{l}\text { Violet-red } \\
\text { with long } \\
\text { stems }\end{array}$ & $\begin{array}{c}\text { Violet-red } \\
\text { with short } \\
\text { stems }\end{array}$ & $\begin{array}{l}\text { White } \\
\text { with Iong } \\
\text { stems }\end{array}$ & $\begin{array}{l}\text { White } \\
\text { with short } \\
\text { stems }\end{array}$ \\
\hline 1 & 1 & 1 & 1 \\
\hline
\end{tabular}

The actual results obtained were :

$\begin{array}{cccc}\begin{array}{c}\text { Violet-red } \\ \text { with long } \\ \text { stems }\end{array} & \begin{array}{c}\text { Violet-red } \\ \text { with short } \\ \text { stems }\end{array} & \begin{array}{c}\text { White } \\ \text { with long } \\ \text { stems }\end{array} & \begin{array}{c}\text { White } \\ \text { with short } \\ \text { stems }\end{array} \\ 47 & 38 & 40 & 41\end{array}$

Thus Mendel's theory, which may be proved "theoretically," was proved by actual experiment, and so became a law. 


\section{III}

\section{OBSERVATIONS AND DEDUCTIONS}

IN order to facilitate future work, it will be well to set down some observations from Mendel's experiments together with a few simple deductions which will be found useful in the solution of problems and in shortening discussion. Some may seem very obvious, others even trivial, but all will be found useful.

(1) If the original parents differ in $n$ pairs of characters, their hybrids' progeny consist of $\mathbf{2}^{n}$ groups, the numbers in which are to each other in the ratio $(3: 1)^{n}$, thus :

\begin{tabular}{ccc}
$\begin{array}{c}\text { Pairs of } \\
\text { characters }\end{array}$ & $\begin{array}{c}\text { Number of } \\
\text { groups }\end{array}$ & \multicolumn{2}{c}{ Ratio } \\
1 & 2 & $3: 1$ \\
2 & 4 & $9: 3: 3: 1$ \\
3 & 8 & $27: 9: 9: 9: 3: 3: 3: 1$ \\
$\cdot$ & $\cdot$ & $\cdot$ \\
$\cdot$ & $\cdot$ & $\cdot$ \\
$\cdot$ & $2^{n}$ & $(3: 1)^{n}$
\end{tabular}

(2) Conversely, if the hybrids' progeny consist of $2,4,8 \ldots 2^{n}$ groups, the numbers in which are in the ratio $(3: 1)^{n}$, then the original parents differed in $n$ pairs of characters. 


\section{OBSERVATIONS AND DEDUCTIONS 23}

(3) The numbers of groups and the numbers of individuals in each group increase with every additional pair of characters in which the parents differ, according to the following scheme :

Numbers of groups when the parents differ
Numbers of indiviudals in each group

in 1 pr. in 2 prs. in 3 prs. in 4 prs. in 5 prs.

$\begin{array}{rrrrrr}1 & 1 & 1 & 1 & 1 & 1 \\ 1 & 2 & 3 & 4 & 5 & 3 \\ & 1 & 3 & 6 & 10 & 9 \\ & & 1 & 4 & 10 & 27 \\ & & & 1 & 5 & 81 \\ & & & & 1 & 243\end{array}$

$\begin{array}{llllll} & - & - & - & - & - \\ \text { Total } & 2 & 4 & 8 & 16 & 32\end{array}$

For instance, if the parents differ in three pairs of characters, there are eight groups in their hybrids' progeny: 1 containing 1 individual, 3 containing each 3 individuals, 3 containing each 9 individuals, and 1 containing 27 individuals.

(4) Since $2^{n}$ gives the number of groups or kinds in the hybrids' progeny, and 2 of these are the same as the original parents, $2^{n}-2$ gives the number of new kinds, thus :

$\begin{array}{ccc}\text { Pairs } & \text { Groups } & \text { New kinds } \\ 1 & 2 & 0 \\ 2 & 4 & 2 \\ 3 & 8 & 6 \\ 4 & 16 & 14 \\ \cdot & \cdot & \cdot \\ \cdot & \cdot & \cdot \\ n & 2^{n} & 2^{n}-2\end{array}$


(5) When pure parents are mated the hybrids carry all the dominants borne by the parents. This holds whether the dominants are all carried by one parent or distributed between the two. For instance XY mated with $\mathrm{xy}$ gives the same kind of hybrid as $\mathrm{Xy}$ mated with $\mathrm{xY}$.

(6) In a set of hybrids' progeny, the numerically largest group carries all the dominants, the next sized groups carry each one less, the next sized again two less, and so on down to the smallest group, which carries all the recessives. This will be seen by examining the following two-pair and three-pair sets :

$$
\begin{aligned}
& \begin{array}{llll}
X & X & x & x \\
Y & y & Y & y
\end{array} \\
& 9: 3: 3: 1
\end{aligned}
$$

and

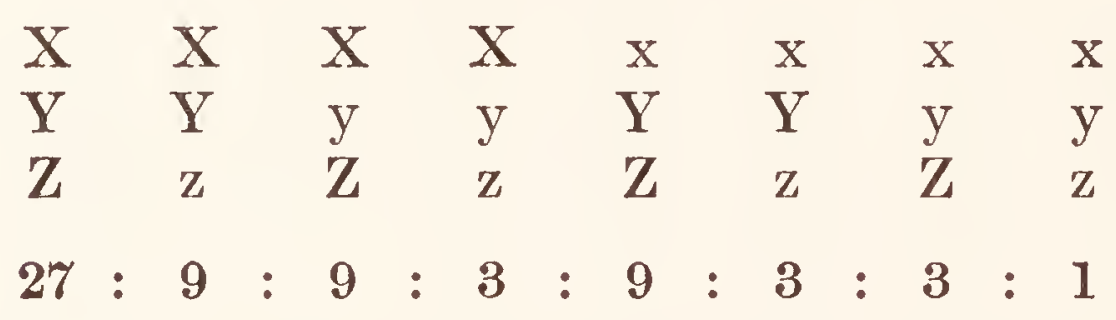

(7) In a two-pair set of four groups, the first differs from the next two groups each in one pair of characters and from the last in two pairs, while the middle groups differ from each other in two pairs and from the last in one pair. Similar relations exist among the groups in larger sets.

(8) If the pairs in which the parents differ are clearly defined at the hybrid generation as regards dominance and recessiveness, the hybrids' progeny can be predicted in number and kind, for the dominants and recessives are distributed according to the scheme 


\section{OBSERVATIONS AND DEDUCTIONS 25}

and so on.

$$
\begin{aligned}
& \begin{array}{cccc}
X & X & x & x \\
Y & y & Y & y
\end{array} \\
& 9: 3: 3: 1
\end{aligned}
$$

(9) Each character in which the parents differ is carried by half the groups in their hybrids' progeny precisely. For instance, two of the four groups in the last section carry $\mathrm{X}$, two carry $\mathrm{Y}$, two carry $\mathrm{x}$, and two carry $\mathrm{y}$.

(10) If more than half the groups in a set of hybrids' progeny carry any character, then that character is carried by all the other groups in the set, for, if it were not, then the groups would differ from each other in more characters than is consistent with the size of the set. If, for instance, the third group in the following two-pair set did not carry $Z$, it would differ from the first and last groups in more than one pair and from the other middle group in more than two :

$\begin{array}{ll}9 & \text { X Y Z } \\ 3 & \text { X y Z } \\ 3 & \text { x Y } \\ 1 & \text { x y Z }\end{array}$

(11) If one or more groups in a set carry a character outside those concerned in the production of the set, then that character is common to all the groups in the set. If, for instance, the first group in the following two-pair set carried $\mathrm{Z}$, then, unless they also carried Z, the middle groups would differ from the first in more than one pair of characters, thus :

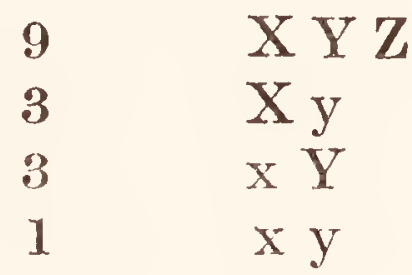


(12) The number of pure-breeding individuals in any one group is equal to the number of individuals in the smallest group in the set.

(13) If two or more groups in the hybrids' progeny are inseparable, then the number of groups will be one less than the normal for every group which is inseparable from another, and the number of individuals in one of the groups will be the sum of the numbers in the inseparable groups together. For instance, if the first two groups in a two-pair set of four be inseparable, there will then be three apparent groups in the ratio $12: 3: 1$, thus :

$$
\begin{array}{lllll}
\mathrm{X} & \mathrm{X} & \mathrm{X} & \mathrm{x} \\
\underbrace{\mathrm{Y}}_{12} & \mathrm{y} & \mathrm{Y} & \mathrm{y} \\
& : & 3 & : & 1
\end{array}
$$

If the last two groups be inseparable, there will be three apparent groups in the ratio $9: 3: 4$, thus :

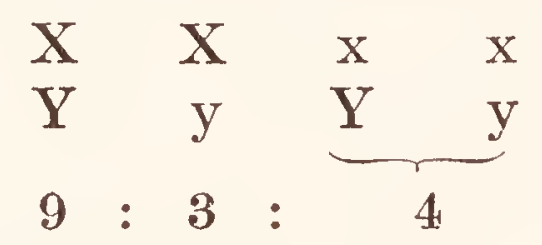

If the first three groups be inseparable, there will be only two apparent groups in the ratio $15: 1$, thus :

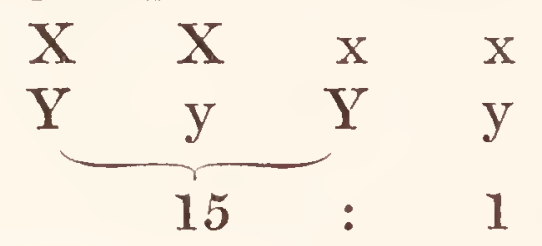

If the last three groups be inseparable, then there will again be only two apparent groups, but in the ratio $9: 7$, thus :

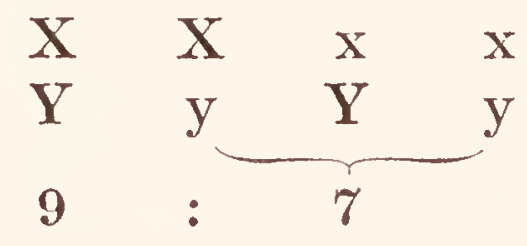




\section{OBSERVATIONS AND DEDUCTIONS 27}

(14) If the hybrids be mated with the smallest group in a set of their progeny, as many different kinds will be produced as there are groups produced when the hybrids are mated with each other, but each will contain equal numbers of individuals. For instance, if the monohybrid $\mathrm{Xx}$ be mated with its recessive, the materials offered are

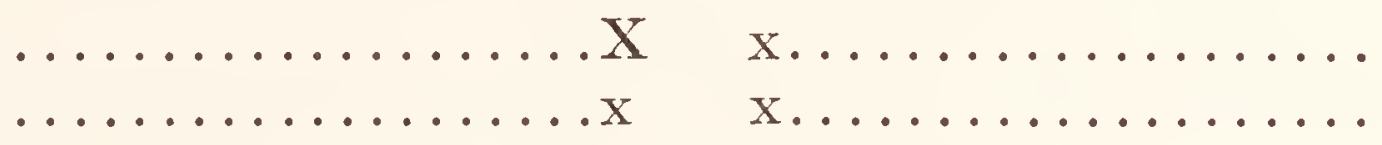

and, $\mathbf{X}$ and $\mathrm{x}$ in the hybrid having equal chances of combining with $\mathrm{x}$ in the recessive, equal numbers of the two kinds $\mathrm{Xx}$ and $\mathrm{xx}$ must be produced. Again, if the dihybrid $\frac{\mathrm{Xx}}{\mathrm{Yy}}$ be mated with the smallest group, which is a double recessive, the materials offered are

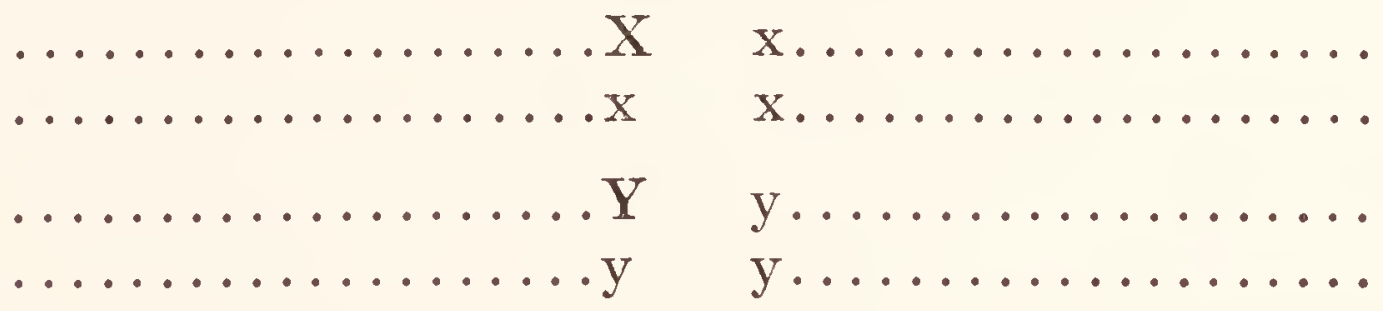

and equal numbers of the combinations $\mathbf{X x}$ and $\mathrm{xx}$ will be formed; but, as equal numbers of the combinations Yy and yy are formed at the same time, half of each of the combinations $\mathrm{Xx}$ and $\mathrm{xx}$ will carry the combination Yy while the other half will carry yy, and there will be four different kinds in all equal in number, thus :

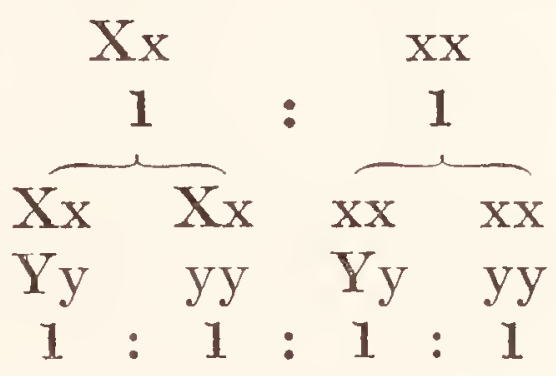


(15) Conversely, if a hybrid be mated with a recessive and both are pure in their other characters, the number of equal kinds produced indicates in how many pairs of characters the hybrid and the recessive differ. If two kinds are produced, the hybrid and the recessive differ in one pair, if four kinds are produced, the hybrid and the recessive differ in two pairs, and so on. For, if they differed in more than $1,2,3 \ldots n$ pairs, they would form more than $2,4,8 \ldots 2^{n}$ different combinations.

(16) It is obvious that, if the parents differ only in certain characters, the remaining characters in both must be the same. It must not be assumed, however, that every character finds another with which it forms a pair, for there may be species every member of which without exception carries certain characters. For instance, every elephant has a trunk.

It has to be remembered that the foregoing deductions hold only when characters are distributed normally ; for, since the discovery of Mendel's papers, many cases have been observed in which the characters are not normally distributed. As nothing has been discovered, however, to modify Mendel's law-to suggest that hybrids do not produce equal numbers of the factors in which their parents differed-it follows that abnormal distributions must themselves be the result of independent disturbing causes, and, when these are identified and allowed for, the foregoing deductions apply.

The chief disturbing causes are :

(a) The inseparability of the effect of one factor from that of another.

(b) The suppression of the effect of one factor by that of another. 


\section{OBSERVATIONS AND DEDUCTIONS 29}

(c) The absence of dominance.

(d) Polygamy, or the mating of a factor with more than one other.

(e) The coupling or tying together of two or more factors so that they are handed on from generation to generation as one.

$(f)$ The production of similar or closely similar effects by different materials.

As the foregoing discussion of Mendel's work should be a sufficient introduction to any case in which the characters are distributed in a normal manner, we shall now give attention to cases in which the distribution is not normal. We shall select a few examples to illustrate the different kinds of abnormality, and, as our object is to make each abnormality as clear as possible, we shall select such examples as suit best for this purpose without regard to their importance from any other point of view. 


\section{IV}

\section{INSEPARABLE EFFECTS}

AN early example of the difficulty of separating the characters produced by different materials or factors, as they may now be called, occurred in Professors Bateson's and Punnett's experiments on the inheritance of fowls' combs. The experiments are detailed in the second and third "Reports to the Evolution Committee of the Royal Society," and summarized in the fourth.

When rose-combed fowl were mated with singlecombed, the hybrids were all rose-combed. Thus rose comb seemed dominant to single comb; and, when the hybrids were mated with each other, this inference was confirmed, for their progeny's combs were roses and singles in the ratio $3: 1$ (actually 695 and 235).

Again, when pea-combed fowl were mated likewise with single-combed fowl, the hybrids were all peacombed. Thus pea comb also seemed dominant to single comb; and this inference also was confirmed when the hybrids were mated with each other, for their progeny's combs were peas and singles in the ratio $3: 1$ (actually 567 and 210 ).

Two different dominants to one and the same recessive was a new phenomenon having no parallel in Mendel's experiments, in which each dominant had only 
one recessive and each recessive only one dominant. It raised the question: how do the two dominants stand to each other: which is the dominant and which the recessive? But when roses and peas were mated, it was found that neither was dominant to the other, for the hybrids' combs were neither roses nor peas, but a new kind different from both, shaped like a half walnut.

This again was another new phenomenon having no parallel in Mendel's experiments; but the significance of both phenomena was brought out when the hybrid walnut combs were bred together, for their progeny consisted of the four kinds, walnut, rose, pea, and single, in numbers approximating to the ratio $9: 3: 3: 1$ (actually, walnut 279 , rose 99 , pea 132 , and single 45). It will be remembered that, if the hybrids' progeny consist of four groups numerically in the ratio $9: 3: 3: 1$, the original parents must have differed in two pairs of characters. At the same time the differentiating characters borne by each group must be the result of two factors. In this case, however, the effects of the factors operating in each of these combs cannot be identified. The two effects which combine to produce single cannot be separated, and still less can either of these effects be traced the one in pea and the other in rose. Therefore we can only represent the two-pair set of walnut, rose, pea, and single by "unknowns," thus :

\begin{tabular}{|c|c|c|c|}
\hline Walnut & Rose & Pea & Single \\
\hline $\mathrm{X}$ & $\mathrm{X}$ & $\mathrm{x}$ & $\mathrm{x}$ \\
\hline$Y$ & $\mathrm{y}$ & $\mathrm{Y}$ & $\mathrm{y}$ \\
\hline 9 & 3 & 3 & I \\
\hline
\end{tabular}


The dominance of both rose and pea to single comb was referred to as a new phenomenon. This can now be explained. Rose carries the characters $\mathrm{Xy}$ while single carries the characters $x y$. Thus they differ in only one pair of characters, $\mathbf{X}$ and $\mathrm{x}$, and, by carrying the dominant of the differing pair, rose behaves as a simple dominant to single. Similarly, pea and single differ in only one pair of characters, $\mathrm{Y}$ and $\mathrm{y}$, and, by carrying the dominant of the differing pair, pea also behaves as a simple dominant to single. In such circumstances the progeny of the hybrids between rose and single and pea and single should consist of three roses to one single on the one hand and three peas to one single on the other.

A parallel example might make the case clearer : if round peas with green albumen were mated with wrinkled peas with green albumen-green being common to both-their hybrids' progeny would consist of three round with green albumen to one wrinkled with green albumen; and, if wrinkled peas with yellow albumen were also mated with wrinkled peas with green albumen -wrinkled being common to both-their hybrids' progeny would consist of three wrinkled peas with yellow albumen to one wrinkled with green albumen.

In connexion with this case, it may have been noticed that the progeny of the hybrid walnut combs were not too close to the ratio $9: 3: 3: 1$. The total number was 555, and this should have divided approximately into $313,104,104$, and 34 , instead of $279,99,132$, and 45. By some statisticians this discrepancy might be considered serious, but the inference from the numbers was proved by other tests, one of which only need be quoted. It will be remembered that Mendel, to prove 


\section{INSEPARABLE EFFECTS}

his theory, mated his hybrids in two pairs of characters with the parents carrying both the recessives, and equal numbers of all the four second-generation groups were produced. In this case the hybrid walnuts were mated with singles, that is, with the parents carrying both the recessives, and there resulted 644 walnuts, 705 roses, 664 peas, and 716 singles.

Another case in which the effects of the individual factors cannot be identified separately occurs in Miss Durham's experiments on the colours of mice, whose details are to be found in the fourth "Report to the Evolution Committee" and in the first volume of the Journal of Genetics. In Miss Durham's first experiment agouti-coloured mice were mated with chocolates, and their hybrids' progeny consisted of agoutis, cinnamonagoutis, blacks, and chocolates in the ratio $9: 3: 3: 1$. Thus there are two pairs of characters concerned, and each of the four colours is the result of two separate factors. As it is impossible, however, to identify the effects of each of the two factors producing any one of the four colours, we must set out the set of four groups with " unknown" symbols, thus :

$\begin{array}{lcc}\text { Agouti } & \text { XY } & \mathbf{9} \\ \text { Cinnamon-agouti } & \text { Xy } & \mathbf{3} \\ \text { Black } & \text { x } & \mathbf{3} \\ \text { Chocolate } & \text { xy } & \mathbf{1}\end{array}$

But the next experiment showed that there were still other factors concerned in the production of these colours. Black was mated with a fifth colour, silverfawn, whose very mating with black proves the presence of one other factor at least. But the hybrids' progeny, which consisted of blacks, blues, chocolates, and silver- 
fawns in the ratio $9: 3: 3: 1$, showed that there was really another pair of factors operating. Since it is the largest group in a set of four, black must carry two dominants at least. One may be the factor $\mathrm{Y}$, which it is already known to carry, and the other a new factor, say Z. Nay, both may be new ; and, if they be called $\mathrm{Z}$ and $\mathrm{A}$, then the characters carried by the four groups in the set should be :

$\begin{array}{ll}\text { Black } & \text { ZA } \\ \text { Blue } & \text { Za } \\ \text { Chocolate } & \text { zA } \\ \text { Silver-fawn } & \text { za }\end{array}$

Then the total characters carried by black and chocolate, as found by both experiments, should be:

Black

Chocolate

$x Y Z A$

$x y z A$

But, thus, black and chocolate would differ in two pairs of characters, whereas both experiments show them to differ in one only. Black carries only one new dominant therefore; and, if it be called $\mathrm{Z}$, the characters now known to be carried by black are $x \mathrm{YZ}$. At the same time chocolate must also carry $\mathrm{Z}$, for it already carries $x y$, and if it carried any other character than $Z$ it would differ from black in more than one pair of characters.

Since $\mathrm{Y}$ and $\mathrm{Z}$ and their recessives $\mathrm{y}$ and $\mathrm{z}$ are the characters combining to form the four colours in the second experiment, and, since blue is shown to be a middle group and silver-fawn the last group, the characters now known to be carried by the four groups in the set are : 


$\begin{array}{lr}\text { Black } & \mathrm{xYZ} \\ \text { Blue } & \mathrm{Yz} \\ \text { Chocolate } & \mathrm{xyZ} \\ \text { Silver-fawn } & \mathrm{yz}\end{array}$

But $x$, carried by black and chocolate, by being outside the characters combining to form the set, must also be carried by blue and silver-fawn. Otherwise black would differ from blue in more pairs than one and from silver-fawn in more than two. Similarly, the characters so far known to be carried by the four colours in the first experiment are :
Agouti
Cinnamon-agouti
XY
Black
$\mathrm{Xy}$
Chocolate
$x Y Z$
$x y Z$

By being outside the characters combining to form the set, $\mathrm{Z}$, which is carried by black and chocolate, must also be carried by agouti and cinnamon-agouti.

Now that three pairs of factors are shown to be in operation, there must be eight related groups in all, two of which remain to be found. In the following scheme the characters carried by the eight possible groups are shown, together with the colours belonging to the six which so far have been identified:

$\begin{array}{ll}\text { Agouti } & \mathrm{XYZ} \\ & \mathrm{XYz} \\ \text { Cinnamon-agouti } & \mathrm{XyZ} \\ \text { Black } & \mathrm{xYZ} \\ & \mathrm{Xyz} \\ \text { Blue } & \mathrm{x} \mathrm{Yz} \\ \text { Chocolate } & \mathrm{xyZ} \\ \text { Silver-fawn } & \mathrm{xyz}\end{array}$


In Miss Durham's third experiment, agouti was mated with blue, and their hybrids' progeny were agoutis, dilute agoutis, blacks, and blues in the ratio $9: 3: 3: 1$. The characters carried by three of these groups are already known, and, if we set down the four groups forming the set in the usual order with the known characters against the groups to which they belong, we shall be able to infer the characters carried by the remaining group :
Agouti
XYZ
Dilute agouti
Black
$\mathrm{xYZ}$
Blue
$\mathrm{xYz}$

Since it is carried by three of the groups in the set, $\mathrm{Y}$ must also be carried by the fourth. The differentiating characters in the set are therefore $\mathrm{X}$ and $\mathrm{x}$ and $\mathrm{Z}$ and $\mathrm{z}$; and, since three of the four possible combinations made by these characters are already appropriated, the remaining combination, $\mathrm{Xz}$, must belong to dilute agouti, whose three characters are thus XYz.

In Miss Durham's last experiment, cinnamon-agouti was mated with silver-fawn, and their hybrids' progeny consisted of cinnamon-agouti, dilute cinnamon-agouti, chocolate, and silver-fawn in the ratio $9: 3: 3: 1$. If we again arrange the four groups in the usual order with the characters of the three groups which are known set down against them, we shall be able to infer the characters belonging to the fourth:

Cinnamon-agouti

Dilute cinnamon-agouti

Chocolate

Silver-fawn

$\mathrm{XyZ}$

$x y Z$

$x y z$ 
$\mathrm{y}$ is common to three of the four groups, and therefore must be carried by dilute cinnamon-agouti, the fourth. The differentiating characters in the set are therefore $\mathrm{X}$ and $\mathrm{x}$ and $\mathrm{Z}$ and $\mathrm{z}$; and, since three of the four possible combinations made by these characters are already appropriated, the fourth, $\mathrm{X} z$, must belong to dilute cinnamon-agouti, whose three characters are therefore Xyz.

Thus the complete set of eight groups formed by all the possible combinations of the three pairs of characters $\mathrm{X}$ and $\mathrm{x}, \mathrm{Y}$ and $\mathrm{y}$, and $\mathrm{Z}$ and $\mathrm{z}$, are :

\begin{tabular}{|c|c|}
\hline gouti & $\mathrm{XYZ}$ \\
\hline Dilute agouti & $\mathrm{XYz}$ \\
\hline Cinnamon-agouti & $\mathrm{Xy}$ \\
\hline Black & $\mathrm{x}$ \\
\hline Dilute cinnamon-agouti & $\mathrm{Xy}$ \\
\hline Blue & \\
\hline Choc & \\
\hline Silver-fawn & \\
\hline
\end{tabular}

Still another example of inseparable effects is disclosed in the experiments on the colours of rabbits carried out by Mr. C. C. Hurst, and Professor Castle of Harvard. Both experimenters were more interested in albinism and colour patterns, but the data concerning these may be neglected and those for the colours themselves, which were reported at the same time, considered separately.

A black rabbit is sometimes found among common wild grey rabbits, more especially in places where the wild race has been mixed with the tame; and young black rabbits have been found in wild litters which could be the progeny of grey parents only upon both 
sides. Thus, since grey parents have black progeny, grey is apparently dominant to black.

In the course of his experiments, which are reported in vol. xxix of the Journal of the Linnean Society, 1904, Mr. Hurst bred both grey and black rabbits which bred true; and, when they were mated, their hybrids were all grey, while the hybrids' progeny were greys and blacks in the ratio $3: 1$ (actually $38: 10$ ). Thus the inference that grey is dominant to black is confirmed; and, symbolizing the two colours by their initial letters, we may write down the one-pair set of two groups in the usual way, as follows :

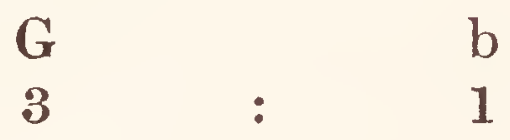

But Professor Castle's experiments, which are summarized in Science, vol. 26, 1907, show this solution to be far too simple, for he found six colours intermateable, grey and black both included : a result indicating three pairs of factors in operation and two more colours remaining to be found. Among the six colours, the following relationships are recorded:

(1) Grey is dominant to blue-grey, black, and yellow.

(2) Blue-grey is dominant to blue.

(3) Black is dominant to blue and tortoise-shell.

(4) Yellow is dominant to tortoise-shell.

(5) Grey is got by crossing black with either blue-grey or yellow.

By being dominant to three other colours, grey must carry three dominant characters, and, by being recessive to it and differing from it therefore in one pair of characters, each of these three colours must carry two of the dominants carried by grey, together with the 
recessive to the third. Obviously these four colours are the first four groups in a set of eight, but, as their effects cannot be identified, the factors which make them different must be represented by "unknowns," thus :

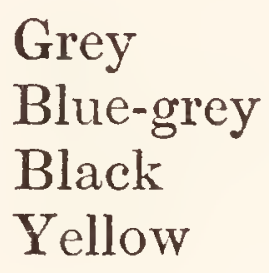

Grey

Blue-grey

Yellow

XYZ
$X Y z$
$X y Z$
XYZ

By being recessive to colours carrying two dominants, that is, to blue-grey and black, blue must carry one dominant less. It may carry therefore the characters $\mathrm{Xyz}$, or $\mathrm{xYz}$, or $\mathrm{xyZ}$. But, if it carried $\mathrm{xYz}$, it would differ from black in three pairs, while, if it carried $x y Z$, it would differ from blue-grey in three pairs. Consequently, it can carry only the characters Xyz.

Similarly, by being recessive to both black and yellow, tortoise-shell must carry the characters $x y Z$.

Thus the colours produced by six of the combinations in which the factors $\mathrm{X}$ and $\mathrm{x}, \mathrm{Y}$ and $\mathrm{y}$, and $\mathrm{Z}$ and $\mathrm{z}$, can be combined have been identified with their factors, while two still remain to be found, as follows:

$\begin{array}{ll}\text { Grey } & \mathrm{XYZ} \\ \text { Blue-grey } & \mathrm{XYZ} \\ \text { Black } & \mathrm{XyZ} \\ \text { Yellow } & \mathrm{xYZ} \\ \text { Blue } & \mathrm{Xy} \mathrm{z} \\ & \mathrm{x} \mathrm{Y} z \\ \text { Tortoise-shell } & \mathrm{xyZ} \\ & \mathrm{xyz}\end{array}$

In his paper "Studies of Inheritance in Rabbits," 
published in 1909 by the Carnegie Institute of Washington, Professor Castle reports the finding and identification of the two remaining colours, which turned out to be cream and dilute tortoise. Cream seems to have been produced for some time without being noticed, for, in reference to the large number of yellows resulting from certain hybrid crossings, it is stated that "the category yellow is probably too large because of a failure to discriminate between yellow and cream, a difference which at first we failed to record." How cream was produced is not recorded; but, if it be noticed that grey, blue-grey, and yellow are the first three groups in the two-pair set

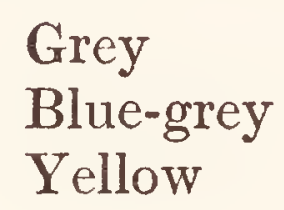

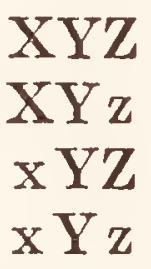

it is obvious that, if blue-grey and yellow were mated, the smallest group in their hybrids' progeny should carry the characters $\mathrm{xYz}$. Similarly, by mating either of the two groups already found carrying two dominants with the group carrying the third dominant belonging to the set, that is blue-grey, $\mathrm{XYz}$, with tortoise-shell, $\mathrm{xyZ}$, or yellow, $\mathrm{xYZ}$, with blue, $\mathrm{Xyz}$, the whole eight groups, including $\mathrm{xYz}$ and $\mathrm{xyz}$ should appear in their hybrids' progeny.

Blue and yellow were mated, and, if it be allowed that some of the yellows were really creams, it will be seen that the expected eight groups are produced and that the two new colours, cream and pale tortoise, are the sixth and eighth in the set, thus: 


\section{INSEPARABLE EFFECTS}

Grey Blue- Black Yellow Blue Cream Tortoise- Pale grey

20 7 8 $12 ?$ 4 shell tortoise

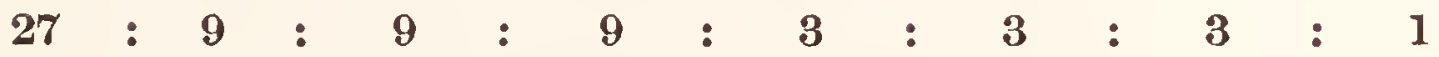

But, irrespective of this result and however found, cream was shown to be the colour carrying the characters $\mathrm{xYz}$ by being mated with black; for their hybrids' progeny consisted of the eight colours each approximately in the proper number, namely :

Grey $\begin{gathered}\text { Blue- } \\ \text { grey }\end{gathered}$ Black Yellow Blue Cream $\begin{gathered}\text { Tortoise- } \\ \text { shell }\end{gathered}$ Pale

$\begin{array}{llllllll}24 & 8 & 8 & 16 & 2 & 3 & 2 & 2\end{array}$

And, since black carries the characters $\mathrm{XyZ}$, there is only one combination of characters, namely, $\mathrm{xYz}$, with which it can be mated and have hybrids which when mated together produce eight colours. Thus cream must carry the characters $\mathrm{xYz}$, and, the only combination left for pale tortoise-shell being xyz, the complete set of eight colours consists of :

$\begin{array}{ll}\text { Grey } & \mathrm{XYZ} \\ \text { Blue-grey } & \mathrm{XYz} \\ \text { Black } & \mathrm{XyZ} \\ \text { Yellow } & \mathrm{xYZ} \\ \text { Blue } & \mathrm{Xyz} \\ \text { Cream } & \mathrm{xYz} \\ \text { Tortoise-shell } & \mathrm{xyZ} \\ \text { Pale tortoise-shell } & \mathrm{xyz}\end{array}$




\section{V \\ SUPPRESSED EFFECTS}

AN early example of the suppression of the effect of one factor by that of another is to be found in $\mathrm{Mr}$. Hurst's experiments on rabbits which were quoted from in the last chapter.

Belgian rabbits, whose colour is given as "yellowgrey," were crossed with albinos, and all but one of the seventy hybrids produced were ordinary wild greys. The exception "had, when young, more yellow on the chest and flanks than the others; but after the second moult it became almost wild grey like the rest." The parents crossed and the hybrids produced are given in the following table:

Parents

Bucks

Albino No. 2

Yellow-grey No. 4 Yellow-grey No. 4 Albino No. 2 Grey No. 25

\section{Does}

Yellow-grey No. 1

Albino No. 3

Albino No. 6

Yellow-grey No. 13

Albino No. 23
HYBRIDS

Wild Yellowgrey grey

$\begin{array}{rl}26 & 0 \\ 15 & 1 \\ 8 & 0 \\ 4 & 0 \\ 16 & 0\end{array}$

From the hybrid generation two pairs of factors can be inferred. In one pair, a factor which produces the 
wild grey shade is dominant to another which produces the yellow-grey shade, while, in the other, a factor which is concurrent with either shade of grey is dominant to a factor which is concurrent with albino; and, as the factor producing the wild grey shade must have come from the albino parent, albino therefore carries a factor whose effect is invisible. If we symbolize these two pairs of characters by $\mathrm{W}=$ wild grey shade, $\mathrm{y}=$ yellowgrey shade, $\mathrm{C}=$ the factor concurrent with grey, irrespective of shade, and $\mathrm{c}=$ that concurrent with albino, then the four groups in the hybrids' progeny should be :

$\begin{array}{cccc}\mathrm{C} & \mathrm{C} & \mathrm{c} & \mathrm{c} \\ \mathbf{W} & \mathrm{y} & \mathrm{W} & \mathrm{y} \\ \text { Wild } & \text { Yellow- } & \text { Albino } & \text { ? } \\ \text { grey } & \text { grey } & & \end{array}$

Unfortunately the connexions between the two shades of grey were not followed up in Mr. Hurst's experiments. Of the seventy hybrids, only seven were bred from; and, although the yellow-grey was one of these, its colour was not observed again. Among the hybrids' progeny and in later generations, "a few individuals appeared to have rather more yellow and less black than the wild grey; but, curiously enough, not one was a true yellow-grey like the Belgian grandparent." This may perhaps be accounted for by the small number of hybrids bred from or by the fact that most of their progeny were killed very young. It may even be that there are many factors producing different shades and yellow-grey is mainly the result of several recessives. At any rate, nothing more can be said meantime about the factors in which yellow-grey and wild grey differ. 
But, by their progeny, the hybrids showed that they were really of two different kinds-the differences resulting from other factors still-for, while some threw greys and albinos only, others threw blacks in addition; and, since the yellow-grey parents were known to be all of one kind, the differences in the hybrids must have been due to differences among the parent albinos. Thus, since there are at least two kinds of albinos, they must carry between them more than one factor whose effects are invisible.

The progeny thrown by the two kinds of hybrids are shown in the tables on page $\mathbf{4 5}$.

If the progeny of the hybrids in both tables be examined, it will be seen that No. 7 is hybrid in one pair of characters while the other hybrids are hybrid in more, and, because it is pure in certain characters in which Nos. 10 and 12 are hybrid, the progeny of 7 with 10 and 12 bear the character in which 7 is pure. If, for instance, hybrids carrying the following materials are mated
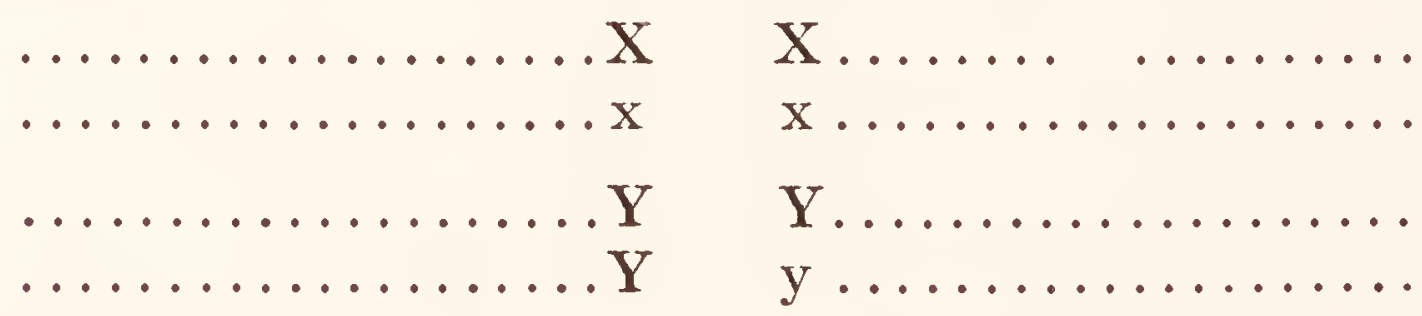

their progeny will all bear the character $\mathrm{Y}$.

The figures in the first table confirm the inference suggested by the hybrids that grey is dominant to albino; and, since the greys in the hybrids' progeny are to the albinos in the ratio $3: 1$, that albino differs from grey in one pair of characters.

In the previous chapter grey was shown to differ from three other colours each in one pair of characters. 
I

The Hybrids

Dams

No. 7 (the yel- No. 10 lowish grey)

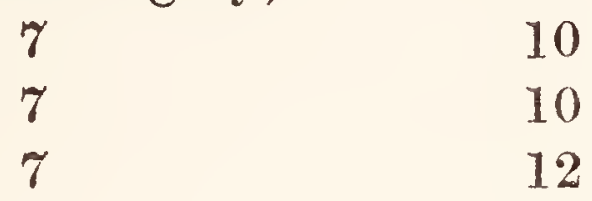

Their Progeny

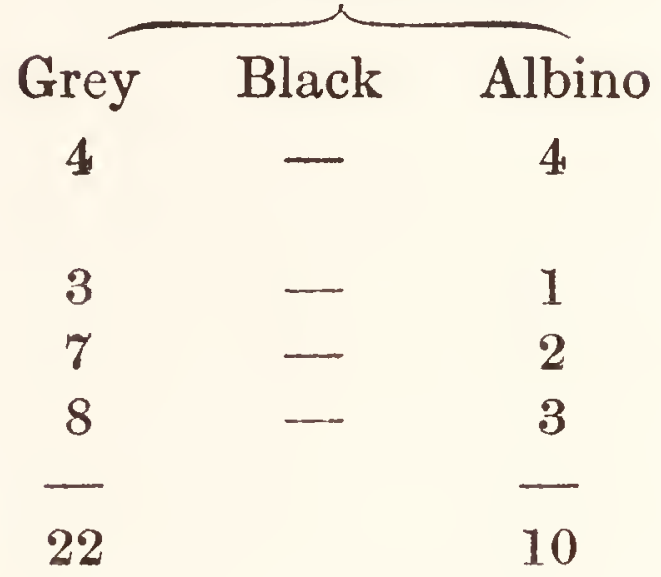

\section{II}

\section{The Hybrids}

Dams

No. 5

5

8

8

8

8

9

9

9

9

9

9

9

11

11

11

11
Sires

No. 12

10

10

10

10

10

10

10

10

10

10

10

12

12

12

12

12
Their Progeny

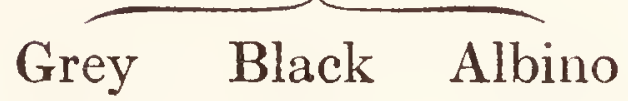

$\begin{array}{ccc}4 & 2 & 3 \\ 4 & 3 & 1 \\ 5 & 3 & 1 \\ 8 & 0 & 1 \\ 6 & 2 & 1 \\ 3 & 1 & 1 \\ 5 & 3 & 0 \\ 5 & 0 & 2 \\ 5 & 1 & 2 \\ 7 & 0 & 1 \\ 2 & 5 & 2 \\ 3 & 1 & 3 \\ 6 & 0 & 4 \\ 5 & 1 & 2 \\ 6 & 1 & 1 \\ 5 & 2 & 3 \\ 6 & 0 & 2 \\ - & - & - \\ 85 & 25 & 30\end{array}$


Now it is shown to differ from still another-albinoin another pair; and, if we call the new pair $\mathrm{C}$ and $\mathrm{c}$, the characters now known to be carried by grey and the four colours albino, blue-grey, black, and yellow, which differ from it each in one pair of characters, are :

Grey
Albino
Blue-grey
Black
Yellow

XYZC

$\mathrm{XYZc}$

$\mathrm{XYzC}$

$\mathrm{XyZC}$

$x Y Z C$

But the second table reveals a new phenomenon. The number of groups is not in accordance with the Mendelian scheme. Too many for one pair of characters and yet not enough for two, three groups suggest two pairs of characters and four groups, two of which are inseparable by the eye. If this hypothesis be correct, then, since grey, the largest group in the set, corresponds to one of the original parents, the smallest group in the set should correspond to the other and should be an albino which, by its position in the set, should differ from grey in two pairs of characters. There being a total of 140 individuals in the set, the last group should contain about $9(140 \div 16=8 \cdot 75)$ and the 21 remaining albinos should belong to one of the middle groups and differ from grey in one pair of characters. They should thus be of the kind concerned in the production of the hybrids and progeny enumerated in Table I. Then, since the characters carried by three of the groups are already known, those carried by the fourth may be inferred:

Grey
Albino No. 1
Black
Albino No. 2

XYZC

$\mathrm{XYZ}$ c

X y ZC 
Since $\mathbf{X}$ and $\mathbf{Z}$ belong to more than half the groups, the differentiating characters in the set are $\mathrm{Y}$ and $\mathrm{y}$, and $\mathrm{C}$ and $\mathrm{c}$; and, since three of the combinations which these four characters can form are already claimed, the only combination left for the last group in the set is XyZc. If the characters common to all four groups be neglected, those with which we are at present concerned are :

$\begin{array}{ll}\text { Grey } & \text { YC } \\ \text { Albino No. 1 } & \text { Y c } \\ \text { Black } & \text { y C } \\ \text { Albino No. 2 } & \text { y c }\end{array}$

But were two such albinos found among the thirty hybrids' progeny, or, since similar individuals must be produced again, among subsequent generations of the hybrids' descendants when mated among themselves or with the original parents?

This question could be answered by mating the albinos so produced with all the possible varieties of black and grey and observing the progeny at each different kind of mating. Of the albinos themselves, there should be three different kinds, namely :

$\begin{array}{ll}\text { Albino No. 1, pure in } Y \text {, and of the constitution } * & \text { Yc } \\ \text { Ac } & \text { Albino No. 1, hybrid in Y, and of the constitution } \\ & \text { Yc } \\ \text { Albino No. 2, pure, and of the constitution } & \text { y c } \\ & \text { y c }\end{array}$

* When we speak of an individual's constitution we refer to the factors it carries, 
The greys and blacks should be of the following constitutions :

$\begin{array}{lr}\text { Grey, pure, } & \text { YC } \\ \text { Grey, hybrid in Y, } & \text { YC } \\ \text { GC } \\ \text { Grey, hybrid in C, } & \text { yC } \\ \text { GC } \\ \text { Grey, hybrid in both Y and C, YC } \\ \text { Black, pure, } & \text { yc } \\ & \text { yC } \\ \text { Black, hybrid in C, } & \text { yC } \\ & \text { yC } \\ & \text { yc }\end{array}$

Mated with each of these coloured kinds, the three albinos should produce the following assemblages of progeny :

with

\begin{tabular}{cccccc}
$\begin{array}{c}\text { Grey, } \\
\text { pure }\end{array}$ & $\begin{array}{c}\text { Grey, } \\
\text { hybrid } \\
\text { in Y }\end{array}$ & $\begin{array}{c}\text { Grey, } \\
\text { hybrid } \\
\text { in C }\end{array}$ & $\begin{array}{c}\text { Grey, } \\
\text { hybrid } \\
\text { in Y } \\
\text { and C }\end{array}$ & $\begin{array}{c}\text { Black, } \\
\text { pure }\end{array}$ & $\begin{array}{c}\text { Black, } \\
\text { hybrid } \\
\text { in C }\end{array}$ \\
YC & YC & YC & YC & yC & yC \\
YC & yC & Yc & yc & yC & yc \\
\hline
\end{tabular}

Albino No. 1,

gr. bl. al. gr. bl.al. gr. bl. al. gr. bl. al. gr. bl.al. gr.bl.al pure, should

produce :- all $: 0: 0 ;$ all $: 0: 0 ; 1: 0: 1 ; 1: 0: 1 ;$ all $: 0: 0 ; 1: 0: 1$ Albino No.1, hybrid in $\mathrm{Y}$, should produce :- all $: 0: 0 ; 3: 1: 0 ; 1: 0: 1 ; 3: 1: 4 ; 1: 1: 0 ; 2: 2: 4$ Albino No. 2 should produce :- $\quad$ all $: 0: 0 ; 1: 1: 0 ; 1: 0: 1 ; 2: 2: 4 ; 0:$ all $: 0 ; 0: 2: 2$

Not devised for such a test, Mr. Hurst's experiments cannot be expected to afford examples of all the possible 
matings. Indeed they afford very few examples; yet they afford enough. If an albino can be found which throws with the various greys and blacks whose constitutions are known such an assemblage of colours as should be thrown by albino No. 1, pure, or albino No. 1, hybrid, or albino No. 2, then that albino is albino No. $\mathbf{1}$, pure, or albino No. 1, hybrid, or albino No. 2. The following table gives the assemblages of progeny thrown by five different albinos with various greys and blacks whose constitutions were known :

Grey and Black Parents

Grey, Grey, Grey, Grey, Black, Black, pure hybrid hybrid hybrid pure hybrid in $\mathrm{Y}$ in $\mathrm{C}$ in $\mathrm{Y}$ in $\mathrm{C}$ and $\mathrm{C}$

Progeny's Colours

Albino

No. No.

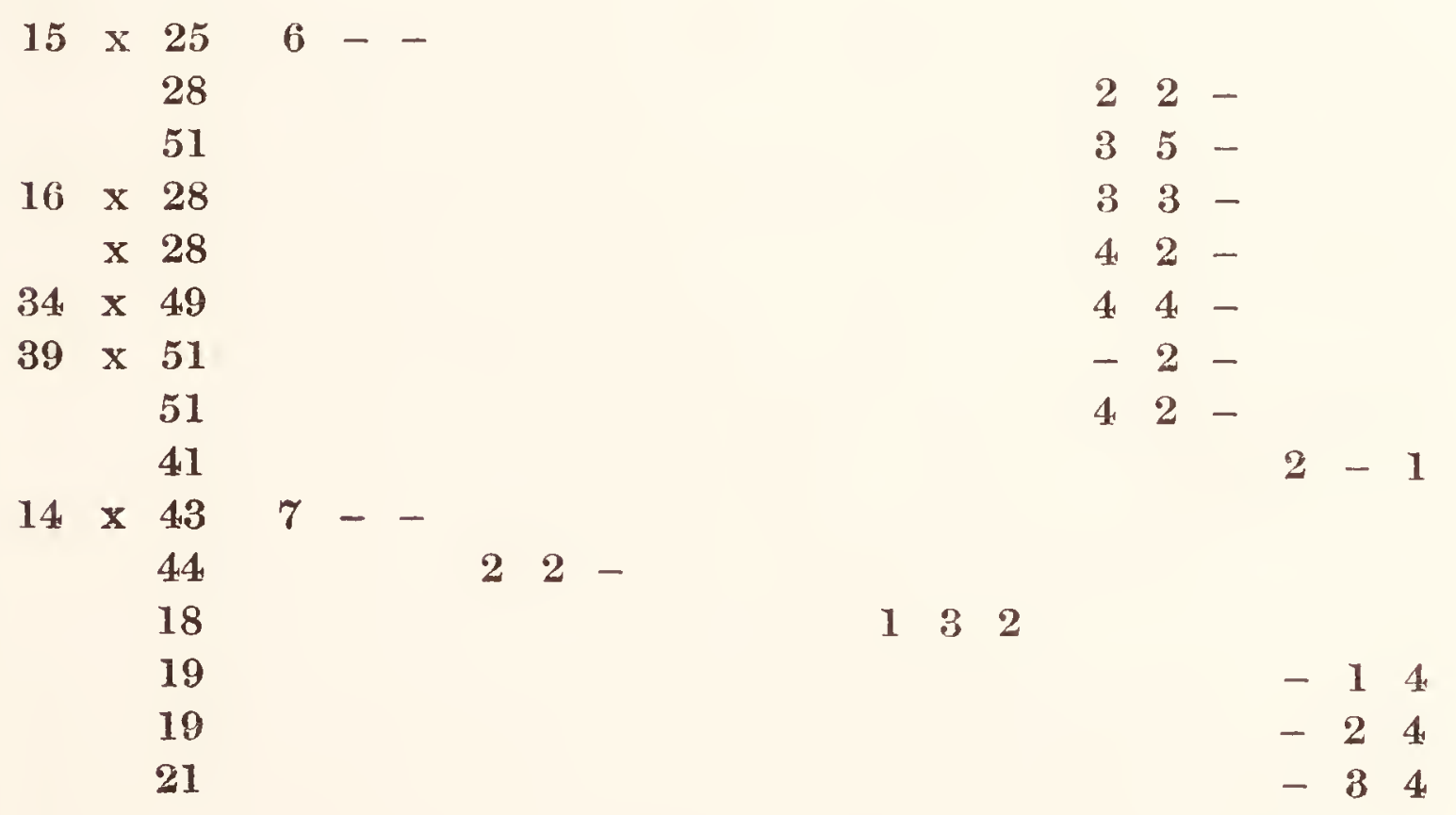

D 
One albino (No. 14) was found which, with grey pure, threw 7 greys; with grey hybrid in $\mathrm{Y}, 2$ greys and 2 blacks; with grey hybrid in $\mathrm{Y}$ and $\mathrm{C}, 1$ grey, 3 blacks, and 2 albinos; and, with black hybrid in $\mathrm{C}, 6$ blacks and 12 albinos. That is to say: an albino was found which, in four out of the six possible tests, showed itself, by its progeny, to be of the kind we have called albino No. 2, and therefore of the constitution $\mathrm{y} \mathrm{c}$.

Another albino (No. 39) was found which, with black hybrid in $\mathrm{C}$, gave 2 greys, 0 blacks, and 1 albino-thus showing itself different from No. 14-and, with black pure, gave 4 greys and 4 blacks, thus showing itself, in two out of the six possible tests, to be of the kind we have called albino No. 1 hybrid in Y. Three others (15, 16, and 34), with pure blacks, threw 16 greys, 16 blacks, and no albinos, and thus showed themselves to be of the same kind. No albino of the kind No. 1, pure, seems to have been found and bred from.

Thus among the descendants of the original grey and albino parents there were two kinds of albinos, and the three groups of hybrids' progeny, consisting of 85 greys, 25 blacks, and 30 albinos, were really four groups as follows :

\begin{tabular}{|c|c|}
\hline Grey & YC 85 \\
\hline Albino No. 1 & Yc 21 (say) \\
\hline Black & $\mathrm{yC} \quad 25$ \\
\hline Albino No. 2 & 9 (say) \\
\hline
\end{tabular}

We are now in a position to suggest what may be the effects of the factors $\mathrm{C}$ and $\mathrm{c}$. It will be noticed that grey differs from albino No. 1 in containing $\mathrm{C}$ instead of c, while black differs similarly from albino No. 2 . 


\section{SUPPRESSED EFFECTS}

When $\mathrm{C}$ is present with the other factors which produce either colour, the rabbit is grey or black, as the case may be, while, when C's place is taken by c, its recessive, the rabbits are albinos. Thus the pair $\mathrm{C}$ and $\mathrm{c}$ are concerned with colour: $\mathrm{C}$ being concurrent with its production-whether grey, black, or, presumably, any other colour-and c with its non-production.

Now that the four pairs of characters, $\mathbf{X}$ and $\mathbf{x}$, $\mathrm{Y}$ and $\mathrm{y}, \mathrm{Z}$ and $\mathrm{z}, \mathrm{C}$ and $\mathrm{c}$, have been shown to combine in producing rabbit colours, it will be instructive to set down all the possible combinations these four pairs of characters can form, together with the colours belonging to each. It will be noticed that six more albinos are possible; and, since the substitution of $\mathrm{C}$ for $\mathrm{c}$ makes a definite colour of what would otherwise be an albino, we may speak of each albino as carrying the factors for the colours which the substitution produces, thus:

\begin{tabular}{|c|c|}
\hline rey & XYZC \\
\hline Albino carrying grey & $\mathrm{XYZc}$ \\
\hline Blue-grey & $\mathrm{XYZ}$ \\
\hline Black & $\mathrm{Xy} Z$ \\
\hline Yellow & $\mathrm{x} \mathrm{YZ}$ \\
\hline Albino carrying blue-grey & $\mathrm{XYz}$ \\
\hline Albino carrying black & $\mathrm{XyZ}$ \\
\hline Blue & $\mathrm{Xyz}$ \\
\hline Albino carrying yellow & $\mathrm{xYZ}$ \\
\hline Cream & $\mathrm{x} \mathrm{Yz}_{\mathrm{z}}$ \\
\hline Tortoise-she & $x y Z$ \\
\hline Albino carrying blue & $\mathrm{xyz}$ \\
\hline Albino carrying cream & $\mathrm{x} \dot{\mathrm{Y} z}$ \\
\hline Albino carrying tortoise-shell & $x y Z$ \\
\hline Pale tortoise-shell & $\mathrm{xyz}$ \\
\hline Albino carrying pale tortoise s & $\mathrm{x} \cup$ \\
\hline
\end{tabular}


Albinism, or, at any rate, whiteness, producible by either of two separate factors was revealed in Professors Bateson's and Punnett's experiments with sweet-peas, the details of which are found in the "Reports to the Evolution Committee." Two plants were found with colourless flowers which bred true, but, when crossed with each other, threw coloured hybrids. The coloured hybrids, by being different from both parents, are evidence of two pairs of characters at least and four groups of hybrids' progeny, as follows :

\begin{tabular}{|c|c|c|}
\hline $\begin{array}{l}\text { Coloured } \\
\text { group }\end{array}$ & $\begin{array}{c}\text { Colourless } \\
\text { parent No. } 1\end{array}$ & $\begin{array}{c}\text { Colourless } \\
\text { Parent No. } 2\end{array}$ \\
\hline $\mathbf{X}$ & $\mathrm{X}$ & $\mathrm{x}$ \\
\hline $\mathbf{Y}$ & $y$ & $\mathbf{Y}$ \\
\hline 9 & 3 & : \\
\hline
\end{tabular}

If the hypothesis of two pairs of characters be correct, it will be observed that, when the dominants carried by the two middle groups are brought together, the flower which carries them is coloured. From this it is a fair inference that the colourlessness of the two parents and therefore of the two middle groups is due to the recessives they carry. And, since it carries both these recessives, it is to be inferred again that the fourth group should also be colourless. Thus, in the hybrids' progeny there should be only one coloured group and three colourless, and the numbers in the coloured group should be to those in the three colourless groups together in the ratio $9: 7$, i.e. $9:(3: 3: 1)$. When the hybrids' progeny were counted, they were found to consist of 2132 plants with coloured flowers and 1593 with colourless. If these figures be divided by $232 \cdot 81$, the figure 
which brings their total to 16 , they will be found to be to each other in the ratio $9 \cdot 16: 6 \cdot 84$; that is, approximately $9: 7$.

There is a striking contrast between these colourless flowers and the albino rabbits. The progeny of two albino rabbits are always albinos. If, for instance, an albino having the factors for grey be mated with another having the factors for black, the materials offered are $\mathrm{XYZc}$ and $\mathrm{XyZc}$; and the recessive factor $\mathrm{c}$, which is concurrent with albinism, must be carried by all the progeny. In the present case, however, both parents must carry factors for whiteness which must be different : else their hybrids would also be colourless. And both these factors must be recessive to factors having to do with colour production: else again their hybrids would be colourless.

In connexion with albinism and colourlessness, the word "white" needs to be closely watched, in case an animal or plant popularly called "white" but yet not white should be mistaken for an albino or a true white. Among fowl there are certain so-called white breeds having small specks of colour, sometimes no more than a very few feathers. But such fowl are not truly white and must carry a factor concurrent with the production of colour. Similarly the "wild white" cattle of the English parks are not true whites, for small portions about the eyes, ears, and legs are coloured either black or red. It is an historical fact that these cattle have occasionally thrown black and red calves, and, within recent years, two which had black "points" and were confined in the London Zoological Gardens actually threw black calves. These are therefore coloured cattle carrying a factor for blackness-or redness-together 
with other factors which have to do with the distribution of colour over all the body and with its restriction to the parts mentioned above. In this case it is not a factor for whiteness which is dominant to another for blackness, but a factor which restricts the distribution of colour dominant to another which allows it to be fully distributed.

We may also consider a case in which suppression is not entirely complete, the details of which are to be found in the "Reports to the Evolution Committee of the Royal Society" and in Professors Bateson's and Punnett's volumes on Mendelism. We saw in the last chapter that there are two pairs of factors operating among fowls' combs to produce the four different kinds :

$\begin{array}{ll}\text { Walnut } & \text { XY } \\ \text { Rose } & \text { X } \\ \text { Pea } & \text { x Y } \\ \text { Single } & \text { x y }\end{array}$

But there are other kinds of combs mateable with these, and, therefore, other pairs of characters. Professors Bateson and Punnett found two other kinds. One, which was an ordinary single comb excepting that it was split in two, was brought from Cairo. This comb was mated with the ordinary single comb, over which it "proved to be a distinct dominant." That is to say, their progeny were split single combs. The parents differed in one pair of characters only. Both had single combs, and carried therefore the characters xy; but the Cairo comb carried a factor for splitting which was dominant to a factor for non-splitting in the ordinary single comb. If we call this new pair of factors $S$ and $s$, then the characters of the Cairo and the 
ordinary single comb are xyS and xys; and, since the other combs in the set in which the single comb appeared must also carry s, the characters of the five combs considered so far are :

Walnut
Rose
Pea
Single
Cairo comb

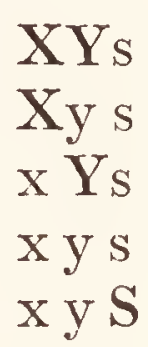

and the eight combinations which can be made by the three pairs of characters $\mathrm{X}$ and $\mathrm{x}, \mathrm{Y}$ and $\mathrm{y}$, and $\mathrm{S}$ and $\mathrm{s}$, and the kinds of combs which belong to them are :

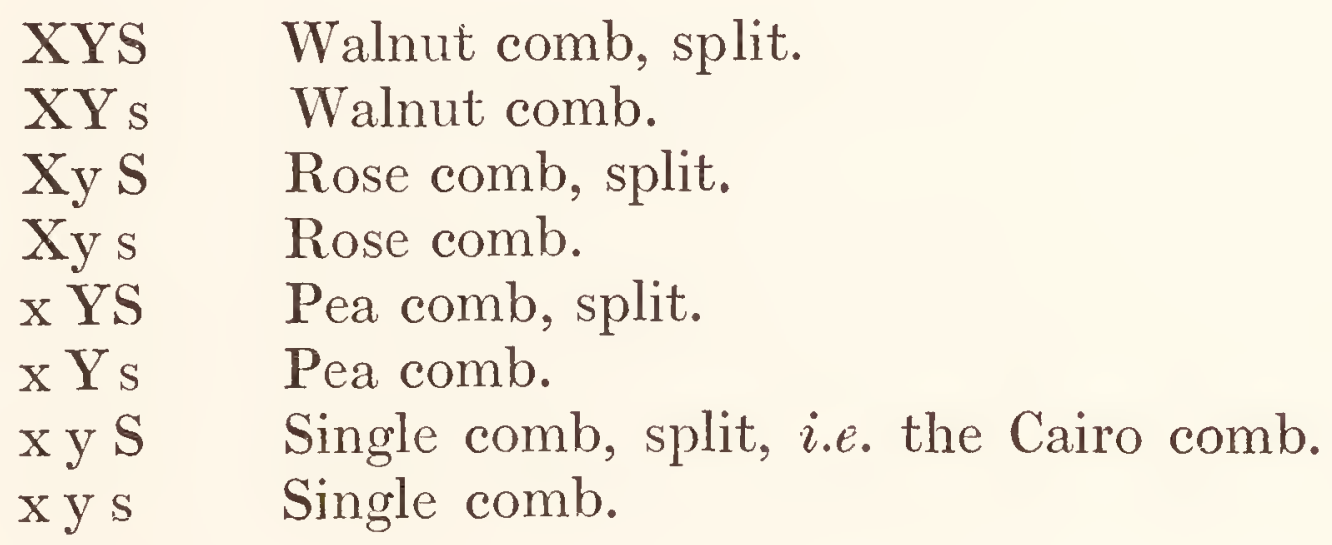

The other kind of comb found by Professors Bateson and Punnett belonged to a Dutch breed called the Breda. This comb was really no more than rudimentary, but it disclosed another pair of characters. It is described thus: "In the cocks there are two minute papillæ standing one on each side of the middle line, which are rudiments of a comb structure. As experience shows, the hens have the duplicity of which these papillæ are the evidence, but in examination of the heads of hens practically no comb tissue can be seen or felt." 
This comb was mated with both single and rose combs. When mated with singles, the hybrids had "a large double comb formed as two divaricating singles, not unlike that of the Egyptian." Thus the Breda comb carries the dominant factor for splitting just as the Cairo comb does. It also carries the factors $\mathrm{x}$ and $\mathrm{y}$, for, had it carried either $\mathrm{X}$ or $\mathrm{Y}$, its hybrids with single comb would have been something else than singles. But it carries still another factor, for, though merely a rudiment, its hybrids with single comb are real combs, not rudiments. Thus it carries a factor for a rudimentary comb which is recessive to a factor for a real comb in the single. If we symbolize these two factors by $\mathrm{r}$ and $\mathrm{R}$, then the factors now known to be carried by the Breda comb are xySr and by ordinary single comb xysR. The other real combs, walnut, rose, and pea, must also carry $\mathbf{R}$.

This finding was confirmed when the Breda comb was mated with rose comb. If Breda carry the characters $\mathrm{xySr}$ and rose comb XysR, then the two differ in three pairs of characters, and, while their hybrids should be split rose combs showing the characters XySR, their hybrids' progeny should consist of the eight kinds formed by all the possible combinations of the three pairs of factors $\mathbf{X}$ and $\mathrm{X}, \mathrm{S}$ and $\mathrm{s}$, and $\mathrm{R}$ and $\mathrm{r}$, with the factor y common to all. The hybrids were actually split rose combs, but, unfortunately, in their progeny, only six different kinds were distinguished. Six is an impossible number, however, and two groups must have each consisted of two kinds which were not separated. The following table gives the eight groups which should have been found and the six actually found : 


\section{SUPPRESSED EFFECTS}

Groups expected

XySR Rose comb, split.

XyS r Rose rudiment, split.

Xys R Rose comb, unsplit.

$\mathrm{x}$ ySR Single comb, split.

Xys $\mathrm{r} \quad$ Rose rudiment, unsplit.

$\mathrm{x} y \mathrm{~S} \mathrm{r}$ Single rudiment, split.

$\mathrm{x}$ ys $\mathrm{R}$ Single comb, unsplit.

$x$ ys $r$

Single rudiment, unsplit.
Groups found

Duplex rose.

Duplex Breda.

Rose.

Duplex single.

Simplex Breda.

Duplex Breda.

Single.

Simplex Breda.

The duplex and simplex Bredas were not discovered to be some of them roses, some singles, in each case.

As there are now at least four pairs of characters known to be distributed among fowls' combs, we may set down the sixteen combinations they can form with the kind of comb belonging to each and the names of such as have so far been named:

$\begin{array}{rll}81 & \text { XYRS } & \text { Walnut comb, split. } \\ 27 & \text { XYRs } & \text { Walnut comb, unsplit (the ordinary walnut). } \\ 27 & \text { XYr S } & \text { Walnut rudiment, split. } \\ 27 & \text { XyRS } & \text { Rose comb, split. } \\ 27 & \text { xYRS } & \text { Pea comb, split. } \\ 9 & \text { XYrs } & \text { Walnut rudiment, unsplit. } \\ 9 & \text { XyRs } & \text { Rose comb, unsplit (ordinary rose). } \\ 9 & \text { XyrS } & \text { Rose rudiment, split. } \\ 9 & \text { xYRs } & \text { Pea comb, unsplit (ordinary pea). } \\ 9 & \text { xYrS } & \text { Pea rudiment, split. } \\ 9 & \text { xyRS } & \text { Single comb, split (the Cairo comb). } \\ 3 & \text { Xyrs } & \text { Rose rudiment, unsplit. } \\ 3 & \text { xYrs } & \text { Pea rudiment, unsplit. } \\ 3 & \text { xyRs } & \text { Single comb, unsplit (ordinary single). } \\ 3 & \text { xyrS } & \text { Single rudiment, split (the Breda comb). } \\ 1 & \text { xyrs } & \text { Single rudiment, unsplit. }\end{array}$




\section{VI \\ THE ABSENCE OF DOMINANCE}

IT is well known that every breed of live stock traces back to different varieties and that, at their origin, all breeds are impure in a larger or smaller number of their characters. Breeders prefer certain characters, however, and, by breeding from animals bearing these and discarding those bearing others, gradually make their breeds purer and purer in an ever-increasing number of characters. With some characters purity is obtained at once, with others slowly, with others never at all. The breeders of the Suffolk horse, for instance, found the chestnuts they preferred throwing no other colour, and, therefore, pure at once in this character. On the other hand, AberdeenAngus breeders found their black cattle throwing red calves and Hereford breeders their white-faced cattle throwing calves with coloured faces for many years, in spite of the persistent elimination of calves of the wrong colours. We now know the reasons for these divergent experiences. The chestnut of the Suffolk horse is a recessive and can throw no other colour, while the black colour of the Aberdeen-Angus and the white face of the Hereford are dominants which may carry the factors for their respective recessives unseen and even unsuspected. 


\section{THE ABSENCE OF DOMINANCE}

Phenomena of this kind, which are usually spoken of as "reversions," are a measure of the purity of a breed. The more numerous they are the more impure the breed. It is worth noting that, if a particular character in a breed throws only one reversion, as the black Aberdeen-Angus colour throws only the red reversion, then the breed character and the reversion differ from each other in one pair of characters only.

But there are characters which are not to be bred pure even by the most persistent and long-continued efforts. The example first made clear is the colour of the Blue Andalusian breed of fowl, which is thus described by Professor Bateson: "Andalusians are in general colour what fanciers call blue-namely, a diluted black. In the cocks the hackles and saddle feathers are full black, and the feathers of the breast are edged or "laced" with black. The hens are blue, laced with black more or less, all over. This breed is recognized by the fanciers as never breeding true to colour. When blue is bred with blue three colours are produced, blacks, blues, and a peculiar white splashed with grey."

In 1902 Professors Bateson and Punnett learned from a breeder of these fowl that her blue birds of that year had thrown 36 blues, 22 blacks, and 17 whites; and, having procured birds of all three kinds, they found that their blue birds also threw blues, blacks, and whites in similar proportions, namely, 42, 19, and 22, while the other two kinds, black and white, bred true. They also found that the blacks and the whites threw blue Andalusians when mated with each other.

Stated in the usual order, this means that blacks mated with whites throw hybrids different from both : from which it is to be inferred that there are at least two pairs of 
factors operating and that there should be four groups in the hybrids' progeny, as follows :

\begin{tabular}{|c|c|c|}
\hline Blue & Black & White \\
\hline $\mathbf{X}$ & $\mathbf{X}$ & $\mathrm{x}$ \\
\hline $\mathrm{Y}$ & $\mathrm{y}$ & $\mathrm{Y}$ \\
\hline 9 & 3 & 3 \\
\hline
\end{tabular}

Instead, however, the hybrids' progeny consist of only three kinds in a proportion which is entirely new, namely, adding both the above results together,

\begin{tabular}{|c|c|c|c|}
\hline & Blue & Black & White \\
\hline & 78 & 41 & 39 \\
\hline i.e. & 2 & 1 & 1 \\
\hline
\end{tabular}

with the further deviation from the usual Mendelian result that the largest group contains no true-breeding individual while every individual in the other two groups breeds true. To meet these phenomena, a new hypothesis or, at any rate, a modification of the ordinary Mendelian hypothesis is necessary. It will be remembered that, ordinarily, when the parents differ in one pair of characters, say $\mathbf{X}$ and $\mathrm{x}$, the hybrids' progeny consist of two groups, the larger of which can be divided into hybrids and truebreeding individuals, while the smaller contains truebreeding individuals only, thus :

$\mathrm{X}$

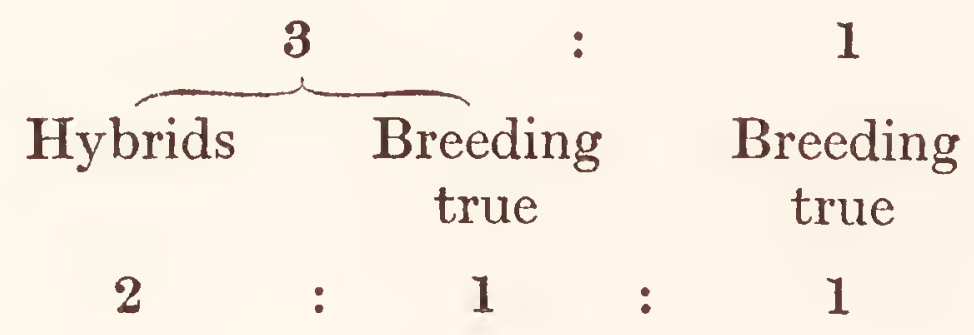




\section{THE ABSENCE OF DOMINANCE 61}

and that the largest of these is the hybrid group over again while the others are the original parent groups. Clearly this is a similar case, excepting that neither black nor white is dominant the one to the other and the hybrid is something intermediate between them. Thus there is only one pair of characters in operation.

Although it is obviously sound, it may be well to show that this hypothesis can be proved. If there were more than one pair of factors, say two, namely, $\mathbf{X}$ and $\mathrm{x}$ and $\mathrm{Y}$ and $\mathrm{y}$, the constitutions of the hybrids and the two parents should be:

$\begin{array}{ccc}\text { Hybrids } & \text { Blacks } & \text { Whites } \\ \text { Xx } & \text { XX } & \text { x x } \\ \text { Yy } & \text { y y } & \text { YY }\end{array}$

Then, if the hybrids were mated with their black parents, the materials offered should be :

By the Hybrids

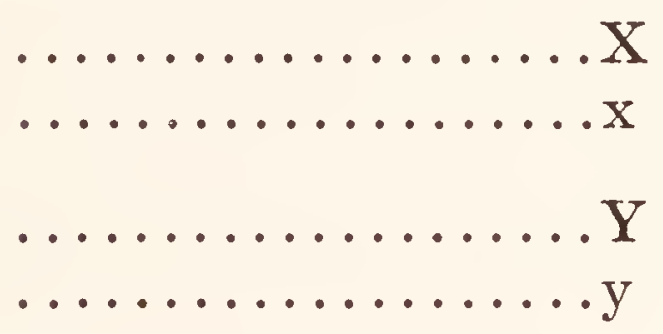

By the Blacks

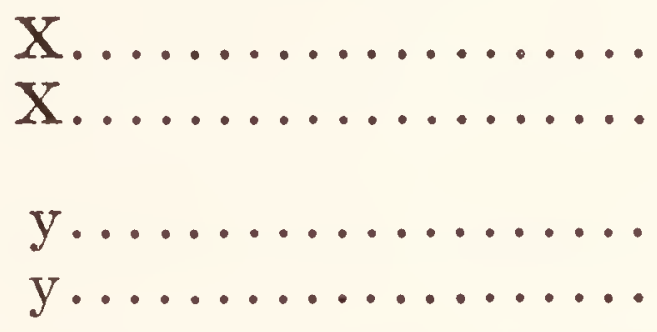

and equal numbers of the following four kinds of progeny should be produced, three of which should be hybrid in one or in both pairs of characters:

$\begin{array}{llll}X X & X X & X x & X x \\ Y y & y y & Y y & y y\end{array}$

Instead of this, however, only two kinds were produced, namely, 27 blue hybrids and 19 true-breeding blacks. 
Similarly, if the hybrids were mated with their white parents, the materials offered should be :

By the Hybrids

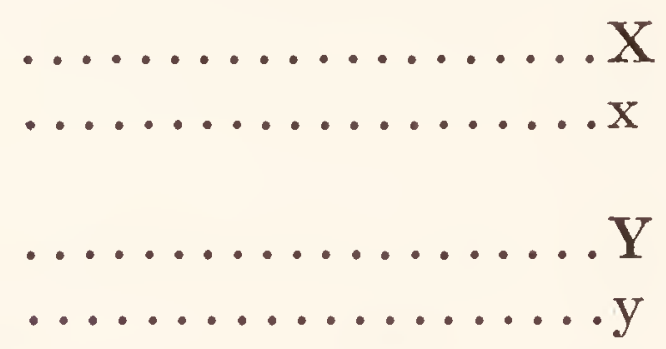

By the Whites

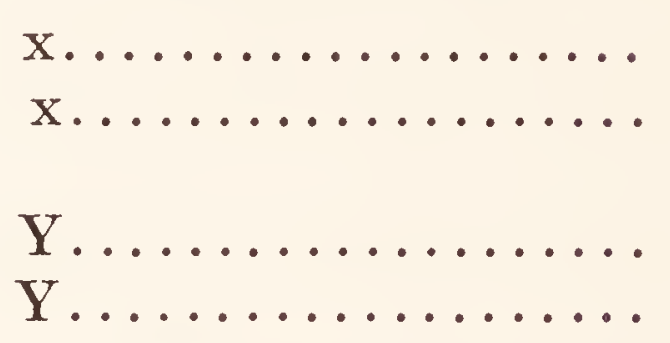

and equal numbers of the four following kinds should be produced, three of which should be hybrid in one or both pairs of characters :

$\begin{array}{llll}\text { Xx } & \text { Xx } & \text { Xx } & \text { Xx } \\ \text { YY } & \text { Yy } & \text { YY } & \text { Yy }\end{array}$

Again, instead of this only two kinds were produced, namely, 34 hybrid blues and 20 true-breeding whites.

Thus there are not more than one pair of factors in operation.

With this solution of the Blue Aldalusian problem several questions come to the surface without, as yet, finding a clear answer, as, for instance: Is blue the result of mating black with white or with grey or with white and grey combined? If with either white or grey, what becomes of the white or grey splashing which should appear in the hybrids' progeny? If with white and grey combined, is the same pattern carried by all three colours, but obscured in the white partially and entirely in the black?

In addition to white, there are four true-breeding colours among cattle and a still larger number which do not breed true. These true-breeding colours are black, red, light or steel dun, and brown, a colour found among Longhorns, Highlanders, and Ayrshires, as well as among 


\section{THE ABSENCE OF DOMINANCE}

Jerseys, Swiss, and French-Canadians. These colours may all be spotted and flecked with white, and the tastes of breeders vary so that the gradations run from whole colours at the one extreme through numerous varieties of spots and flecks to animals so little coloured at the other extreme that, like the "wild white" cattle, they are frequently regarded as whites. The black AberdeenAngus, Galloways, and Welsh are whole-coloured breeds, although small white markings on the underline are not uncommon; the red Devons and Sussex are also wholecoloured, but for the white tail-switch ; the red Herefords have white faces, chines, and underlines; the red Shorthorns have many varieties of white marks and flecks; the Dutch have large white flecks, one pattern of which encircles the animal like a belt; and many Ayrshires have only a few small spots of colour about the neck: the rest of the body being an unbroken white. Yet all these cattle carry the factor for one or other of the ordinary colours together with other factors which determine how much of the body shall or shall not be pigmented.

It may be that the pure whites are not absolutely colourless, for their white is not just that of an albino, and sometimes it seems to assume a darker tint within the ears; but, since these white cattle can be crossed with coloured cattle and their coloured descendants from such crosses carry the usual spots and flecks, there can be no doubt that they also carry factors for spots and flecks whose effects are invisible in the whites themselves.

The colours which do not breed true are yellow, dun, the several varieties of brindle, and the two roans, blue and red. These are known to be hybrids between one or another pair of the true-breeding colours. Red roan, which has been a Shorthorn colour since the foundation 


\section{4}

of the breed in the eighteenth century, has been most fully investigated. Since the beginning of the nineteenth century, Shorthorn breeders have disliked white and preferred the other two colours, red and roan: sometimes the one being in higher favour, sometimes the other. Thus white has been much less frequently bred from; yet whites have not decidedly decreased, for the reason that they are still thrown when roans are mated with each other. Reds are thrown from the same matings, but, being not unwelcome, their appearance occasions no remark. Breeders have been aware that there were whites among the ancestry of their breed, but, by breeding from reds and roans only, have hoped to eliminate the "reversionary white" taint and eventually have their roans breeding true. In this, however, they have never succeeded.

Before coming to the solution, it will be well to examine the nature of the evidence upon which the problem is solved. Because of their slow reproduction and therefore of the time and expense which would be involved, experiments with large animals are not readily undertaken. We must have resort therefore to pedigree records in which the results of all the possible matings are to be foundin the present case to Coates's "Shorthorn Herd Book." But such volumes are liable to errors which must be identified and allowed for before the records can be used as evidence. The chief errors in the "Shorthorn Herd Book" arise from misdescriptions, non-registration of calves of the undesired colour, mistakenly attributed paternity, and the substitution of a calf of a desired for another of the undesired colour. The last two errors may be neglected generally and eliminated almost completely by selecting data from the records of careful and reliable breeders only. 


\section{THE ABSENCE OF DOMINANCE}

Reds are not infrequently described as roans and roans as reds. Lacking the experimenter's motive, breeders may be inaccurate without being negligent, and may even be biased unconsciously by the wish to have a calf of one colour rather than of another. As already mentioned, red may run from whole red to very nearly white. When the individual flecks are large or well defined, the chances of misdescription are small, but, when they are small and in some number, and, more especially, when the margins between the white and the red are ragged and irregular, the chances of a red being called a roan are not inconsiderable.

Roans may also be whole-coloured or flecked as the reds are, but the areas which would be red in the red are a mixture of red hairs with white in the roan. The chances of misdescription lie in the fact that the proportion of white hairs among the red varies, and, when it is small, a roan is liable to be mistaken for a red. The reasons for this variation are still obscure, although there are indications that the amount of white in the mixture and the amount of flecking are related: the white hairs being fewer when flecking is absent or small and plentier when flecking is extensive. In crosses between whole-coloured black Galloways, for instance, and white Shorthorns, the proportion of white hairs is usually small, while in crosses between highly flecked Ayrshires and white Shorthorns, the proportion is usually large.

The experience in pure white breeds, such as the Charolais, and in red breeds, of which there are several in Britain, is that both colours always breed true; and, from data collected in volumes 37 to 49 of the "Shorthorn Herd Book" and cited in 1906 in "Biometrika" by Miss Barrington and Professor Karl Pearson, the whites and 
the reds among English Shorthorns also breed true. In consequence of the breeders' aversion to white, only 94 white with white matings were found, and these gave 89 white calves, 4 roans, and 1 red. At the same time, 438 red with red matings gave 413 reds and 25 roans. Taking the chances of error into consideration together with the fact that white breeds and red breeds breed true, the 4 roans and the red in the first case and the 25 roans in the second may be set aside with full confidence. They represent inaccuracies of only $5 \cdot 3$ and $5 \cdot 7$ per cent.

One hundred and thirty-five matings of white with red were found. These produced 128 roans and 7 reds, and, again setting aside the 7 reds as inaccuracies- $5 \cdot 2$ per cent. - the result shows roan to be a hybrid between red and white. The question as to whether it is hybrid in one or more pairs of characters was determined by 514 matings of itself with itself, from which there resulted 278 roans, 152 reds, and 84 whites. These figures approximate to none of the $(3: \mathbf{1})^{n}$ ratios, and, allowing for the usual inaccuracies, more especially for that of the non-registration of whites, may be taken as being in the proportion 2:1:1 and showing that roan is hybrid in one pair of characters only. This finding was confirmed by the matings of roan with both the parent colours. 1008 matings of roan with red gave 521 roans, 483 reds, and 4 whites, while 74 matings of roan with white gave 47 roans, 24 whites, and 3 reds.

It has to be mentioned that Miss Barrington and Professor Pearson did not arrive at this conclusion. Following the breeders' convention, which is only loosely adhered to, they arranged the reds in the three categories "red," "red with little white," and "red and white," and, crediting the Herd Book records with 


\section{THE ABSENCE OF DOMINANCE}

an accuracy to which they are not entitled, they found no very clear Mendelian ratio. It was therefore desirable that further data should be collected from the records of more recent breeders known to be reliable and careful beyond the average; and this was done by the present writer in a paper published in $\mathbf{1 9 0 8}$ in the "Scientific Proceedings of the Royal Dublin Society." Two other sets of data have since been collected : one by Mr. Robert Bruce, from the records of Mr. Amos Cruickshank, the famous breeder, and published in 1908 in the Breeders' Gazette, and the other collected in America by Professor E. N. Wentworth and published in the American Breeders' Magazine in 1913. The four sets of data are brought together in the following table, in which $\mathrm{BP}$ represents Miss Barrington and Professor Pearson's, Wn the present writer's, Br Mr. Bruce's, and Wh Professor Wentworth's :

Matings

Red x Red

White $\mathrm{x}$ Red

\section{Colours of Calves}

White Red Roan

White $\mathrm{x}$ White
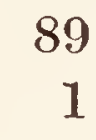

2

141

89
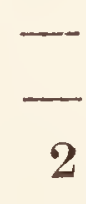

39

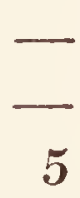

18

$\begin{array}{rrl}1 & 4 & \mathrm{BP} \\ -1 & - & \mathrm{Wn} \\ 4 & -8 & \mathrm{Br} \\ 413 & 25 & \mathrm{BP} \\ 90 & 5 & \mathrm{Wn} \\ 189 & 40 & \mathrm{Br} \\ 1710 & 102 & \mathrm{Wh} \\ 7 & 128 & \mathrm{BP} \\ - & 78 & \mathrm{Wn} \\ 2 & 42 & \mathrm{Br} \\ 20 & 891 & \mathrm{Wh}\end{array}$


Matings

Roan x Roan

White x Roan

Red x Roan
Colours of Calves

White Red Roan

$\begin{array}{rrrl}84 & 152 & 278 & \mathrm{BP} \\ 102 & 90 & 178 & \mathrm{Wn} \\ 60 & 66 & 183 & \mathrm{Br} \\ 471 & 664 & 1275 & \mathrm{Wh} \\ 24 & 3 & 47 & \mathrm{BP} \\ 19 & - & 34 & \mathrm{Wn} \\ 12 & - & 12 & \mathrm{Br} \\ 72 & 8 & 169 & \mathrm{Wh} \\ 4 & 483 & 521 & \mathrm{BP} \\ 3 & 214 & 209 & \mathrm{Wn} \\ 2 & 347 & 305 & \mathrm{Br} \\ 15 & 1763 & 1336 & \mathrm{Wh}\end{array}$

Considering their sources, the Wn data contain probably the smallest proportion of inaccuracies.

Professor Wentworth has suggested that there are two pairs of factors operating to produce whites, reds, and roans, namely, red and its recessive white, and roan pattern and its recessive plain. If this theory be correct, there ought to be four groups, as follows :

$\begin{array}{cccc}\begin{array}{c}\text { Red } \\ \text { Roan }\end{array} & \begin{array}{c}\text { Red } \\ \text { Plain }\end{array} & \begin{array}{l}\text { White } \\ \text { Roan }\end{array} & \begin{array}{c}\text { White } \\ \text { Plain }\end{array} \\ 9 & : & 3 & :\end{array}$

On this theory, the roans and the whites should both be more numerous than they are, and reds should produce reds and whites in the proportion not very much less than $3: 1$. At the same time, since some of the red roans should be pure not only for red but also for roan pattern, the mating of red roan with red roan should produce red roans to reds in even higher propor- 


\section{THE ABSENCE OF DOMINANCE 69}

tion than $3: \mathbf{1}$. Mr. Wentworth bases his suggestion on the fact that certain hybrid roans (i.e. the progeny of whites and reds) threw 64 calves, of which 36 were roans, 11 reds, and 17 whites. These figures are certainly very close to the $9: 3: 4$ ratio, but they are not far from the figures demanded by the other theory, namely, 32 roans, 16 reds, and 16 whites. 


\section{VII \\ POLYGAMOUS FACTORS}

In the last chapter it was stated that five true-breeding cattle colours are known. Two only behave as dominant and recessive-black being dominant to red-the others produce intermediate hybrids. So far as yet known, the following table gives the pure-breeding parent colours and the hybrids they produce :

\begin{tabular}{|c|c|c|c|}
\hline \multicolumn{2}{|c|}{ Parents } & & HybRIDS \\
\hline Black & $\mathrm{x}$ & Red & Black \\
\hline , & $\mathrm{x}$ & Light Dun & Dun \\
\hline, & $\mathrm{x}$ & Brown & Brindle (dark or black) \\
\hline & $\mathrm{x}$ & White & Blue Roan \\
\hline Red & $\mathrm{x}$ & Light Dun & Yellow \\
\hline ", & $\mathrm{x}$ & Brown & Brindle (reddish brown) \\
\hline & $\mathrm{x}$ & White & Red Roan \\
\hline Light Dun & $\mathrm{x}$ & Brown & Brindle (light) \\
\hline & $\mathrm{x}$ & White & $?$ \\
\hline Brown & $\mathrm{x}$ & White & ? \\
\hline
\end{tabular}

In this table three anomalies are obvious : first that there are five true-breeding groups-an impossible number; second, that, since black differs from each of the other colours in one pair and, so, reveals four pairs of characters in operation, there are no more than five true-breeding groups in all ; and third, that the colours 70 
other than black and red differ from each other abnormally. Setting them out in the usual way, without attributing to them either dominance or recessiveness, the characters carried by black and the other four colours should be :

Black
Red
Light Dun
Brown
White

XYZA

$\mathrm{XYZ}$ a

$\mathrm{XY} z \mathrm{~A}$

XyZA

$x$ YZA

and the last four colours should differ each from every other in two pairs of characters. Yet we saw in the last chapter that red and white differ from each other in one pair only, and sufficient evidence has been collected from the "Highland Cattle Herd Book" to show that the other colours differ similarly in only one pair of characters. Data with regard to the crossing of white with light dun and brown have not been found, but it is inconceivable that these crossings should not be like the others. How are these phenomena, which may be condensed into the statement that five intermateable colours differ each from every other in only one pair of characters, to be accounted for ?

The problem may be simplified by considering only three colours at a time, for what holds for three will hold for the five. Black differs from red in one pair of factors and from white also in one pair. Ordinarily, without attributing dominance or recessiveness, the colours and the characters they bear would be set out as follows :

$\begin{array}{ll}\text { Black } & \text { XY } \\ \text { Red } & \text { Xy } \\ \text { White } & \text { X Y }\end{array}$


But, by this arrangement, white and red must differ in two pairs of characters, which is not in accordance with the facts. Obviously, if each colour is the result of more than one factor, two must always differ in more than one pair; and this they do not do. Thus the only possible solution of the problem is that each colour is the result of one factor only and that the factors are polygamous: the factor for black, say, mating with that for red, or white, or brown, or light dun; and so on all round. Unfortunately this solution cannot be tested satisfactorily, because some of the necessary crosses are seldom made and, if made, are not recorded. Putting the initial letters of the colours for the factors producing them, blue roan (BW) by red roan (RW) should produce 1 black $(\mathrm{BR})$ : 1 blue roan $(\mathrm{BW})$ : 1 red roan $(\mathbf{R W})$ : $\mathbf{1}$ white $(\mathrm{WW})$. In Ireland, here and there, are a few blue-grey heifers and cows which are mated with Shorthorn bulls, and the Department of Agriculture's County Instructors and Overseers very kindly took notes of what information they could gather as to the results of mating blue roans with red roan Shorthorns. The blue roans were mostly in the hands of small farmers who found greater difficulty than Shorthorn breeders in distinguishing not only red from roan but black from blue. They were inclined to call red roans red and blacks with white spots blue. Besides, in cases, they spoke from memory of animals no longer in their possession. As collected the figures are:

Black Red $\begin{gathered}\text { Blue } \\ \text { Roan Red White } \\ \text { Roan }\end{gathered}$


Considering the possible errors, these figures are not against the theory that the colours concerned are due to single factors, but no more can they be taken as completely satisfactory evidence in its favour.

Among Highland cattle, crosses are made by which the solution of single factors for each colour could be tested, but here again the errors arising from misdescription and non-registration of undesirable colours are as prevalent as among Shorthorns. The crosses, with the results they should give and the actual figures obtained from volumes 13, 14, and 15 of the "Highland Cattle Herd Book" are as follows :

Colours Expected

Black Red Brindle Yellow Dun $\begin{gathered}\text { Light } \\ \text { Dun }\end{gathered}$

Black x Yellow

(BB and BR $\times$ RL)

Red $\mathrm{x}$ Yellow

(RR x RL)

Yellow x Dun

(RL x BL)

$\mathrm{x}$

$\mathrm{x}$

$\mathrm{x} \quad \mathrm{x}$

-

Black x Yellow

(BB and BR $\times$ RL)

$18 \quad 5$

(8)

19

16

Red x Yellow

(RR $\times$ RL)

77

(27)

92

(4)

Yellow x Dun

(RL x BL)

1

$-\quad-$

4

2

3

The colours which should not have been found are enclosed within brackets. Excepting the brindles, they will be seen to be few. The brindles may be neglected 


\section{4}

\section{A MANUAL OF MENDELISM}

altogether, as they are exceedingly liable to misdescription and are the progeny of browns, which are seldom described as such but generally as blacks. The numbers of each kind of progeny expected from black and yellow cannot be given, as the pure black parents cannot be distinguished from those containing red. Red and yellow should give equal numbers of reds and yellows and yellow and dun equal numbers of the four kinds expected: The figures found are therefore in reasonable agreement with expectation.

But, if the data used to prove that cattle colours are the result of single factors which are polygamous leave something still to be desired, it is satisfactory to know that the factors for the colours of horses are also single and polygamous and that the available data are much more reliable and less confusing. In their case no intermediate hybrids are produced and, because all the colours are related to each other as dominants and recessives, the manner in which they group themselves as a whole is of unusual interest.

Among horses there are five colours : grey, dun, bay, black, and chestnut - another impossible number. Through all runs a series of shade factors which have the effect of varying the chestnuts from bright gold at the one extreme to dark liver at the other, the bays from light bay to dark brown, and the duns from cream to bluish dun, but have no identifiable effect upon black and grey although undoubtedly present in both. As yet little is known as to the inheritance of these shade factors, and, in what follows, they are entirely neglected. In addition to these, a pair of factors is in operation whose effects are readily distinguishable in every colour but grey. The dominant 


\section{POLYGAMOUS FACTORS}

has the effect of mixing the coloured hairs with whitethe animal carrying the mixture being then called a roan-while the recessive leaves the coat unmixed. Thus there are chestnut roans, black roans, bay roans, dun roans, and grey roans; but the last cannot be distinguished from ordinary greys unless the animals be very young. The roan factor has effect upon the body only and leaves the face and lower limbs the normal colour; but it has effect from birth. A grey horse, on the other hand, is usually born black and does not begin to turn grey till its first coat has been cast. The greying begins about the head and face. Thus a foal with black face and legs and the rest of its body a mixture of black and white hairs is not a grey but either a black roan or a grey roan. If its face remains black it is a black roan, if its face turns grey it is a grey roan.

Two roans are seldom mated, consequently few horses pure for roan can be found. So far only one-in America --has been identified, but, as hybrid roans produce equal numbers of roans and normals when mated with normals and two normals do not produce a roan, the dominance of the factor for roan is clear.

The first important evidence as to the inheritance of horse colours was that collected from the records of German official studs by Doctors M. Wilckens and H. Crampe and published as far back as $\mathbf{1 8 8 7}$ and $\mathbf{1 8 8 8}$ in volumes xvii and xviii of Landwirtschaftliche Jahrbücher. Dr. Crampe makes two very significant observations, namely:

(1) That chestnuts with chestnuts have chestnut foals, including chestnut roans and chestnut greys.

(2) That blacks with blacks have both black and chestnut foals, and roans and greys of these colours. 
Knowing as we do now that chestnut roans and black roans are merely chestnuts and blacks carrying the additional effect of another independent factor and that greys are very liable to misdescription, we can infer that chestnut is recessive to all other colours and that black, by throwing both blacks and chestnuts but no others, is a simple dominant to chestnut but recessive to the others.

The first of these inferences is of course confirmed by the experience of the breeders of the Suffolk Punch, while the second is confirmed by data collected by Dr. Walther in the records of the Trakehnen, Beberbeck, and Halbturn studs and published in his " Beiträge zur Kentniss der Vererbung der Pferdefarben" in 1912, for, excluding 3 greys entries as erroneous, he found that black with black gave 852 black foals and 74 chestnuts.

The first inference was also confirmed by data collected from the Thoroughbred Stud Book, that is, Weatherby's "General Stud Book," by Mr. C. C. Hurst and published in the "Proceedings of the Royal Society" in 1906. But Mr. Hurst arrived at another conclusion of new and equal importance, namely, that bay-that is bay and brown taken together as one--is also dominant to chestnut. His figures were :

With chestnut mares, 101 chestnut sires get . • $\cdot{ }^{\circ} \cdot{ }^{\circ}$

With chestnut mares, 6 pure bay
sires get.
With chestnut mares, 12 hybrid bay

Bay Chestnut foals foals

$9 \quad 1095$ sires get . . . . 
The first of these results, drawn from a breed which also contains greys and possibly a few blacks, confirms the first inference from Dr. Crampe's observations that these other colours are dominant to chestnut while the second and third are definite that bay is dominant to and differs from chestnut in one pair of characters only ; for, if it differed in more, the mating of hybrid bay with chestnut would produce more than equal numbers of bays and chestnuts.

Thus there are now two colours, black and bay, both of which are simple dominants to chestnut. So far the case is parallel to that of the fowls' combs at the stage when both rose and pea were found dominant to single comb; but the parallelism goes no farther, for, when black and bay are mated, no new colour is produced, but blacks and bays only and chestnuts, their common recessive. Two sets of figures are available: one from Dr. Walther's volume and the other from the Stud Book of the English Shire Horse Society:

Bays Blacks Chestnuts

With black German mares,

68 bay sires get . $\quad$. 281

124

20

With black Shire mares, 28

bay sires get

409

225

35

No inference can be drawn from the relative numbers of each colour because it is impossible to tell how many of the black and bay sires were hybrid and how many pure.

How is this phenomenon to be explained? It might be suggested that there are two pairs of factors and two inseparable bay groups according to the scheme:

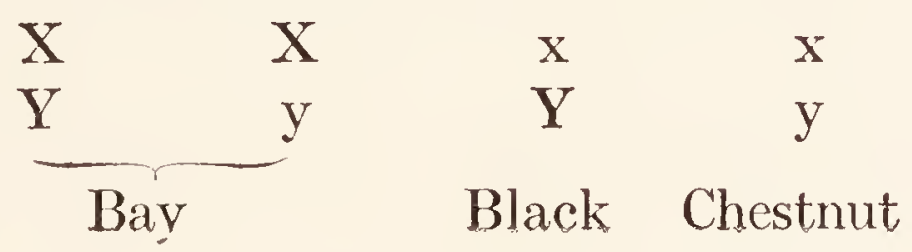


But this would mean that some bays differ from chestnut in two pairs of characters: a result entirely opposed to that brought out by Mr. Hurst's figures. Clearly, therefore, there are not two pairs of characters, and, since there are three colours, there must be three factors, one for each colour, and each factor must mate with the other two severally and indifferently. If this be so, then, since no fourth colour, intermediate or other, is produced, either black or bay must be dominant the one to the other and the two must differ in one pair of characters only. In the Shire Stud Book 14 sires were found which, by their progeny with bay mares, were proved to be pure bays; and these sires, with black mares, got bay foals only. Dr. Walther found also 11 German sires which, with black mares, got bay foals only. Thus bay is dominant to black. The actual figures, with erroneous entries enclosed within brackets, are as follows :

Bays Blacks Chestnuts

With bay mares 14 bay Shires get 618

With black mares the same sires

$$
\text { get • . . . } 163
$$

With black mares 11 German sires

get . . . . . 200

But in how many factors do bay and black differ ? Sixteen bay Shires, which got both bays and blacks when mated with bay mares and thus showed that they carried the factor for black in addition to that for bay, were mated with black mares, and got equal numbers of bay and black foals. Dr. Walther also found 10 similar German sires. Thus bay differs from black in one pair of characters. The figures, with the erro- 
neous entries again enclosed within brackets, are as follows :

Bays Blacks Chestnuts

With bay mares 18 bay Shires get

366

57

With black mares the same sires

$$
\text { get . . } \quad . \quad \text {. } \quad 51 \quad 41
$$

With bay mares 10 bay German sires get . . . . 141

28

With black mares the same sires

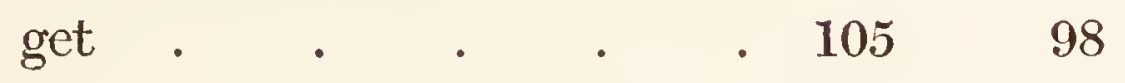

Thus we have a series of three colours, bay, black, and chestnut, in which bay is dominant to black and chestnut, and black to chestnut, and each colour is the result of a single factor which mates separately and indifferently with either of the factors for the other two colours.

The foregoing proof of this hypothesis may be confirmed still farther. If it be sound, then there should be pure bays, constitutionally represented by $\begin{aligned} & \text { By } \\ & \text { By bays }\end{aligned}$ carrying the black factor, $\mathrm{By}$, and bays carrying the chestnut factor, $\mathrm{By}$, pure blacks, $\mathrm{Bl}$, blacks carrying chestnut $\mathrm{Bl}$, and chestnuts, $\mathrm{Ch}$. Then, in a mixed population of bays, blacks, and chestnuts, there should be sires and dams of each of these six constitutions, and the different varieties of bay and black sires should leave different assemblages of progeny as indicated in the following table: 


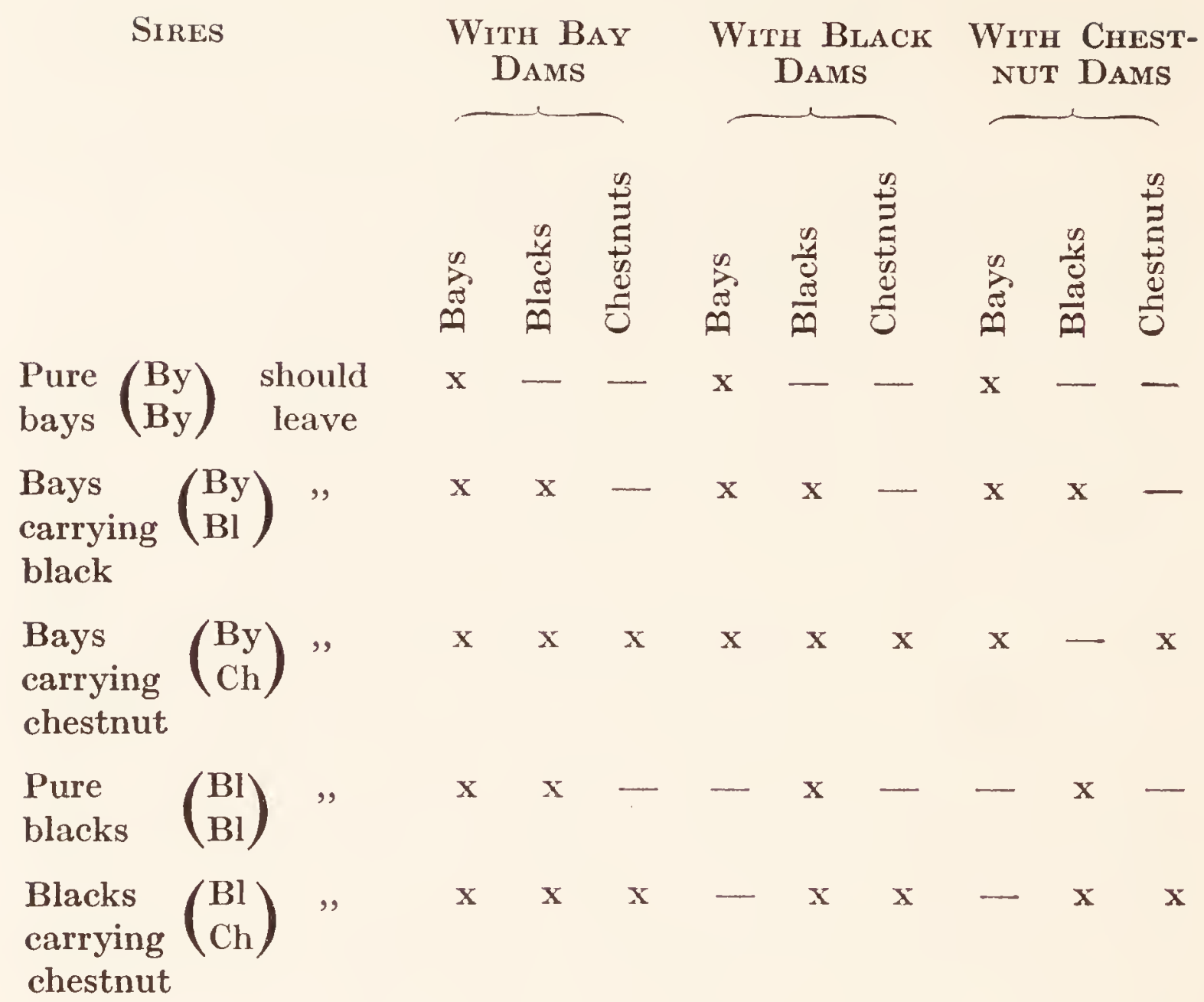

The table on page 81 gives the actual progeny of 84 Shire horses with dams of all three colours, from which it will be seen that sires of the five expected kinds can be identified. Obviously erroneous entries are again enclosed within brackets.

In one case only are the errors serious, that, namely, in which 16 black foals are found among the progeny of the 36 bay sires with chestnut mares. One of the chief errors in registration is that of calling a very dark brown horse black; and, of the 16 foals, 5 were the progeny of a horse so very dark brown that he was frequently referred to as black. The other 11 foals were in all probability similarly sired.

But what of the remaining colours, grey and dun? 


\section{POLYGAMOUS FACTORS}

Are they further members of the series with bay, black, and chestnut? The question is really two questions, namely, How do grey and dun stand to each other and to the others as regards dominance and recessiveness? and, Are they also the result of single factors?

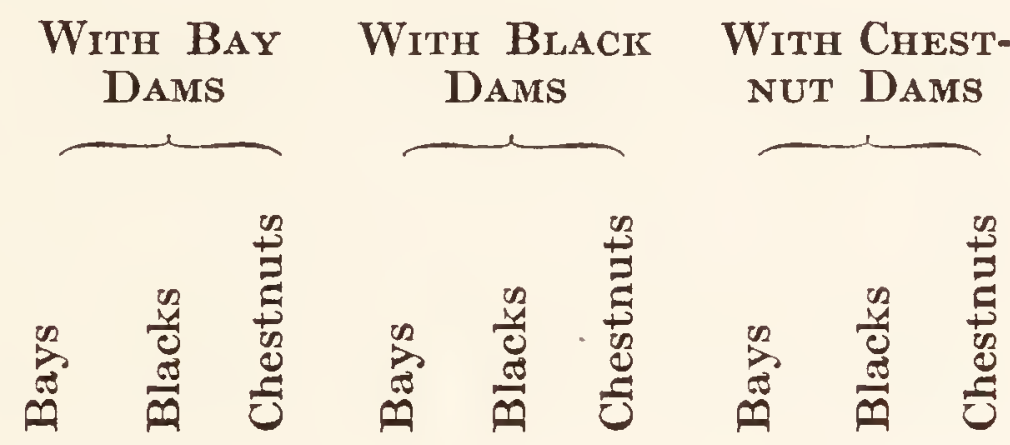

Fourteen bay sires got . . .

Eighteen bay sires
$616 \quad(2)$

(2) 163

(6) -

68

got . .

Thirty-six bay sires

got $\cdot$.

Four black sires got.

$366 \quad 57$

(3)

51

41

(1) 359

Twelve black sires

got.$\quad \cdot \quad \cdot \quad 266 \quad 75 \quad 37$

$\begin{array}{rrrrrrrrr}1296 & 92 & 134 & 167 & 83 & 19 & 103 & (16) & 88 \\ 13 & 12 & - & (1) & 19 & - & (3) & 11 & -\end{array}$

Because of their paucity in modern breeds, both colours are very short in data, and reliance has to be placed upon early Thoroughbred and similar records supplemented by more recent but scantier information collected from more modern but smaller breeds and among unregistered stock.

There is also the further difficulty that grey data must be handled with unusual care because no grey horse is born grey, and greys are frequently registered as of some other colour while the original misdescription is not always corrected later. White foals, which may be albinos, are occasionally born, but the foal which is to become grey is usually dull black or of some dark 
shade approximating to dark chestnut or brown. The first grey hairs usually appear with the casting of the first coat, most conspicuously about the head, and the greying process increases with every new coat, till, in seven or eight years, the body is quite grey and the legs are visibly becoming so. Eventually all is grey, and, if the horse live long enough, white.

While the data were being collected, it soon became evident that every grey horse must have a grey parent. Some may have two, but all have one. From this it was inferred that grey is dominant to all other colours; but it was some time before complete proof could be found. The difficulty, because of the very infrequent mating of grey with grey, was to find a grey which was pure. In view of the error of misdescription, two English Thoroughbreds, the Coombe Arabian, with 19 grey foals out of 20 , and Rib, with 11 out of 12 , might have been relied upon, but, as both had been dead a century and a half, the evidence their cases afforded could not be pressed too far. Eventually, however, evidence was found which put the dominance of grey beyond dispute. Mr. Robert Bunsow found that Celle Amurath, a grey Arabian belonging to the Prussian Government, had got 600 foals from mares of all colours, and every one was grey, while Dr. Walther found that a grey sire called Zigeuner had got 13 foals from grey mares and 46 from mares of other colours, and every foal, with the exception of one which died young, was grey.

The position of dun was still more difficult to decide, for the data were still scantier. Dun was a Thoroughbred colour till about the end of the eighteenth century, and it was found that every early dun in the Stud Book 
whose parents' colours could be determined had one dun parent. It was also found to be similar with most recent duns. Thus dun seemed dominant to all other colours, not excluding grey: but, when the records of their progeny were examined, it was found that duns, though they leave all colours, leave no greys unless the other parent be a grey. Thus dun is recessive to grey.

The position thus assigned to dun was confirmed by the progeny of two dun sires, Oscar and Norseman, stationed on Clare Island off the coast of Mayo, the former from 1901 to 1903 and the latter from 1904 to 1906. The mares on the island were of all colours; no other sires were there at the same time; and all the progeny of both sires were dun. In 1908, another dun sire, obviously a hybrid, was placed on the island, and, while more than half his progeny were duns, the remainder, with a grey exception which was out of a grey mare, were of the ordinary colours.

There remains still another colour, cream, but, as the evidence regarding it is very scanty, all that can be said is that it may be a variety shade of dun.

Thus we have a series of five colours, grey, dun, bay, black, and chestnut, in which those coming first are dominant to all coming later and those coming later recessive to all before them. And it has been shown that bay, black, and chestnut are each the result of single polygamous factors. But the question still remains: Are grey and dun also the result of single polygamous factors? It is scarcely conceivable they could be otherwise, for, then, they would carry factors which could find no other factors to mate with in bay, black, and chestnut. 
If greys and duns be the result of single polygamous factors, then there should be greys and duns of the following constitutions:

Greys

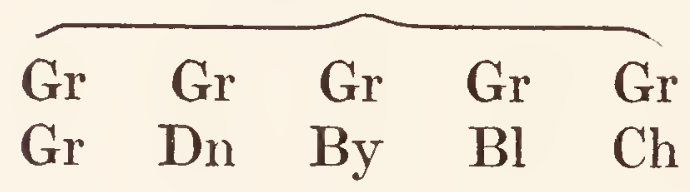

Duns

\begin{tabular}{llll}
\hline Dn & Bn & Dn & Dn \\
Dn & By & Bl & Ch
\end{tabular}

and each of these kinds should produce different assemblages of progeny when mated with themselves and the other colours. So far as grey, which we shall consider first, is concerned, the following phenomena should be found :

(i) There should be pure grey sires of the constitution $\mathrm{Gr}$ Gr, and, with all colours of mares, these should leave grey foals only. As already stated, four such sires have been found:

\section{SIRES}

The Coombe Arabian

Rib

Celle Amurath

Zigeuner
Their Progeny

Other

Grey

19

11

600

58 colours

(ii) Hybrid greys with hybrid greys, which, since almost all greys are hybrids, means in ordinary experience greys with greys, should leave grey foals and foals of other colours, and the former should be to the latter in the proportion $3: 1$; for, since the parents may be of any of the following constitutions: 


\section{POLYGAMOUS FAC'TORS}

Sires

Gr

Dn

Gr

By

Gr

$\mathrm{Bl}$

Gr

$\mathrm{Ch}$
Dams

Gr

Dn

Gr

By

$\mathrm{Gr}$

$\mathrm{Bl}$

Gr

$\mathrm{Ch}$

the chances are equal

(a) that the grey factor in the sire combines with the grey factor in the dam,

(b) that the grey factor in the sire combines with whichever recessive the dam may carry,

(c) that the recessive which the sire may carry combines with the grey factor in the dam, and

(d) that the recessive in the sire combines with the recessive in the dam.

Consequently there should be three grey foals to one of all the other colours together.

Greys Other colours

69 grey with grey matings among early $\begin{array}{lllll}\text { Thoroughbreds produced } & \cdot & & 53 & 16\end{array}$

(iii) Hybrid greys with other colours should leave grey foals and foals of all other colours and the greys should be to all the others together in the proportion $1: 1$; for the parental constitutions should be 
On the One Side

Gr
Dn

Gr

By

Gr

Bl

Gr

$\mathrm{Ch}$
ON THE OTHER

$\begin{array}{llll}\text { Dn } & \text { Dn } & \text { Dn } & \text { Dn } \\ \text { Dn } & \text { By } & \text { Bl } & \text { Ch }\end{array}$

$\begin{array}{lll}\text { By } & \text { By } & \text { By } \\ \text { By } & \text { Bl } & \text { Ch }\end{array}$

Bl $\quad \mathrm{Bl}$

$\mathrm{Bl} \quad \mathrm{Ch}$

$\mathrm{Ch}$

$\mathrm{Ch}$

and the chances are equal that either the grey factor in the grey parent or the recessive factor, whichever it may happen to be, should combine with either factor in the other parent. Thus half the progeny should be grey and half of other colours.

\section{Other
Greys}

In 288 early Thoroughbred matings the

$\begin{array}{rrrr}\text { progeny consisted of } . & \cdot & 140 & 144 \\ 125 \text { Shire matings the progeny were } & 64 & 81\end{array}$

(iv) While half the foals of a hybrid grey sire with mares of other colours should be grey and the other half of other colours, no foal should carry a colour lower in the scale than the recessive carried by the grey sire. In grey sires containing bay, for instance, the bay factor should combine with the bay or black or chestnut factor in the dams, but, as black and chestnut are recessive to bay, the foals carrying black or chestnut along with bay should be bays. Similarly, grey sires carrying black should leave no foals lower in the 


\section{POLYGAMOUS FACTORS}

scale than black. At the same time grey sires carrying recessives low in the scale should leave the intermediate colours in addition to grey and that produced by their own recessive. The chestnut factor, for instance, in a grey carrying chestnut should combine not only with chestnut but also with black and bay, and the foals concerned should be blacks and bays. In the following table, which gives the colours of the progeny of $\mathbf{1 8}$ grey sires, it will be seen that, in the first five cases, no colour is found below bay, in the next, black is found, and, in the remainder, chestnut. The absence of blacks in some of these last cases is to be accounted for by the fact that unless in very early days the breed to which the sires belonged, with the exception of Sir John Falstaff's, contained very few blacks. In all these cases there were no dun matings or matings which could have produced duns. The sires were all Thoroughbreds excepting those against whose names the letter (S) is placed, which were Shires. The date against each sire's name is approximately that of his birth.

SIRES

Gimcrack, 1760

Bell's Arabian, 1760

True Briton (S.), 1858

Lincolnshire Lad II (S.), 1872

Buchanan, 1877

The Colonel (S.)

Crab, 1722

Starling, 1727

Blank, 1740

Progeny

Grey Bay Black Chestnut

$\begin{array}{rrl}12 & 9 & - \\ 9 & 5 & - \\ 24 & 35 & - \\ 64 & 79 & (2) \\ 26 & 29 & -\end{array}$

$\begin{array}{llll}6 & 5 & 3\end{array}$

23

19

9

3

3

$14 \quad 13$ 
SiRES

Panton's Arabian, 1750

Mambrino, 1768

Bordeaux, 1774

Delpini, 1781

Stratheonan, 1863

Sir John Falstaff (S.), 1873

Pepper and Salt, 1882

Grey Friars, 1883

Grey Leg, 1891
Progeny

(v) The last test for which there are available data is that greys containing chestnut recessive should produce equal numbers of greys and chestnuts when mated with chestnuts, for the constitutions are ${ }_{\mathrm{Ch}}^{\mathrm{Gr}}$ and ${ }_{\mathrm{Ch}}^{\mathrm{Ch}}$.

The following table gives the progeny of twenty grey sires containing chestnut when mated with chestnut mares. As chestnut Thoroughbreds were less common in the eighteenth century and chestnut matings therefore comparatively few, the progeny of the seven eighteenthcentury grey sires named above are lumped with those of eight other similar sires, while the progeny of the five nineteenth-century sires are given separately:

SiRES

Progeny

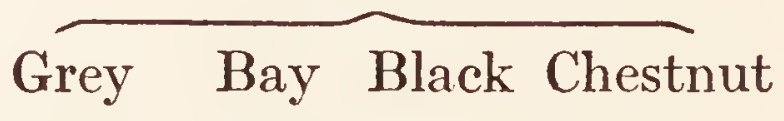

Fifteen eighteenth-century sires 23

Strathconan

Pepper and Salt

Grey Leg

Grey Friars

Sir John Falstaff
(8) 1

(3) $\quad$ - 16

24

17

13

15

2
17

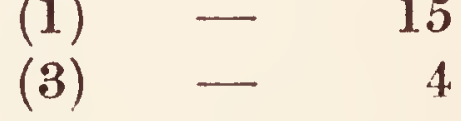

2 
The data concerning dun are so few that it is impossible to give that colour similarly full treatment. One result, however, is sufficient to show that it is parallel with the other colours. When hybrid duns were mated with colours lower in the series, equal numbers of duns on the one hand and of all the other colours together on the other were produced. The numbers are duns 55, bays 43 , blacks 9 , and chestnuts 3 . It might also be mentioned that Brilliant, a dun Thoroughbred foaled in 1750 , containing chestnut recessive, got 5 duns, 1 bay, 1 black, and 1 chestnut with bay mares, and 1 dun and 1 chestnut with chestnut mares.

Not the least interesting point in connexion with this series of colours is that it does not end with the horse but continues down to the donkey, whose colours are recessive to every horse colour. This is evident from the fact that mules are always one or other of the colours belonging to the horse; and not only so, but chestnut mules are chestnut right down to the heels just as chestnut horses are, while bay mules (i.e. bays and browns) have not only the black "points" but also the light or tan muzzle as they are found in bay horses. The only two dun mules the writer has ever seen had black "points" just as they are usually found in dun horses; and grey mules become grey gradually just like grey horses.

Indeed it is possible that the series continues into the colours of all the Equidæ, for, if their striping be neglected-and striping is probably the result of separate factors-the Zebra hybrids bred by Professor Cossar Ewart were scarcely, if at all, distinguishable from horses, in the matter of colour. 


\section{VIII}

\section{COUPLING}

The outstanding features in sex are the numerical equality and the physical inequality of males and females. With certain unusual methods of reproduction, one sex is more numerous than the other, but, ordinarily, the two are numerically equal.

Males and females usually differ from each other in a number of characters, and the differences are such that there is little difficulty in distinguishing the sexes of familiar species at a glance. Sometimes the characters of one sex diverge decidedly from those of the other, and in certain varieties the sexes differ not only in size, markings, and pattern but even in general colour. Thus there are characters linked or coupled with one sex or the other; and, since the sexes are always equal in number and, at the same time, carry different characters, it is possible that a theory which will explain one of these phenomena will, at the same time, help to explain the other.

The numerical equality of males and females suggests an inference. It will be remembered that, when a pure kind is mated with its hybrid, the progeny consist of equal numbers of the pure kind and the hybrid. Is it possible that either the male or the female character is a hybrid? This hypothesis would account for the 
production of equal numbers of males and females. But which is the hybrid? Let us assume, in the meantime, that it is the female. If the assumption be wrong, it can be revised.

But will this hypothesis fit in with the phenomenon that certain definite characters accompany either one sex or the other? There is a well-known American breed of fowl called the Barred Plymouth Rock on whose feathers the distribution of the black colour is not continuous but interrupted by cross bars of a lighter shade. This breed is now half a century old and is known to have originated in a cross in which one parent was an earlier barred breed called the Dominique, a native of the West Indies. In the Barred Rock breed, an occasional black chicken is thrown, though both parents are barred. Thus barring is dominant to nonbarring. There are strains in which, through the persistent elimination of offending parents, black chickens have not been thrown for many years, but, in the breed as a whole, these unwelcome black chickens appear not very infrequently; and the extraordinary thing about them is that, both parents being barred, they are always hens. How is this to be accounted for?

Non-barring being recessive, these black hens must be pure for non-barring and must have received a non-barring factor from each of their parents. Both parents therefore must have been of the constitution, putting $\mathbf{B}$ for barring and $b$ for non-barring :

Males

B

b
Females

B

b 
But why does none of the cocks get a second nonbarring factor? It can only be that this second nonbarring factor is intransmissible to males and therefore always tied up with or coupled with femaleness. The hypothesis now is that the Barred Rock birds which throw barred sons always but non-barred daughters occasionally are of the constitutions-the closed bracket being used to indicate the tied factors :

\begin{tabular}{cc|c|} 
Males & Female: \\
MM & M & F \\
B b & B & b \\
\hline
\end{tabular}

The male progeny of such parents must take M from each parent, but, while they may take either $\mathrm{B}$ or $\mathrm{b}$ from their fathers, they must always take B from their mothers. The female progeny, on the other hand, must always take $\mathrm{F}$ and the tied $\mathrm{b}$ from their mothers, but, while they must always take M, they may take either $\mathrm{B}$ or the untied $\mathrm{b}$ from their fathers. The progeny should consist therefore of the four following kinds :

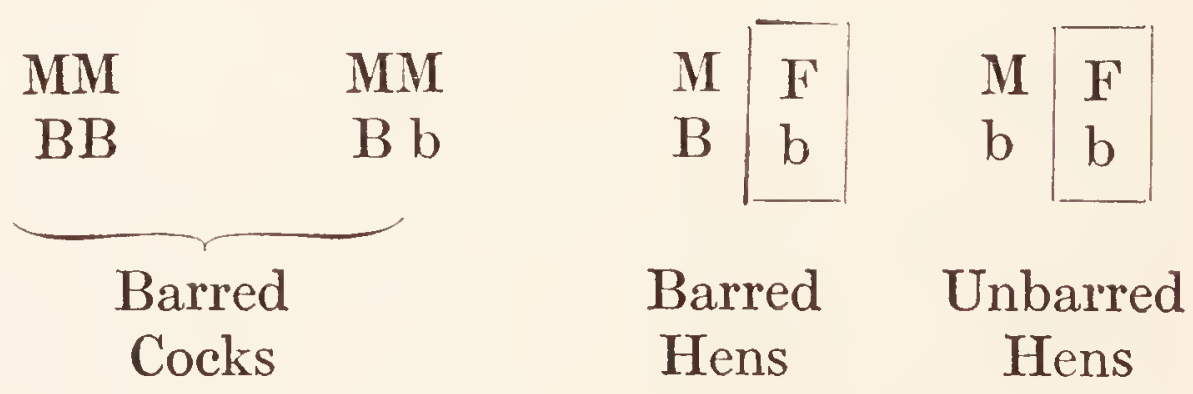

Thus the occasional appearance of unbarred hens in the Barred Rock breed is explained. Some of the cocks are hybrids.

But will this hypothesis, which was first suggested by Mr. W. J. Spillman, stand the test of other cases? 
If it be sound, then the constitutions of males and females in barred and unbarred breeds which breed true should be :

\begin{tabular}{|c|c|c|c|c|c|}
\hline \multicolumn{2}{|c|}{ Barred } & & \multicolumn{3}{|c|}{ Unbarred } \\
\hline Males & Fem & ales & Males & Fem & ales \\
\hline MIM & $\mathbf{M}$ & $\mathrm{F}$ & MM & M & $\mathrm{F}$ \\
\hline $\mathrm{BB}$ & B & b & $\mathrm{bb}$ & $\mathrm{b}$ & b \\
\hline
\end{tabular}

and barred males with unbarred females should produce equal numbers of males and females, and both sexes should be barred.

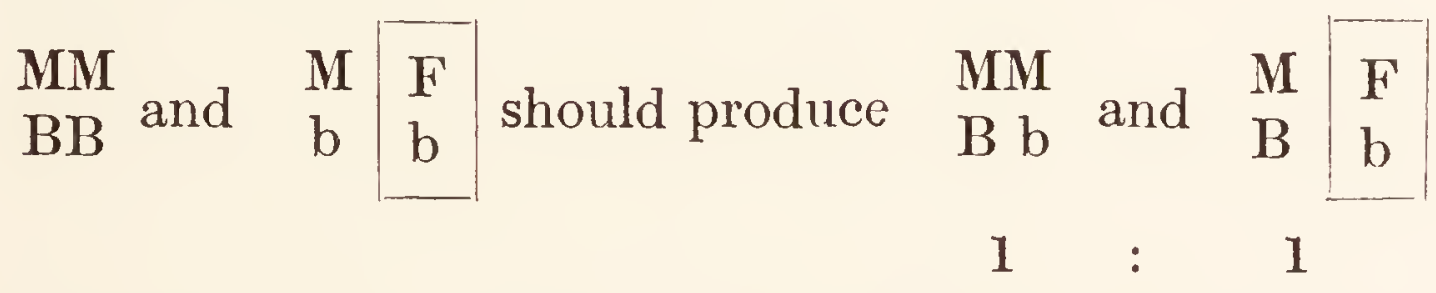

for the males must take $\mathbf{B}$ from their sires and the free factor $b$ from their dams, while the females must take $B$ from their sires and the coupled factor $b$ from their dams. Dr. Raymond Pearl crossed Barred Plymouth Rock cocks with Cornish Indian Game hens, which are black and unbarred, and their adult progeny consisted of 60 cocks and 68 hens, all barred.

On the other hand, the reverse cross, unbarred cocks with barred hens, should again produce equal numbers of males and females, but, while all the males should be barred, the females should all be unbarred.

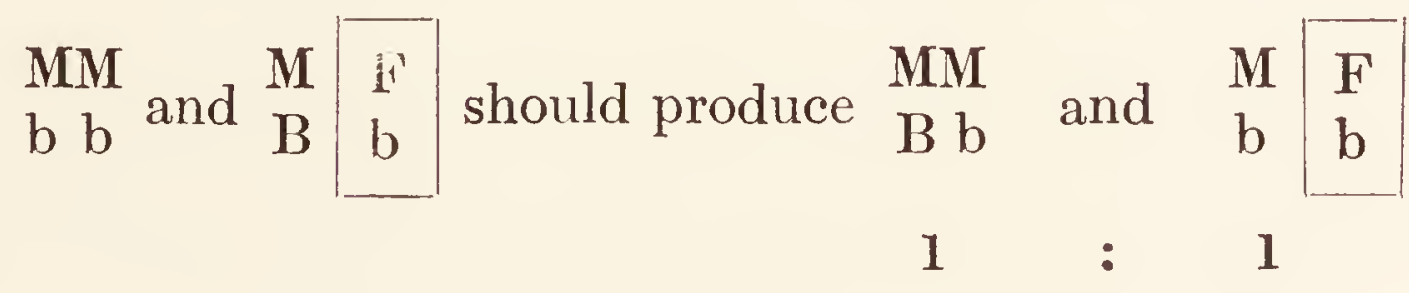


for the males can only take the free factor $b$ from their sires, but must take B from their dams, while the females can only take the free factor $b$ from their sires but must take the tied factor b from their dams. Dr. Pearl mated Cornish Indian Game cocks, which are black and unbarred, with Barred Plymouth Rock hens, and their adult progeny consisted of 95 males, all barred, and 96 females, all unbarred.

Professor Castle of Harvard, in his volume "Heredity in Relation to Evolution and Animal Breeding," tells of another test which is really similar to that of the Barred Plymouth Rock fowl producing unbarred females, with the addition that the numbers of each kind of progeny are counted. He tells us that when hybrid cocks are mated either with hybrid hens or with Barred Plymouth Rock hens, which are hybrid for barring, the progeny are again male and female in equal numbers, but, while the cocks are all barred, half the hens are barred, the other half unbarred. This is exactly according to expectation, for

\begin{tabular}{|c|c|c|c|c|c|c|}
\hline MM M & $\mathrm{F}$ & should & MM & MM & M & $\mathrm{F}$ \\
\hline $\mathrm{B} \mathrm{b}$ and $\mathrm{B}$ & $\mathrm{b}$ & produce & B B & $\mathrm{B} \mathrm{b}$ & B & $\mathrm{b}$ \\
\hline
\end{tabular}

The cocks must take $\mathbf{B}$ from their dams, but they may take either $\mathrm{B}$ or the untied $\mathrm{b}$ from their sires, while the hens must take the tied $b$ from their dams and either $\mathrm{B}$ or $\mathrm{b}$ from their sires.

Thus the double hypothesis that hens are hybrids and that non-barring is coupled with femaleness is sound.

But there are other factors coupled with that for femaleness. In addition to the Plymouth Rocks, there 
are other breeds in which the barring is slightly different in pattern but the fundamental colour the same: black. Such breeds are frequently described as "silver." Another fundamental colour is buff or gold, and barred breeds whose fundamental colour is gold are frequently described as "golden." In Belgium there are two similarly barred varieties of fowl, the silver Campine and the gold Campine. When silver males are mated with gold females, the progeny are all silver, but, when gold males are mated with silver females, the males are all silvers while the females are all golds. Thus another pair of factors is related to each other precisely as those for barring and nonbarring are related. Black, the fundamental colour in silver, is dominant to buff or gold, the fundamental colour in golden; and, of the factors for the latter, one is free while the other is coupled with that for femaleness.

Still another pair of factors is revealed by these Belgian varieties. In both varieties, both sexes are barred, but not equally, for, while the hackle-, rumpand tail-feathers are barred in the hens, the same feathers are not usually barred in the cocks. Male chickens barred like the females are occasionally hatched, but are not retained by the Campine breeders.

Since the hens are always completely and the cocks not always incompletely barred, it is clear that the hens must carry both factors, that the factor for complete barring is dominant, and that it is coupled with femaleness. It is also clear that the completely barred cocks occasionally thrown must be sons of such hens as are sometimes found carrying a second untied factor for complete barring. Thus the usual constitution of 
male and female Campines, putting $\mathrm{C}$ for complete and c for incomplete barring, must be :

Males

MM

c c
Females

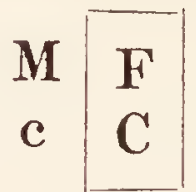

This hypothesis is tested by the experience of English breeders, by whom both varieties of Campine fowl were introduced from Belgium a quarter of a century ago. Preferring completely barred male birds, they retained such of these as were occasionally thrown and bred from them. Mated with ordinary Campine hens, these hybrid males should produce both completely and incompletely barred sons and only completely barred daughters, as follows :

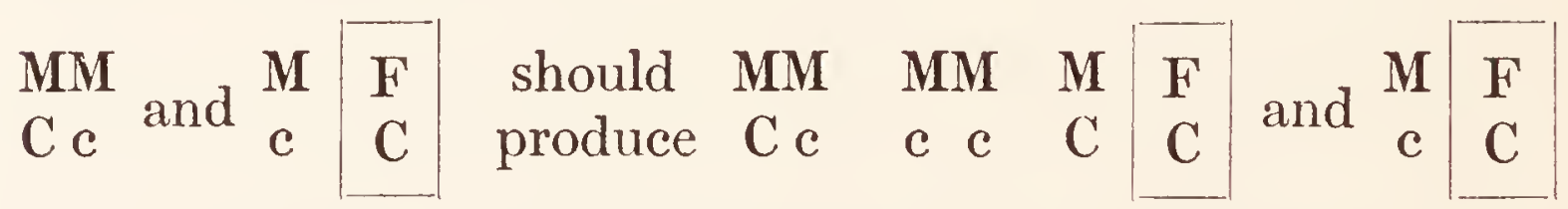

This result occurred among the stock belonging to the Rev. E. Lewis Jones.

On the other hand, males which are pure for the complete barring factor should leave all their progeny completely barred when mated with ordinary Campine hens, as follows :

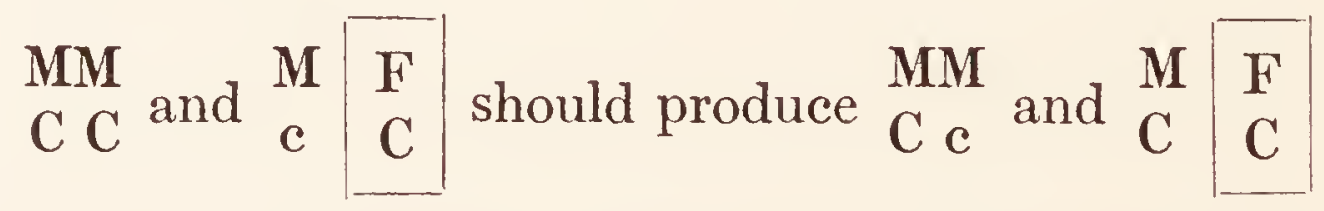

From this mating Mr. Jones got 6 completely barred cocks and 6 completely barred hens.

Thus three factors coupled with femaleness in poultry 
are demonstrated, together with three pairs of untied factors operating alongside them; and the possible constitutions in a population of hens in which all three sets of factors are operating are :

$$
\begin{array}{ccc|c|}
\mathrm{B} & \text { or } & \mathrm{M} & \mathrm{F} \\
\mathrm{Bl} & \text { or } & \mathrm{g} & \mathrm{g} \\
\mathrm{C} & \text { or } & \mathrm{c} & \mathrm{C} \\
\hline
\end{array}
$$

At this stage the question might be asked: Are these tied and free factors for plainness, gold colouring, and complete barring the same in each case, or are they different factors having similar effects? If it be answered that they are the same, then further questions are suggested, as: At what stage in ornithic history did they take different courses? When did the tied factor become tied or the free factor become free? But although the thoughts raised by these questions are of great interest, their relevance to the matters now in hand is not immediate and they can be little else than interesting speculations.

But Dr. Raymond Pearl found still another factor coupled with femaleness and, at the same time, made a discovery of great economic importance. From 1898 to 1908 the Agricultural Experiment Station at Orono in Maine was engaged in the attempt to improve the laying capacity of its Barred Rock breed of poultry. Relying on the theory that this could be done by breeding from the best laying hens and their progeny, the hens were divided in two sections: the good layers in one and the poor layers in the other. Sons of best laying hens only were used in both sections, and pullets hatched in either section were moved from that 
in which they had been hatched so soon as their performances showed them to belong to the other. Yet, after ten years, the pullets produced in the section with good hens were no better than those produced in that with bad. The proportions of good and bad layers produced in each were about the same. No simpler experiment could be devised, for the two sections differ in one point only: the one in containing good hens while the other contains bad: yet the result is the same in both. Clearly, therefore, improvement is not to be achieved through the hens.

In 1908, the work was placed in Dr. Pearl's hands, and his solution of the problem, together with all the essential data, can be found in Bulletins 166, 192, and 205 of the Maine Agricultural Experiment Station.

Problems of production the result of vital activity are surrounded with difficulties, not the least of which is the collection and orderly arrangement of the large amount of necessary data. Animals are very liable to vary in food-supply, comfort, and health and, accordingly, in productive activity, and much information has to be collected in order to determine the normal rates of production before any inferences can be drawn and to identify abnormal results and treat them with fairness and good judgment. Besides, animals, as a rule, must have covered a considerable portion of their normal lifetime before their rate of production is revealed, and, in the meantime, many disturbing factors may have intervened.

Happily Dr. Pearl was able to discover a method of determining a hen's laying capacity shortly after she had begun to lay, and, by this, to decrease not only the necessary statistical labour but also the chances 
of the data being upset by disturbing causes. He found that hens fall into three grades: one laying over 30 eggs in their first winter, another under 30, and still another none at all : and he found also that, in their subsequent productivity, hens remain in the grades in which they have begun. Dr. Pearl's dividing figure30-must not, of course, be taken as an absolute fixture, but as movable in some degree according to circumstances.

When Dr. Pearl's discovery was known in this country, Miss Murphy of the Munster Institute, Cork, made the same observation but expressed it in a way which is perhaps more effective in the mind of the poultry-keeper. Miss Murphy found that spring-hatched pullets are of three kinds: one beginning to lay early in winter-early in November even-and laying about 5 eggs a week till the end of January, another either beginning equally early but laying only half as many eggs or beginning near the end of winter and laying at a slightly higher rate, and a third laying no winter eggs at all or only a very few just at the end of winter. The table on page $\mathbf{1 0 0}$ gives the numbers of eggs laid during each week of the three winter months, November and December 1913 and January 1914, by eight typical hens belonging to each of these three classes. The total eggs laid by each hen during the whole year from November to November are also given.

Thus Dr. Pearl's discovery is confirmed, and, judging by the large amount of data at the Munster Institute, we may take it that a hen laying over 30 winter eggs will lay, in round numbers, from 150 to 220 before next winter, one laying under 30 winter eggs will lay from 80 to 120 , and one laying no winter eggs will lay from 40 to 60 . 
Numbers of Weeks

\begin{tabular}{|c|c|c|c|c|c|c|c|c|c|c|c|c|c|c|c|}
\hline $\begin{array}{l}\text { Numbers } \\
\text { of Hens }\end{array}$ & & & & & Egg & s la & id & per & wee & & & & & $\begin{array}{l}\text { during } \\
\text { Winter }\end{array}$ & Year \\
\hline 48 & - & - & - & - & 2 & 2 & 5 & 4 & 4 & 7 & 6 & 6 & 5 & 41 & 200 \\
\hline 235 & - & 4 & 6 & 5 & 5 & 6 & 5 & 5 & 5 & 5 & 5 & 5 & 7 & 63 & 99 \\
\hline 50 & - & 1 & 6 & 4 & 5 & 4 & 6 & 4 & 4 & 4 & 5 & 4 & 4 & 51 & 03 \\
\hline 158 & 5 & 5 & 5 & 5 & 4 & 5 & 5 & 4 & 5 & 4 & 5 & 5 & 4 & 62 & 202 \\
\hline 53 & - & - & - & 3 & 5 & 5 & 7 & 6 & 6 & 5 & 5 & 6 & 7 & 55 & 18 \\
\hline 51 & - & - & 3 & 6 & 4 & 6 & 6 & 5 & 5 & 6 & 5 & 5 & 7 & 58 & 209 \\
\hline 9 & 6 & 5 & 5 & 5 & 5 & 4 & 5 & 4 & 5 & 4 & 5 & 5 & 4 & 62 & 09 \\
\hline 176 & 6 & 6 & 6 & 5 & 5 & 5 & 5 & 5 & 5 & 5 & 4 & $\theta$ & & 64 & 08 \\
\hline 58 & 1 & 2 & 4 & 3 & 4 & 4 & - & - & - & - & - & $\ldots$ & - & 18 & \\
\hline 163 & - & 1 & 3 & 3 & 3 & 3 & 1 & - & - & - & 3 & 3 & 2 & 22 & 19 \\
\hline 204 & - & - & - & - & - & - & - & 2 & 5 & 6 & 6 & 1 & - & 20 & 12 \\
\hline 131 & - & - & - & - & - & - & - & - & - & - & 2 & 4 & 4 & 10 & 8 \\
\hline 43 & - & - & - & - & - & - & - & - & - & 5 & 5 & 7 & 5 & 22 & 98 \\
\hline 172 & - & - & - & - & - & - & - & 2 & 4 & - & 4 & 4 & 3 & 17 & 98 \\
\hline 78 & - & - & - & - & - & - & - & - & - & - & 5 & 5 & 6 & 16 & \\
\hline 253 & - & - & - & - & 2 & 6 & 5 & 5 & 3 & 3 & 4 & 3 & 3 & 34 & \\
\hline 57 & - & - & - & - & - & - & - & 1 & 1 & 1 & - & 1 & 3 & 7 & \\
\hline 105 & - & - & - & - & - & - & - & - & - & - & - & - & - & 0 & 49 \\
\hline 149 & - & - & - & - & - & - & - & - & - & - & - & - & 3 & 3 & 43 \\
\hline 87 & - & - & - & - & - & - & - & - & - & - & - & - & - & 0 & 4 \\
\hline 173 & - & - & - & - & - & - & - & - & - & - & - & - & - & 0 & 60 \\
\hline 170 & - & - & - & - & - & - & - & - & - & - & - & - & - & 0 & 9 \\
\hline 155 & - & - & - & - & - & - & - & - & - & - & - & - & - & 0 & 0 \\
\hline 77 & - & - & - & - & - & - & - & - & - & - & - & - & - & 0 & \\
\hline
\end{tabular}

Total

Eggs Total during for the Winter Year

The outstanding feature of the ten years' experience at Orono is that, though they may carry it, hens cannot transmit the factor for prolific egg-laying to their daughters. The factor for femaleness must therefore be coupled with a factor for poor egg-laying which is recessive to a prolific factor transmitted to hens by their fathers. If the tied factor were a dominant the daughters of all good hens would be good layers. Thus, if we call these factors $\mathbf{X}$ and $\mathbf{x}$, the following constitutions are possible: 
Cocks

Hens

\begin{tabular}{|c|c|c|c|c|c|c|}
\hline MM & MM & MM & $\mathrm{M}$ & $\mathbf{F}$ & $\mathbf{M}$ & F \\
\hline XX & $\mathrm{Xx}$ & $\mathrm{xx}$ & $\mathbf{X}$ & $\mathbf{x}$ & $\mathrm{x}$ & $x$ \\
\hline
\end{tabular}

But since there are three grades of hens, there must be more than one pair of factors.

The first suggestion occurring is that there are three free factors which are polygamous, and, if we call the new factor $\mathbf{Y}$, without questioning whether it be dominant or recessive to $\mathbf{X}$, there should then be three different kinds of hens, and, from the reproductive point of view, six different kinds of cocks, namely:

Hens

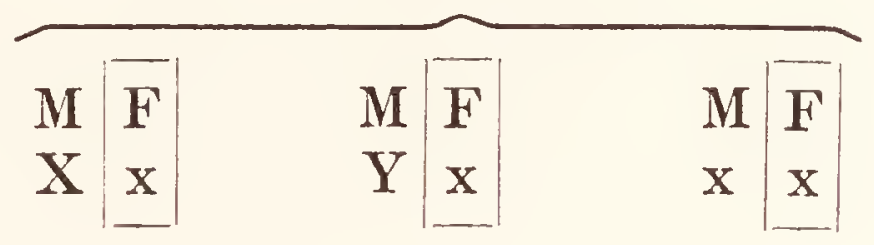

Cocks

\begin{tabular}{llllll}
\hline MM & MM & MM & MM & MM & MM \\
$\mathrm{XX}$ & $\mathrm{XY}$ & $\mathrm{Xx}$ & $\mathrm{YY}$ & $\mathrm{Yx}$ & $\mathrm{x} \times$
\end{tabular}

But, though there are just the three grades of hens, there are certainly more than six kinds of cocks, as can be told by the different assemblages of progeny they produce. Thus there must be more than three factors.

A glance at the figures of production for the middlegrade hens at the Munster Institute suggests another theory. It will be noticed that the middle-grade hens may possibly be of two kinds: those that begin to lay 


\section{A MANUAL OF MENDELISM}

early in winter at the rate of about three a week, and those that begin later but at a higher rate. If this be so, then there are four different groups of hens, two of which are inseparable, as judged by their total winter eggs only. And, if the factor which either of these groups carries be a dominant whose recessive is carried by hens laying no winter eggs, then, under ordinary circumstances, the usual two-pair set should be produced:

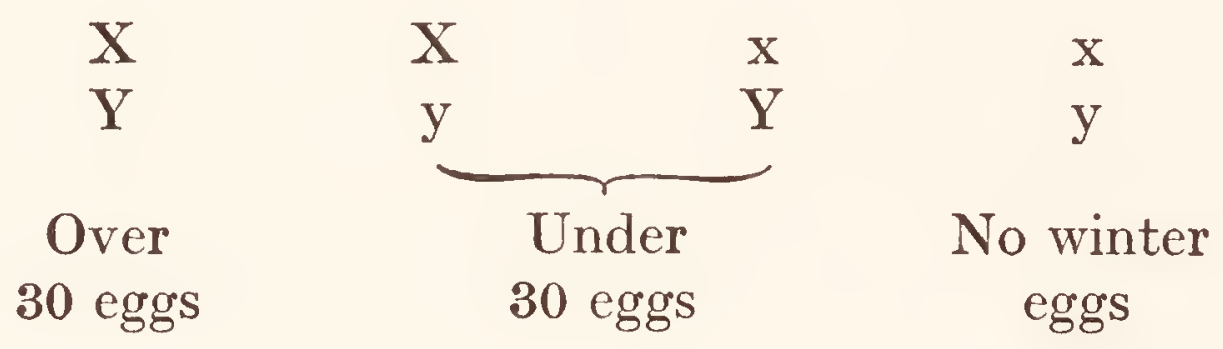

But, with the tied and untied factors, there should be hens of six different constitutions and cocks of nine, as follows :

Hens

\begin{tabular}{|c|c|c|c|c|c|c|c|c|c|c|c|}
\hline & $\mathbf{F}$ & $M$ & $\mathrm{~F}$ & $\mathbf{M}$ & $\mathrm{F}$ & M & $\mathrm{F}$ & M & $\mathrm{F}$ & $\mathbf{M}$ & $\mathrm{F}$ \\
\hline & $x$ & $\mathrm{X}$ & $\mathrm{x}$ & $\mathrm{X}$ & $x$ & $\mathrm{x}$ & $\mathrm{x}$ & $\mathrm{x}$ & $\mathrm{x}$ & $\mathrm{x}$ & $\mathrm{x}$ \\
\hline & $\mathrm{Y}$ & $\mathrm{Y}$ & $y$ & $\mathrm{y}$ & $\mathrm{y}$ & $Y$ & $\mathbf{Y}$ & $Y$ & $\mathrm{y}$ & $\mathrm{y}$ & $y$ \\
\hline
\end{tabular}

Cocks

\begin{tabular}{lllllllll}
\hline MM & MM & MM & MM & MM & MM & MM & MM & MM \\
XX & XX & XX & Xx & Xx & Xx & Xx & Xx & xx \\
YY & Yy & y y & YY & Yy & y y & YY & Yy & yy
\end{tabular}

Unfortunately no observations have been made by which the suggested division among the medium laying 
KINDS OF PULLETS EXPECTED FROM ALL

POSSIBLE MATINGS

\begin{tabular}{|c|c|c|c|c|c|c|c|c|c|c|}
\hline & & & & ENS & & & & & & \\
\hline $\begin{array}{r}\text { laying } \\
\text { wi }\end{array}$ & $\begin{array}{l}\text { th } \\
\text { ggs }\end{array}$ & & & & unte & de & rty & & $\begin{array}{l}\text { layi } \\
\text { winte }\end{array}$ & $\begin{array}{l}\text { ng no } \\
\text { r eggs }\end{array}$ \\
\hline $\mathbf{M}$ & M & $\mathrm{F}$ & $\mathbf{M}$ & $\mathbf{F}$ & $\mathbf{M}$ & $\mathbf{F}$ & $\mathbf{M}$ & F & $\mathbf{M}$ & $\mathbf{F}$ \\
\hline$X$ & $X$ & $\mathbf{x}$ & $\mathrm{X}$ & $\mathbf{x}$ & $x$ & $\mathbf{x}$ & $\mathrm{x}$ & $\mathrm{x}$ & $\mathrm{x}$ & $x$ \\
\hline$Y$ & $\mathbf{Y}$ & $\bar{y}$ & $\mathrm{y}$ & $\mathbf{y}$ & $\mathbf{Y}$ & $\bar{Y}$ & $\mathrm{Y}$ & $\mathrm{y}$ & $\mathrm{y}$ & $\bar{y}$ \\
\hline
\end{tabular}

Their Daughters

Cocks

$$
\begin{array}{cccccccccccccccccc}
+ & - & & + & - & & + & & & + & & & + & & & + & - & \\
30 & 30 & 0 & 30 & 30 & 0 & 30 & 30 & 0 & 30 & \overline{30} & 0 & 30 & 30 & 0 & 30 & 30 & 0
\end{array}
$$

(1) $\underset{\mathrm{XX}}{\mathrm{MM}} 8^{*}--8--8--8--8--8-$ YY

(2) $\underset{\mathrm{MX}}{\mathrm{MM}} 8-{ }_{-6} \mathrm{2}-44-8-{ }_{-6}-4-$ Y y

(3) $\underset{\mathrm{XX}}{\mathrm{MM}} 8--44--8-8-{ }_{-}-4-8-$ y y

(4) $\mathrm{MM} 44-44-44-44-44-4$ $\mathrm{X} \mathrm{X}$ YY

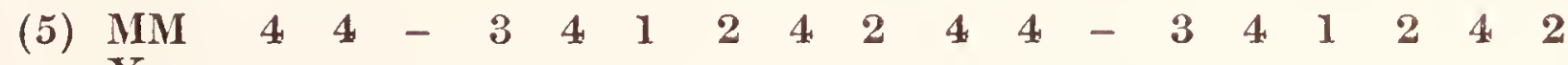
$\mathrm{X} \times$ Y y

(6) $\underset{\mathrm{X}}{\mathrm{MM}} 44-24 \quad 2-4 \quad 4 \quad 4 \quad 4-244$ y y

(7) $\mathrm{MM} 44-44-44--8--8--8-$ $\mathrm{X} \mathrm{x}$ YY

(8) $\underset{\mathrm{XX}}{\mathrm{M}}-8--62-44-8-64$ Y y

(9) $\underset{\mathrm{XX}}{\mathrm{M}} \mathrm{x}-8--44--8-8-4-4$ y y

* The figure 8, which means "all," is set down because the proportions in the remaining eases are brought to a standard total of 8. 


\section{4}

\section{A MANUAL OF MENDELISM}

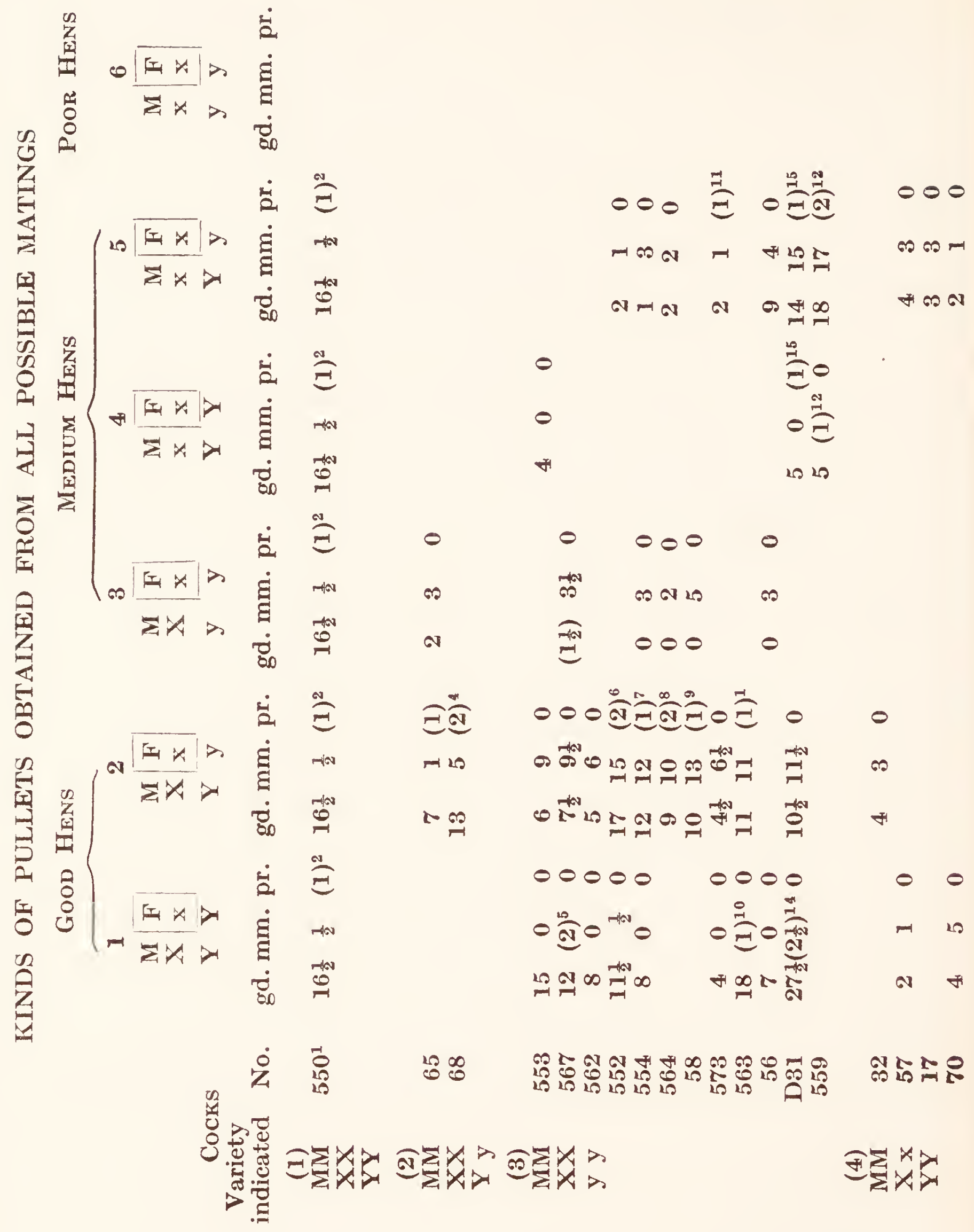




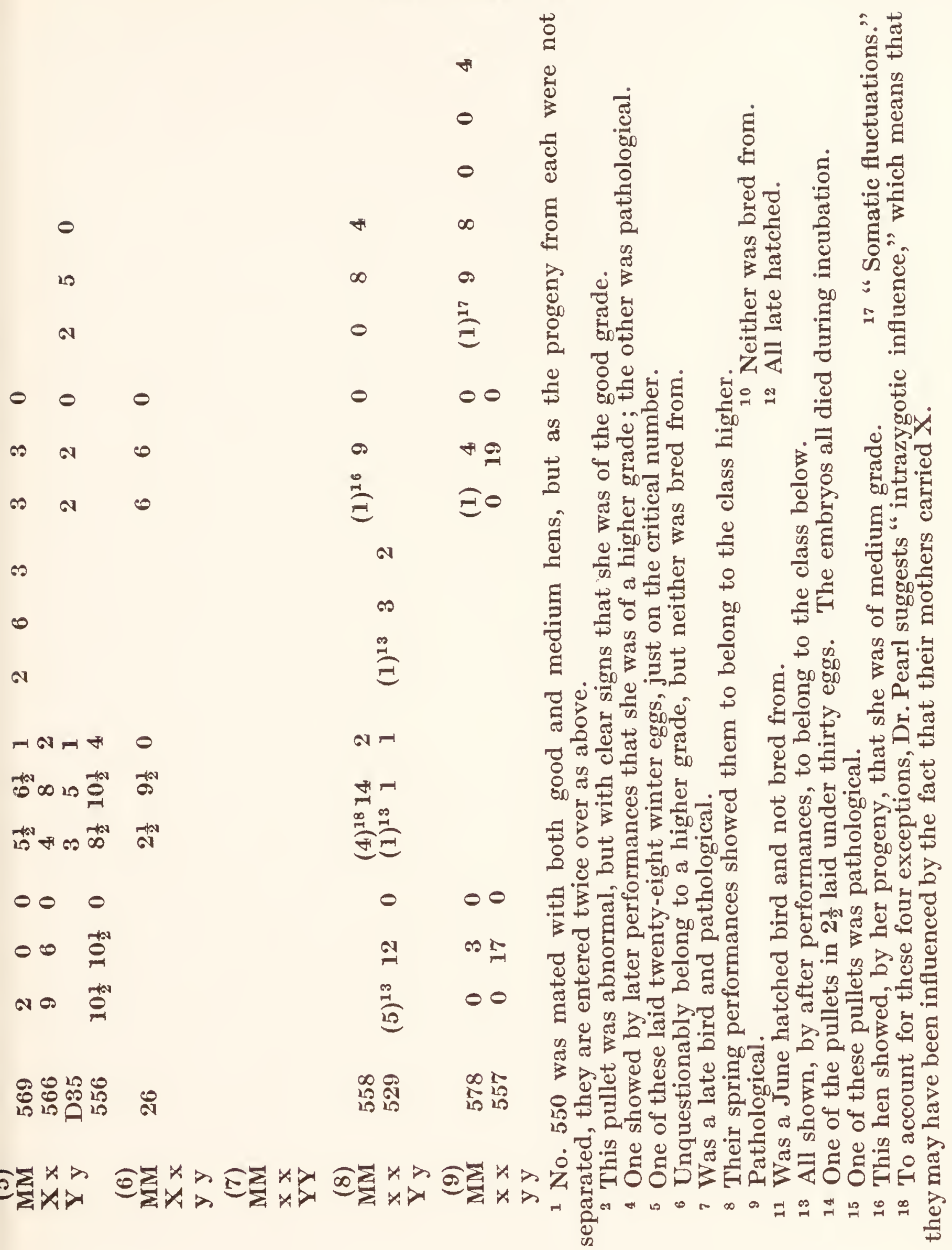


hens could be tested, but, as Dr. Pearl puts forward the same theory, minus the suggestion, we may put the suggestion aside, not necessarily with regret, since it may have helped us to understand a problem so difficult, and proceed to the proofs.

The proof is parallel to that adopted for the colours of cattle and horses. If, from the reproductive point of view, there are nine different kinds of cocks and six of hens, then, in flocks containing all kinds of hens, each of the nine different kinds of cocks should leave different assemblages of pullets, as indicated in the table on page 103 .

The table on pages 104 and 105, taken from Dr. Pearl's statistics other than those relating to second and later crosses, shows, by their daughters, that eight of the nine different kinds of cocks have been identified. Figures which are not in accordance with expectation are enclosed within brackets. It will be noticed that several times the figure $\frac{1}{2}$ is set down. This is to indicate hens which laid exactly 30 winter eggs and were recorded in two grades by $\frac{1}{2}$ being placed in each.

With such close agreement between expectation and actual results - the disturbances to which vital activity are liable being allowed for-there can be no doubt that Dr. Pearl's hypothesis is established. Another factor, therefore, is found coupled with that for femaleness, and, at the same time, two factors are found whose effects are similar when operating separately but cumulative when operating together. Thus the possible constitutions in a population of hens in which all the factors which have been discussed are operating may be represented thus : $\mathbf{B}=$ barred, $\mathrm{b}=$ unbarred; 
$\mathrm{Bl}=$ black, $\mathrm{g}=$ gold $; \mathrm{C}=$ completely barred, $\mathrm{c}=$ incompletely barred; $\mathbf{X}=$ high yield, $\mathrm{x}=$ low yield :

$$
\begin{array}{lll|l|} 
& & \mathrm{M} & \mathrm{F} \\
\mathrm{B} & \text { or } & \mathrm{b} & \mathrm{b} \\
\mathrm{Bl} & \text { or } & \mathrm{g} & \mathrm{g} \\
\mathrm{C} & \text { or } & \mathrm{c} & \mathrm{C} \\
\mathrm{X} & \text { or } & \mathrm{x} & \mathrm{x} \\
\hline
\end{array}
$$

In plants there is coupling apparently unconnected with sex. In the course of their experiments with sweet-peas, Professors Bateson and Punnett found several cases. We need not trouble about the experimental figures. These are to be found in the Reports to the Evolution Committee, and general statements of results are to be found in Professors Bateson's and Punnett's volumes on Mendelism. There were peas with infertile anthers and others with fertile. There were also peas with darkish spots in the axils of the leaves and others with ordinary green-coloured axils. When a plant having a dark-coloured axil and infertile anthers was crossed with another having a light-coloured axil and fertile anthers, the hybrids had dark axils and fertile anthers. There were therefore two pairs of characters, and dark axils and fertile anthers were the two dominants. Putting D for dark, d for light, $\mathbf{F}$ for fertile, and $\mathbf{f}$ for infertile, we should expect the usual two-pair set of four groups, thus :

$\begin{array}{lllllll}\text { D } & & \text { D } & & \text { d } & & \text { d } \\ \text { F } & & \text { f } & & \text { F } & & \text { f } \\ & & & & & & \\ 9 & : & 3 & : & 3 & : & 1\end{array}$




\section{8}

A MANUAL OF MENDELISM

Instead of this, however, the progeny of the hybrids turned out to be as follows :

$\begin{array}{cccccc}\text { D } & & \text { D } & & \text { d } & \text { d } \\ \text { F } & & \text { f } & & \text { F } & \text { f } \\ 2 & : & 1 & : & 1 & \end{array}$

The hybrid and each of the original parents appeared again in such groups and numbers as are produced by intermediate hybrids. The factors $\mathrm{D}$ and $\mathrm{f}$ on the one hand and $\mathrm{d}$ and $\mathrm{F}$ on the other did not separate but behaved in each case as one factor, as is proved by the fact that the combination df was not formed. The only possible explanation is that either $D$ and $f$ or $\mathrm{d}$ and $\mathbf{F}$ or both are coupled. Again, plants having a red flower with a hooded standard and long-shaped pollen were crossed with other red ones having an erect standard and round pollen. The hybrids were red with long pollen and erect standards. Red being common to both parents, we should expect the usual two-pair set of four groups, as follows $(\mathrm{E}=$ erect, $\mathrm{h}=$ hooded, $\mathrm{L}=$ long, $\mathrm{o}=$ round) :

$\begin{array}{llcllll}\mathrm{E} & & \mathrm{E} & & \mathrm{h} & & \mathrm{h} \\ \mathrm{L} & & \mathrm{o} & & \mathrm{L} & & \mathrm{o} \\ & & & & & & \\ 9 & : & 3 & : & 3 & : & 1\end{array}$

Instead, however, the hybrids' progeny were as follows :

$\begin{array}{cccccc}\text { E } & & \text { E } & & \text { h } & \text { h } \\ \text { L } & & \text { o } & & \text { L } & \text { o } \\ 2 & : & 1 & : & 1 & \end{array}$


Again the hybrids behaved as intermediates. Consequently there was coupling of $\mathrm{E}$ and $\mathrm{o}$, or $\mathrm{h}$ and $\mathrm{L}$, or both.

But a case occurred in which three factors were coupled. There is a sweet-pea called Painted Lady in which the standard is erect and the flower red, but the standard is a bright red while the wings are only faintly coloured. Thus the variety may be called bicoloured. There is another variety called Duke of Westminster which has a hooded standard. In this case the colour is purple, but both standard and wings are almost equally coloured. This variety may therefore be called unicoloured. The following tabular statement shows the differences between these varieties :

$\begin{array}{lc}\text { Painted Lady } & \text { Duke of Westminster } \\ \text { Red } & \text { Purple } \\ \text { Bicolour } & \text { Unicolour } \\ \text { Erect standard } & \text { Hooded standard }\end{array}$

When they were crossed, their hybrids were purple and bicoloured, with erect standards; and we should expect their progeny to have formed the following three-pair set of eight groups :

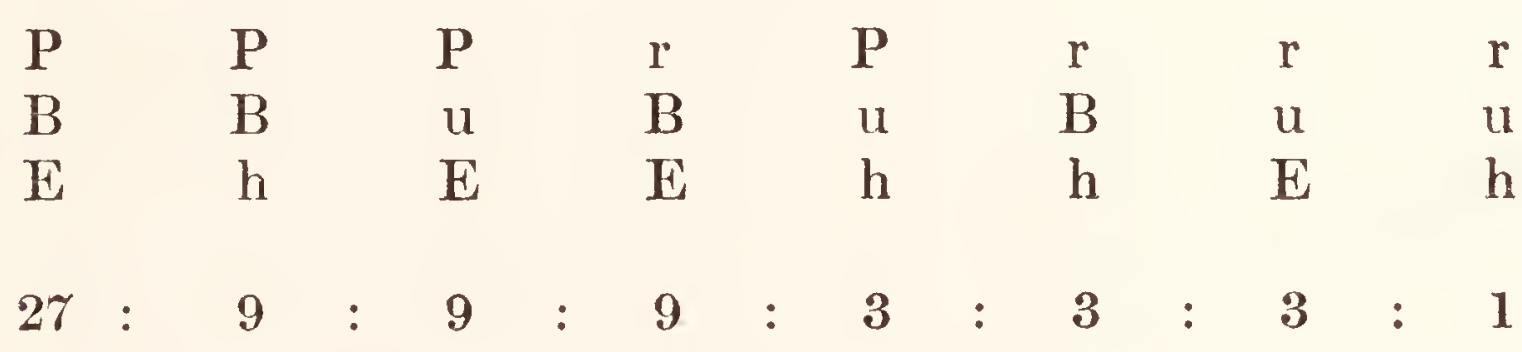

Instead, however, the hybrids' progeny were as follows: 


$\begin{array}{llllllll}\text { P } & \text { P } & \text { P } & \text { r } & \text { P } & \text { r } & \text { r } & \text { r } \\ \text { B } & \text { B } & \text { u } & \text { B } & \text { u } & \text { B } & \text { u } & \text { u } \\ \text { E } & \text { h } & \text { E } & \text { E } & \text { h } & \text { h } & \text { E } & \text { h }\end{array}$

Now we have three factors in the parents behaving as one and the hybrids reproducing themselves and their two parents as ordinary intermediates do. The only possible explanation is that $\mathrm{rBE}$ or Puh or both are coupled and move as one factor. 


\section{IX}

\section{SIMILAR EFFECTS}

In the last chapter, a case in which two different factors produced a similar effect was discussed. In this, we shall discuss two others. During the last quarter of a century an enormous amount of work in the production of new varieties of plants has been done at the seedbreeding station at Svalöf in Southern Sweden. Since the discovery of Mendel's papers, this work has vastly increased both in quantity and precision, and no section has been more successful than that now under the care of Professor Nilsson-Ehle which has to do with the production of new varieties of oats and wheat. Professor Nilsson-Ehle has published many papers, but the results with which we have to deal are to be found in two papers "Kreutzunguntersuchungen an Hafer und Weizen" ("Crossing Experiments with Oats and Wheat") published by the University of Lund in 1909 and 1911.

Among oats there are five or six chief colours of grain, namely, black, brown, tawny, grey, yellow, and white, but some are slightly indefinite. It would be difficult to say that there is either an absolutely black or an absolutely white grain. What is generally understood by "black" is a very dark brown, like dark chestnut or dark oak, and by "white" a more or less faded cream or dull white. Besides, there are shades 


\section{A MANUAL OF MENDELISM}

in every variety of colour, and frequently the lighter shades of a darker colour may not be readily distinguishable from the darker shades of a lighter.

So many colours indicate several colour factors with several shade factors in addition, and the possibility of the same colour getting one name from one observer and another name from another is evident.

Professor Nilsson-Ehle crossed a number of "black" oats with white and found the hybrids to be browns of several different shades. This indicated either more than one pair of characters or intermediates between blacks and whites. The hybrids' progeny were still more diverse, but the blacks and browns of all shades were counted together as one kind, and it was found that, on the whole, they were to the whites in the ratio $3: 1$. Thus "black" was read dominant to white.

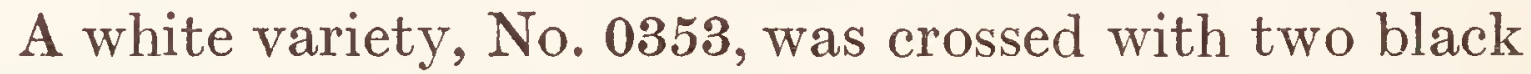
varieties, Nos. 0401 and 0487, and the hybrids in both cases were brown; and, when the hybrids were bred from, their progeny were "blacks" and whites in the ratio $3: 1$. The actual figures and ratios are:

\section{Parents Hybrids Hybrids' Progeny Ratio}

$\begin{array}{ccccccc}0353 \times 0401 & \text { brown } & 86 \text { "black" } & 33 \text { white } & 2 \cdot 6: 1 \\ 0353 \times 0487 & , & 104 & & \end{array}$

The same variety, No. 0353, was crossed with two other "black" varieties, and the result brought other factors definitely into view. The colours of the hybrids are not given, but the following table gives the colours of the parents and the hybrids' progeny: 


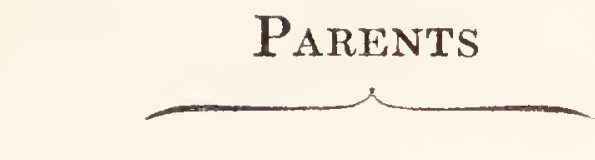

0353, white $\mathrm{x} 0660$, black

0353 , x 0691,

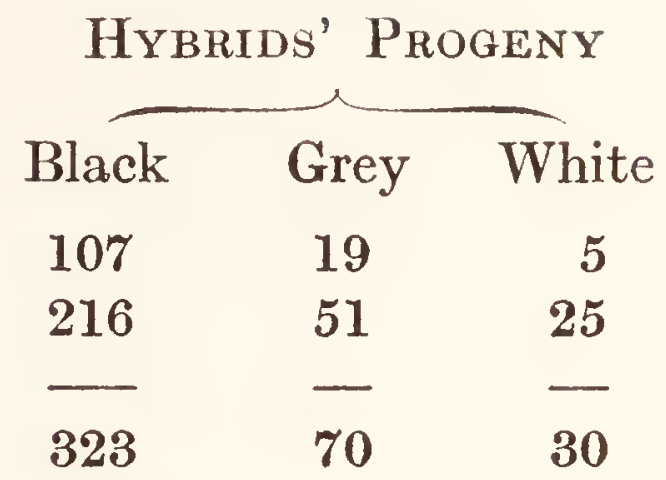

It will be seen that the blacks are about three times as many as the greys and whites together and the greys about three times as many as the whites. Thus, we have the following two-pair set:

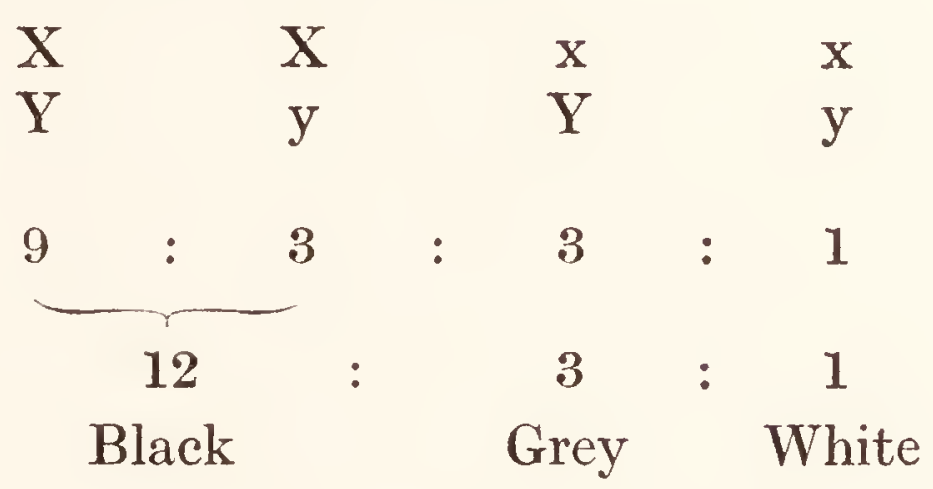

But the same white variety was mated with still another black, with the result that still another pair of factors was disclosed. The nature of the hybrids is not mentioned, but four of them were bred from, and their progeny were as follows :

\begin{tabular}{|c|c|c|c|c|}
\hline \multirow[t]{2}{*}{ Parents } & \multirow[t]{2}{*}{ HyBRIDS } & \multicolumn{2}{|c|}{ ProGeny } & \multirow[t]{2}{*}{ Ratio } \\
\hline & & Black & $\begin{array}{c}\text { Grey and } \\
\text { White }\end{array}$ & \\
\hline \multirow[t]{4}{*}{$0353 \times 0668$} & a & 207 & 12 & $17 \cdot 3:$ \\
\hline & b & 116 & 7 & $16 \cdot 6:$ \\
\hline & c & 191 & 13 & $14 \cdot 7:$ \\
\hline & $\mathrm{d}$ & 116 & 8 & $14.5:$ \\
\hline
\end{tabular}




\section{A MANUAL OF MENDELISM}

Since the blacks are to the greys and whites together in the ratio $15: \mathbf{1}$, and the last experiment showed the greys to be to the whites in the ratio $3: \mathbf{1}$, it is clear that we now have a three-pair set of eight groups, as follows :

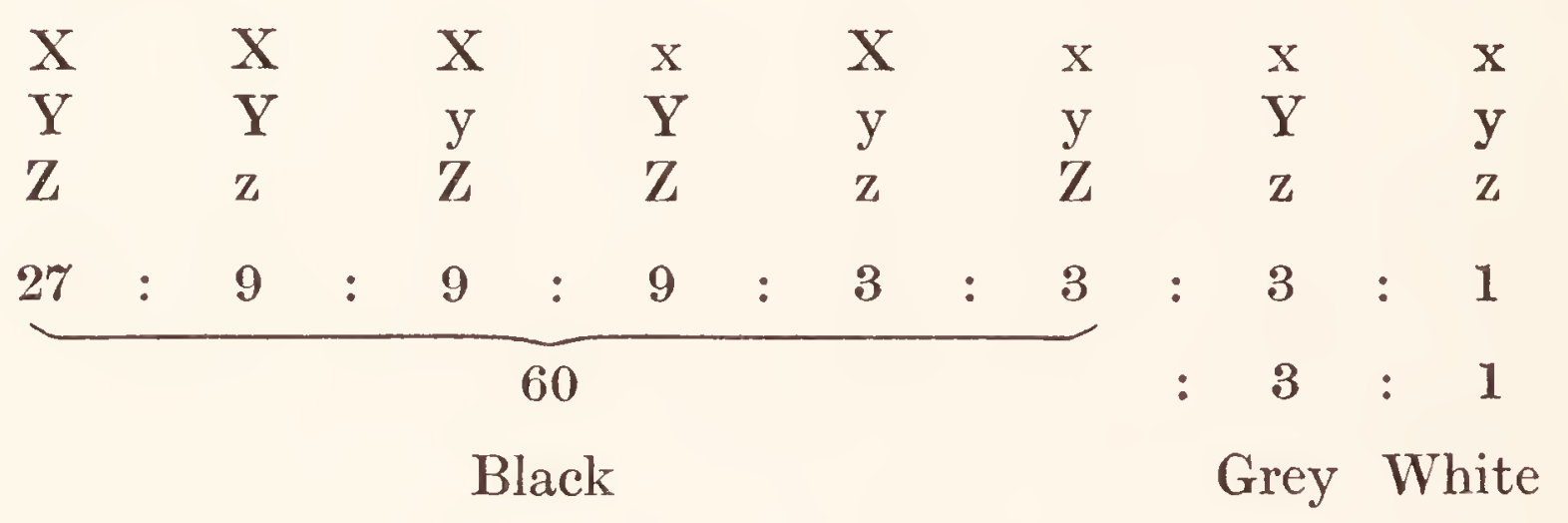

That is to say: there are six groups of unseparated "blacks" which, had they been readily separable, would have been separated without doubt. We may take it, therefore, that the two factors $\mathbf{X}$ and $\mathrm{Z}$ produce approximately the same effect whether they appear together in the same plant or separately, and that the result is still approximately the same even when they are combined in the same plant with $\mathrm{Y}$, the factor which has to do with the production of greyness.

Professor Nilsson-Ehle carried his experiments into another generation by which the foregoing inference was confirmed, but, as the experiments and the argument are parallel with those in another case we shall take the proof in the other case to stand for both.

This time the experiments are with wheat grains. The first experiment showed the red colour in redgrained wheat to be dominant to the white colour in white-grained wheat. The following are the necessary details : 
The Parents

0401 red x 0705 white

0203 , x 0705 ,

0235, x 0470,
The Hybrids' Progeny

Ratio

$\begin{array}{cccc}\text { Red } & \text { White } & & \\ & 31 & 9 & 3 \cdot 4: 1 \\ & 72 & 28 & 2 \cdot 6: 1 \\ \mathrm{a} & 32 & 6 & 5 \cdot 3: 1 \\ \mathrm{~b} & 67 & 13 & 5 \cdot 2: 1 \\ \mathrm{c} & 63 & 15 & 4 \cdot 2: 1\end{array}$

In his next experiments, however, the results were very different indeed, and indicated either that there were hybrid reds which bred true indefinitely-if that were possible-or that there were so many more pairs of factors with dominants producing red and recessives producing white that a very great number of plants must be bred from before a recessive white could appear. The following are the figures :

0315 white $\mathrm{x}$ Swedish

'The Hybrins' Progeny Red White

$\begin{array}{lrrr}\text { Sammets Wheat a } & 78 & 0 \\ & \mathrm{~b} & 30 & 0 \\ \mathrm{c} & 49 & 0 \\ \mathrm{~d} & 31 & 0 \\ \mathrm{e} & 86 & 0 \\ \text { x 0704 white } & \mathrm{f} & 110 & 0 \\ & & 55 & 1\end{array}$

The first six of these experiments suggest a very wide ratio and many factors, while the last suggests three pairs of factors: three producing red and their recessives producing white. To settle the question the whole 78 lots in the first experiment (a) were sown and so a third hybrid generation was produced. We 


\section{A MANUAL OF MENDELISM}

shall proceed first of all on the assumption that there are three pairs of factors, namely, three dominants producing red and their three recessives producing white. If the assumption fails, we can try another.

If there be three pairs of factors, with the three dominants producing red grains and the recessives white, then the 64 possible combinations among the hybrids' progeny should consist of the following different kinds :

37 reds producing reds only

8 reds producing reds and whites in the ratio $63: 1$

12 reds producing reds and whites in the ratio $15: 1$

6 reds producing reds and whites in the ratio $3: 1$

1 white producing whites only.

These being the proportions in which the different kinds should appear in 64 cases, then the 78 red lots bred from should have consisted approximately of the following kinds and numbers:

45 reds producing reds only

10 reds producing reds and whites in the ratio $63: 1$

15 reds producing reds and whites in the ratio $15: 1$

8 reds producing reds and whites in the ratio $3: 1$

It will be noticed that there was no white-grained plant among the 78 whose seeds were sown. One such should have appeared in every 64, yet in 78 none appeared. This is a result which must occur frequently when the chances of the white grain appearing are so small.

It must be pointed out, before giving the actual results of breeding from the above 78 lots, that it will be impossible to say with absolute certainty to which 
group some of them belong. For instance, if a lot produce 100 red grains and no white, whether does it belong to the red group giving no whites or to the group giving reds and whites in the ratio $63: 1$ ?

Or, if a variety produce 60 grains all red, to which of the first two groups is it to be allotted? If a variety produce 30 or 40 red grains without a white, it belongs neither to the 15: 1 nor the $3: 1$ group; but we cannot say whether it belongs to the $63: 1$ or to the group producing red only. If a variety produce 10 red grains and no whites, it does not belong to the $3: 1$ group, but we cannot say to which of the other three it belongs. Thus we are compelled to rely upon the results in the 3:1 and 15:1 groups together with what assistance may be afforded by the remainder. With this object we shall arrange the results in groups as set out on page 118.

Then we see that the numbers in the $3: 1$ and $15: 1$ columns are very close indeed to expectation. So also are those in the 63:1 column, upon which, however, we cannot lay much stress, because some of the lots in the previous column-more especially 30,31 , and 63-probably belong to this or even to the 15:1 column. In any case, two critical groups are so close to expectation that we may now conclude that the wheats with which we have been dealing carry three pairs of factors, namely, three dominants producing red and their three recessives producing white. And, since many of the red grains contained only two of the factors for redness and a smaller number only one, it follows that the red colour may be produced by any one of these, by two, or by all three together. 


\section{A MANUAL OF MENDELISM}

$\begin{array}{ccccc}\begin{array}{c}\text { Producing } \\ \text { Producing } \\ \text { Red only }\end{array} \begin{array}{c}\text { Reds only or only } \\ \text { Reds and } \\ \text { Whites }\end{array} & \begin{array}{c}\text { Red Reds and } \\ \text { Whites }\end{array} & \begin{array}{c}\text { Reds } \\ \text { and } \\ \text { Whites }\end{array} & \begin{array}{c}\text { Reds } \\ \text { and } \\ \text { Whites }\end{array} & \begin{array}{c}\text { Reds } \\ \text { and } \\ \text { Whites }\end{array} \\ 63: 1 & \begin{array}{c}63: 1 \\ \text { or } \\ 15: 1\end{array} & 63: 1 & 15: 1 & 3: 1\end{array}$

No. R. W. No. R. W. No. R. W. No. R. W. No. R. W. No. R. W.

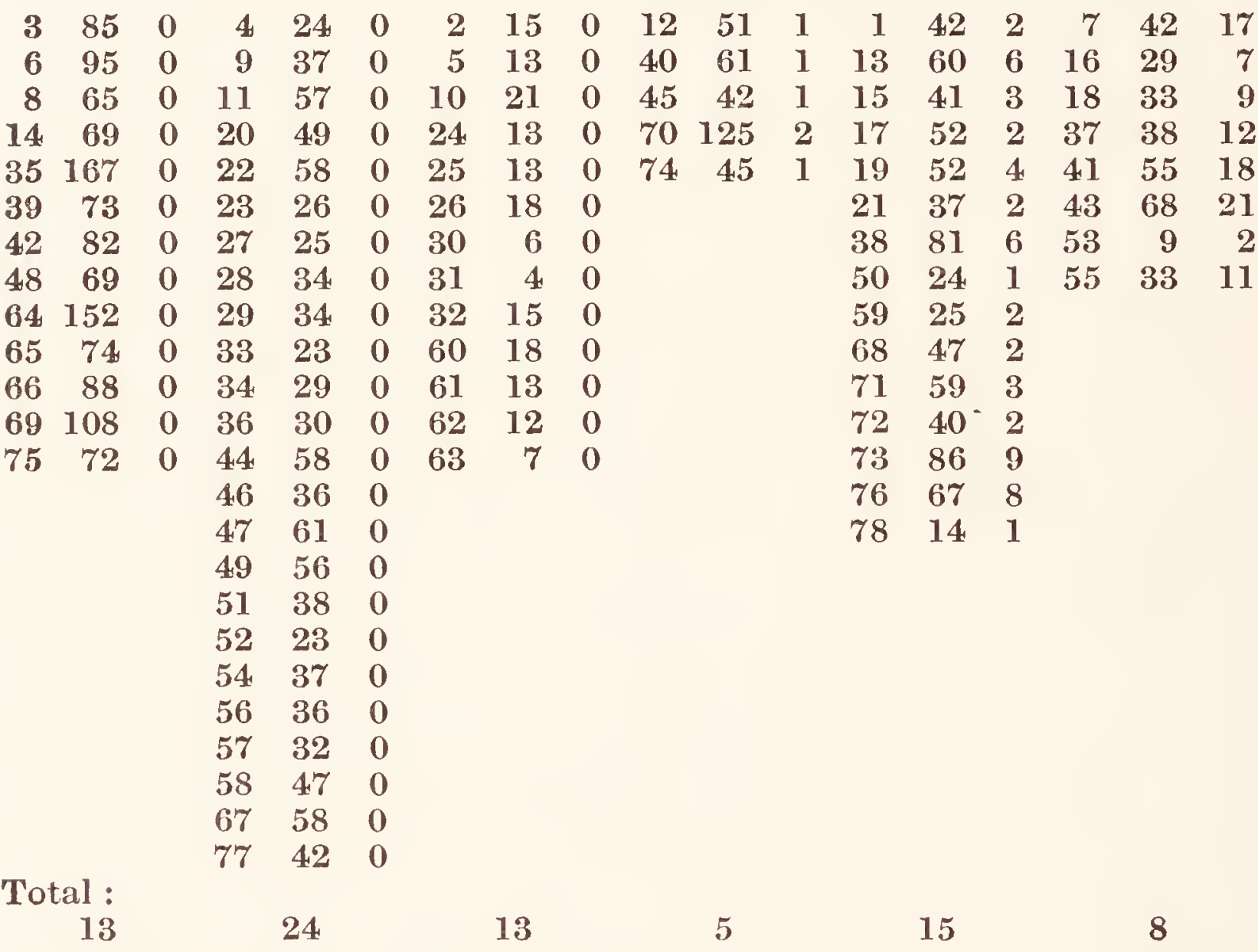

Professor Nilsson-Ehle found the differences among the various grains very slight. Thus it makes little difference to the colour produced whether one, two, or all three factors are operating. His statement of the case is as follows: "It can be asserted that the differences in the externally visible effects of the various units for the redgrain colour are quite inconsiderable, and that in any case nothing can be said as to a qualitative distinction : less even than in the black coat-colour of the oat. . . The units produce only a slightly different depth of red." 


\section{$\mathrm{X}$}

\section{QUANTITY}

IN this chapter we come to that part of the work which is perhaps the most important-at any rate, from the economic standpoint. Yet we can deal with it only tentatively and suggestively, for the effects of the factors operating are usually so difficult to identify that it is next to impossible to connect any one factor with any one character, or, rather, since we are dealing with quantity, with any one measurable result. This chapter therefore may not be considered strictly Mendelian unless in so far as it points to results which are certainly produced by factors working in one or other of the Mendelian ways but not yet identified in detail.

The most inspiring work so far is Professor NilssonEhle's, to understand which it is necessary to understand the circumstances under which it was begun. From 1840 Sweden had been a grain-exporting country, but about 1870 the effects of oversea competition began to be felt and the remuneration for the grain exported to decline. In 1886, seeing that the Swedish farmer's position would be bettered if he grew higher yielding varieties, Herr Birger Welinder and a few neighbours near Svalöf established the Swedish Seed Association whose purpose was to discover the best varieties of grain for Southern Sweden. Believing that the varieties they had been growing had declined in 
yield through the admixture of smaller yielding varieties -that is through impurities- the society's work resolved itself into:

(a) Procuring good yielding varieties from other countries.

(b) Finding the best yielding native varieties.

(c) Growing these side by side and comparing their yields.

(d) Eliminating the poor varieties and propagating the good till a stock had been accumulated.

(e) Keeping the good varieties pure and purifying the impure.

$(f)$ Distributing the good varieties among members of the association and other farmers.

The association acquired land at Svalöf and appointed a director to carry on the work, in which, for ten or twelve years, little else was accomplished beyond finding and testing varieties and keeping the best ones up to standard of purity. Attempts were made to improve some varieties, but with little success. During this period, influenced chiefly by the Darwinian theory of evolution, it was believed that improvement was to be accomplished by what has been called the method of continuous mass selection. This method may be applied to the grain or the plant or to both. It is usually applied to the grain by means of the riddle which has the effect of rejecting a proportion of the smaller seeds in accordance with the size of the mesh and the vigour with which the riddle is worked. Applied to the plant, it consists in eliminating by hand such plants as are clearly different from the bulk in size, length of straw, thickness of straw, length of head, shape of head, and so on.

It is obvious that this method increases the purity of a variety so far as size of grain and certain plant characters are concerned, but it does not necessarily 
improve the yield unless larger and larger grains and particular plant characters are always associated with larger crops. Even in its most drastic application, which consists, say, in selecting the very largest plants with the largest heads and retaining only the very largest grains, this method may not succeed, for it may be that none of these characters is associated with larger yield.

It was early observed at Svalöf that none of the varieties tested was absolutely pure but that all included sub-varieties which were distinguishable by slight botanical differences. At first this was not regarded as important, but, when a few plots which were known to have been descended from single plants were found to be uniform, and uniformity was thus shown to be attainable, it was realized that the method by which improvement had been sought would have to be modified, and pure-breeding kinds only submitted to investigation. Every sound experimenter knows that reliable results are not to be expected with uneven materials.

Professor Hjalmar Nilsson, who was now director, decided to adopt what is known as the "single ear" method: a method by which two British farmers, Shirreff and Le Couteur, had achieved remarkable results early in the nineteenth century. By this method, the descendants of a single plant are kept separate till stock enough has been accumulated to tell whether the line or variety so selected is good or bad. About the same time the idea that botanical characters are indications of yield was abandoned at Svalöf and the indications of the weighing machine adopted as the only reliable criterion. 
By the earlier method and the assistance of nature a number of good yielding varieties had been identified at Svalöf before the end of the nineteenth century, nearly all of which were directly descended from imported varieties. The action of nature had been to indicate and sometimes kill off plants which did not withstand rust and the Swedish winter or were liable to lodging; and such plants as nature failed to kill were picked out by hand. Thus, by the weaker individuals being weeded out, the productivity of a variety was increased. It will be well to compare the yields of some of the varieties so selected with that of a native variety and see, at the same time, how certain varieties are affected by one of the causes contributing to depress the yield. The comparison is made with the yields of the years 1907 to 1912 . These are given in kilogrammes to the hectare, and, for ease in comparison, are reduced to a basis in which the native variety, Sammets wheat, stands at 100.

\begin{tabular}{|c|c|c|c|c|c|c|c|c|}
\hline \multirow[t]{2}{*}{ Variety } & \multicolumn{6}{|c|}{ Kilogrammes per hectare } & \multirow{2}{*}{ 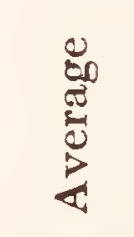 } & \multirow{2}{*}{ 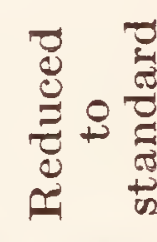 } \\
\hline & 1907 & 1908 & 1909 & 1910 & 1911 & 1912 & & \\
\hline Sammets Wheat & 2370 & 3310 & 2370 & 4140 & 3930 & 3440 & 3260 & 100 \\
\hline $\begin{array}{c}\text { Strubes } \\
\text { head }\end{array}$ & $2540^{1}$ & $3540^{2}$ & $760^{3}$ & 5380 & $4490^{1}$ & $2710^{2}$ & 3220 & $98 \cdot 8$ \\
\hline Stand Up & $3170^{1}$ & $3660^{2}$ & $950^{3}$ & 5360 & 4740 & $3370^{2}$ & 3550 & $108 \cdot 9$ \\
\hline Extra Squarehead & 2460 & 4030 & 2640 & 4500 & - & - & 3647 & 111 \\
\hline $\begin{array}{l}\text { Danish Bore Wheat } \\
\text { Renodland Square- }\end{array}$ & 2760 & 3910 & 2900 & 4580 & 4210 & 4150 & 3752 & $115 \cdot 1$ \\
\hline $\begin{array}{l}\text { Renodland Square- } \\
\text { head }\end{array}$ & & & & & & & 3955 & 12 \\
\hline Grenadier II & 3110 & $4240^{1}$ & $2620^{2}$ & 4950 & 5110 & $3720^{1}$ & 3959 & 121 \\
\hline
\end{tabular}

An examination of the foot-notes will show that, while most of these varieties yield well after a mild winter- 
say in 1910 - several are seriously depressed when the winter has been severe. This having been observed, it was determined that crosses should be made between some of the "winter soft" varieties which yielded well ordinarily and others which were "winter hard" in the hope that the desirable qualities in both parents might be combined in some of their progeny.

Crosses were made before 1900 , but, since the appointment at that time of Dr. Nilsson-Ehle to take charge of the experiments in wheat and oats, crossing and the selection of new varieties from the descendants has been adopted as the chief means of improvement. The details of what has been accomplished, so far as we are now concerned, are to be found in his paper "Berättelse öfver förätlingsarbetena med hösthvete vid Svalöf, 1910-1912."

Two varieties mentioned in the foregoing table, Extra Squarehead and Grenadier II, were crossed in the hope of combining the power of the former to resist rust and winter with the higher yield and power of the latier to resist lodging; and, when the progeny had been produced, the pure-breeding individuals identified, a stock of their descendants accumulated, and the best yielder determined by the necessary measuring and weighing, there resulted the new variety Extra Squarehead II, which was sent out to the farmers in the year 1909. The following table gives the average yield of this variety as compared with those of its parents and the standard native variety, Sammets wheat, over the years 1907 to 1912 , excepting that the average for Extra Squarehead covers the years 1907 to 1910 only : 


\section{A MANUAL OF MENDELISM}

Average Reduced

Standard: Sammets Wheat

$\begin{cases}\text { Parents: } & \left\{\begin{array}{l}\text { Extra Squarehead } \\ \text { Grenadier II }\end{array}\right. \\ \text { Progeny: } & \text { Extra Squarehead II }\end{cases}$

$\begin{array}{ll}3260 & 100 \\ 3647 & 111 \cdot 9 \\ 3959 & 121 \cdot 4 \\ 4255 & 130.5\end{array}$

But another cross gave a still higher result. Among a native variety called Kotte wheat was found a plant which was evidently a natural cross between the native and one or other of the imported high yielding varieties. With good yield this plant combined strong winter resistance and exceptionally strong rust resistance, but was inclined to lodge, late in ripening, and had grain of poor quality. Consequently it was of no economic importance. It was crossed, however, with Grenadier II -Extra Squarehead II being not yet available-and, from the descendants, a variety was selected of good quality whose yield was even higher than that of Extra Squarehead II. When Professor Nilsson-Ehle's paper was published, this new variety was designated by a number only, (0801), but it had been tested over a period of five years, and, if we set down the average yields of itself and its parents, together with similar figures for Extra Squarehead II and its parents, we shall see the advance it made:

Years

tested Average Reduced

Standard: Sammets Wheat

\begin{tabular}{|c|c|c|c|}
\hline & Extra Squarehead & 4 & 3647 \\
\hline Parents: & Grenadier II & 0 & 3959 \\
\hline Progeny: & Extra Squarehead II & 6 & 4255 \\
\hline Parents : & $\begin{array}{l}\text { Kotte Cross } \\
\text { Grenadier II }\end{array}$ & & $\overline{559}$ \\
\hline Progeny : & 0801 & 5 & 4576 \\
\hline
\end{tabular}


Nor perhaps is this yet the end, for, when Extra Squarehead II became available, a child of the cross between it and a high yielding Danish variety called Tystofte Smaawheat gave a higher yield than either of the parents in the one year, 1912, in which it had been tested. In the same year another variety selected from the stock which produced 0801 gave a yield still higher than any. The following table shows the yields of all these varieties for the one year. For ease in comparison, the yields are also reduced to the old basis, but it must be remembered that they represent one year's results only.

Kilogrammes per hectare

\begin{tabular}{|c|c|c|c|}
\hline & Extra Squarehead II & 3950 & $130 \cdot 5$ \\
\hline Parents & Tystofte Smaawheat & 4350 & $143 \cdot 7$ \\
\hline rogeny : & 0860 & 4750 & $154 \cdot 5$ \\
\hline & 0801, new selection & 4950 & $163 \cdot 5$ \\
\hline
\end{tabular}

Reduced

Thus, by procuring higher yielding varieties, then by eliminating the weaker plants, and, finally, by crossing the best yielders and selecting their best descendants, the Swedish farmer is now in possession of wheats which are 50 per cent. better than the old native varieties.

But the question is: what interpretation may be given to these phenomena? Clearly there are pairs of factors with whose distribution the yield varies in one way or another. Professor Nilsson-Ehle mentions three pairs, namely, resistance and non-resistance to rust, resistance and non-resistance to winter, and resistance and non-resistance to lodging. In no case does he say which is the dominant and which the recessive, nor does he indicate what is the numerical value of any 


\section{A MANUAL OF MENDELISM}

one factor in raising or depressing the yield. No doubt it would be very difficult to do so, and it may be doubted whether any serious effort has been made in this direction. Professor Nilsson-Ehle's object is to produce high yielding varieties for Swedish farmers and, if this can be done, as it can be done, without giving heed to the Mendelian relationships of the factors or their definite numerical values, there is no reason why the work in its economic aspect should be delayed out of consideration for another aspect which is of much less importance. But with the three pairs of factors already mentioned and another which can be added we can obtain some idea of what is occurring. The other pair is tillering, or the production of side shoots, and non-tillering. Experimenters with grain crops know that tillering increases the yield, although it has not yet been shown which is the dominant character. No doubt there are other factors, some of greater some of less importance. For instance, there are degrees in resistance to winter and rust which must be dependent upon the factors which produce them, but these may be left out of account in the meantime. Nor need the non-identification of the dominants and recessives detain us, for the problem can be studied without this having been done.

In the case of the four pairs of factors now before us, let us assume that those which raise the yields are dominants and those which depress them recessives. Then, if we symbolize them: resistance to rust $=\mathrm{R}$, non-resistance $=\mathrm{r}$; resistance to winter $=\mathrm{W}$, nonresistance $=\mathrm{w}$; resistance to lodging $=\mathrm{L}$, non-resistance $=1$; and tillering $=\mathrm{T}$, non-tillering $=\mathrm{t}$; the following sixteen combinations are possible: 


\section{RW LT \\ RWL t \\ RW I T \\ R w LT \\ r WL'T \\ RW $1 \mathrm{t}$ \\ R w Lt \\ R w I T \\ $r W L t$ \\ rWl T \\ $r$ w LT \\ R w l t \\ $r W l t$ \\ $r$ wt \\ r w $1 \mathrm{~T}$ \\ $r$ w $l t$}

The variety containing the four recessives would give the lowest yield of all, and any of the varieties containing one of the dominants would give a higher yield. The crossing of one of the varieties containing one dominant with the lowest yielding variety would yield no higher yielding variety, but, if two of the varieties, one with one and another with a second dominant, were crossed, the hybrid would yield more than either parent, and, by retaining and purifying the highest yielding group in the hybrid's progeny and eliminating the other three, a new higher yielding variety could be produced. Similarly, by mating a variety containing two of the dominants with another containing one, a still higher yielding variety could be obtained, and finally, by crossing two groups which contain all the dominants between them, the highest yielding variety of all could be obtained. The chances of getting higher yielding progeny are greatest when the parents are themselves 
high yielding and least when the parents are low yielding. Thus it can be explained how Professor Nilsson-Ehle obtained higher and higher yielding varieties according as he crossed higher and higher yielding parents.

The final result would have been the same had all the high yielding factors been recessives. The hybrids would have been lower in yield than their parents, but among their progeny a number of high yielding varieties would have been found which would have required no purification. Nor would the final result have been different had some of the high yielding factors been dominants and some recessives. It is possible, indeed not improbable, that some of the pairs of factors for yield produce intermediates when crossed, but this again need cause no difference in the final result, although it might make the process of purification more complicated. The essential in every case is the substitution of a high yielding factor for a lower.

Similar phenomena have been found in connexion with the efforts of Danish farmers to improve the quality of their cows' milk. The quantity of butter-fat in cows' milk ranges from about 2.5 per cent. at one extreme to about 6 per cent. at the other; but all statements in connexion with this subject must be regarded as no more than close approximations, for every cow's milk varies from day to day, and even the annual average, which is what is referred to in the following pages, may vary about 10 per cent. in any one year above or below the average of several years. The milk of a cow which contains 4 per cent. of fat on the average of several years may contain as much as $4 \cdot 4$ per cent. in one year and as little as $3 \cdot 6$ per cent. in another. 


\section{QUAN'TITY}

The averages of different breeds show considerable variations: not because all the cows in one breed give milk of one quality while all in other breeds give milk of other qualities, but because some breeds contain a large proportion of cows giving milk of various high qualities, others a large proportion of cows giving milk of various low qualities, and so on. Although some Jerseys' milk contains only 3 per cent. of fat, yet, because the milk of a large number contains from 4.5 to 5.5 per cent., the average for the breed is nearly 5 per cent. Some Ayrshires give milk containing 5 per cent. of fat, yet, because many give milk containing less than 3.5 per cent., the average for the breed is only about $3 \cdot 7$ per cent. The average for Red Danish cows is still lower; that for Dutch cows lowest not only on the average but also in both extremes. The following table shows the variations in these three last breeds, which as yet are the only ones from which reliable data have been obtained in large quantity:

\section{Percentage of Cows giving Different}

Qualities of Milk

\begin{tabular}{|c|c|c|c|}
\hline $\begin{array}{c}\text { Percentage } \\
\text { of Fat } \\
\text { in Milk }\end{array}$ & $\begin{array}{l}\text { Among } \\
2026 \\
\text { Dutch } \\
\text { Cows }\end{array}$ & $\begin{array}{c}\text { Among } \\
1373 \\
\text { Red Danish } \\
\text { Cows }\end{array}$ & $\begin{array}{c}\text { Among } \\
2866 \\
\text { Ayrshire } \\
\text { Cows }\end{array}$ \\
\hline $2 \cdot 3$ & $\cdot 10$ & - & - \\
\hline$\cdot 4$ & $\cdot 24$ & - & - \\
\hline$\cdot 5$ & $\cdot 54$ & - & - \\
\hline$\cdot 6$ & $1 \cdot 33$ & - & $\cdot 07$ \\
\hline$\cdot 7$ & $2 \cdot 76$ & - & - \\
\hline$\cdot 8$ & 6.07 & $\cdot 08$ & $\cdot 38$ \\
\hline$\cdot 9$ & $7 \cdot 94$ & $\cdot 36$ & $\cdot 76$ \\
\hline $3 \cdot 0$ & $12 \cdot 68$ & $1 \cdot 82$ & $1 \cdot 19$ \\
\hline
\end{tabular}


Percentage of Cows giving Different Qualities of MilK-continued

\begin{tabular}{cccc} 
Percentage & Among & Among & Among \\
of Fat & 2026 & 1373 & 2866 \\
in Milk & Dutch & Red Danish & Ayrshire \\
$3 \cdot 1$ & Cows & Cows & Cows \\
$\cdot 2$ & $12 \cdot 09$ & $3 \cdot 42$ & $2 \cdot 37$ \\
$\cdot 3$ & $15 \cdot 45$ & $4 \cdot 45$ & $4 \cdot 33$ \\
$\cdot 4$ & $11 \cdot 50$ & $9 \cdot 83$ & $6 \cdot 63$ \\
$\cdot 5$ & $9 \cdot 58$ & $14 \cdot 86$ & $9 \cdot 46$ \\
$\cdot 6$ & $7 \cdot 89$ & $13 \cdot 40$ & $11 \cdot 54$ \\
$\cdot 7$ & $4 \cdot 68$ & $13 \cdot 91$ & $11 \cdot 54$ \\
$\cdot 8$ & $2 \cdot 96$ & $11 \cdot 94$ & $12 \cdot 21$ \\
$\cdot 9$ & $2 \cdot 07$ & $11 \cdot 58$ & $11 \cdot 20$ \\
$4 \cdot 0$ & $1 \cdot 08$ & $5 \cdot 60$ & $8 \cdot 90$ \\
$\cdot 1$ & $\cdot 54$ & $4 \cdot 73$ & $6 \cdot 70$ \\
$\cdot 2$ & $\cdot 20$ & $2 \cdot 04$ & $5 \cdot 16$ \\
$\cdot 3$ & - & $\cdot 88$ & $3 \cdot 14$ \\
$\cdot 4$ & $\cdot 24$ & $\cdot 51$ & $1 \cdot 50$ \\
$\cdot 5$ & - & $\cdot 22$ & $\cdot 70$ \\
$\cdot 6$ & - & $\cdot 15$ & $\cdot 38$ \\
$\cdot 7$ & - & - & $\cdot 76$ \\
$\cdot 8$ & - & -15 & $\cdot 21$ \\
$\cdot 9$ & - & - & $\cdot 07$ \\
$5 \cdot 0$ & - & -08 & $\cdot 07$ \\
$\cdot 1$ & - & - & $\cdot 03$ \\
\hline & - & &
\end{tabular}

These figures stand out more clearly when expressed diagrammatically, as on the following page.

A feature brought out by the diagram is that, while the Ayrshire and Red Danish breeds contain a considerable number of cows giving milk over the 4 per cent. standard, few such cows are found in the Dutch breeds. Clearly the former breeds carry factors 


\section{QUANTITY}

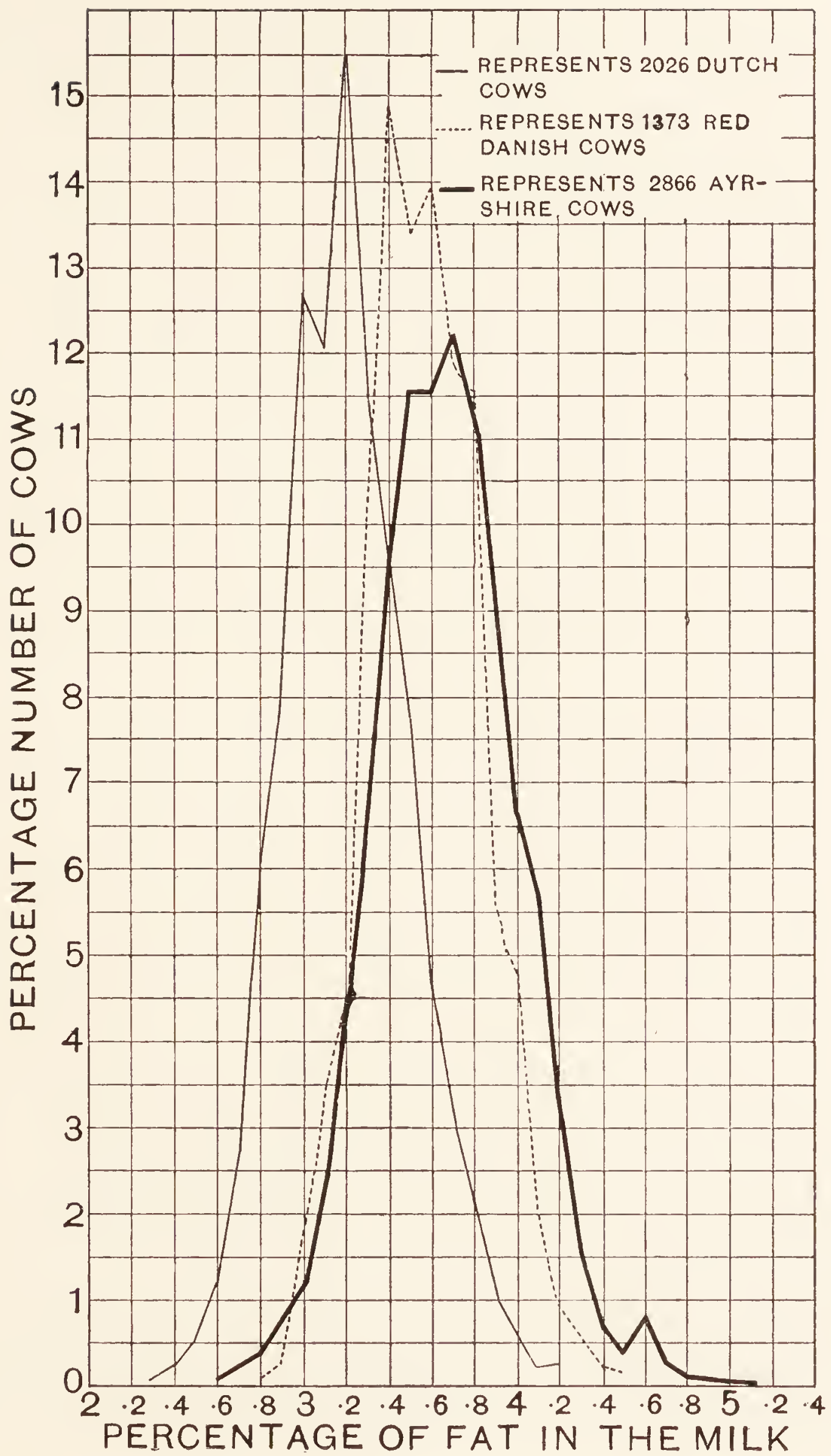




\section{A MANUAL OF MENDELISM}

for high quality which are not carried by the latter, and therefore the chances of improving Ayrshire or Red Danish cows' milk by operating within the breeds themselves are much greater than the chances of improving in a similar manner the milk of Dutch cows.

Milk records have been kept in Denmark for nearly half a century and, using the information so collected, the Danish farmers have been able to raise their cows' yields very substantially. Two sires, Taurus IV, born in 1894, and Lombjerge IV, born in 1897, are regarded as very important, and, in two volumes, "Tyreslagters Indfledelse paa Afkommets Ydelse"-volume i, Lombjerge IV and volume ii, Taurus IV-Mr. A. M. Christensen has shown in detail how the Red Danish breed has been influenced by these sires and their sons and grandsons.

The quantity and quality-where known-of the milk of the dams with which the sires were mated and of the daughters produced are given side by side, and from these it is possible to discover the improvements effected. The yield was improved by both lines of sires, more decidedly by the Lombjerge than by the Taurus line; but the quality, which was practically unaffected by the Lombjerge line, was raised by the Taurus line. The diagram on page 133, which shows the qualities of milk given by the cows with which the Taurus sires were mated and by their daughters, indicates the improvement of the daughters upon the dams. The average rise is from 3.56 per cent. in the dams to 3.75 in the daughters.

But an examination of the results in a few individual cases will show the steps by which the rise takes place. The diagrams on pages 131 and 133 suggest that cows fall 
into grades, of which the following are indicated: $3 \cdot 0$, $3 \cdot 2,3 \cdot 4,3 \cdot 6,3 \cdot 8$, and $4 \cdot 0$, and other data suggest that the grades continue on with similar gaps beyond $\mathbf{5}$ per cent. It has not been possible to follow this clue with precision, however ; but that there are grades and factors to produce them is obvious. We shall consider, first, a case in which the daughters were no better and,

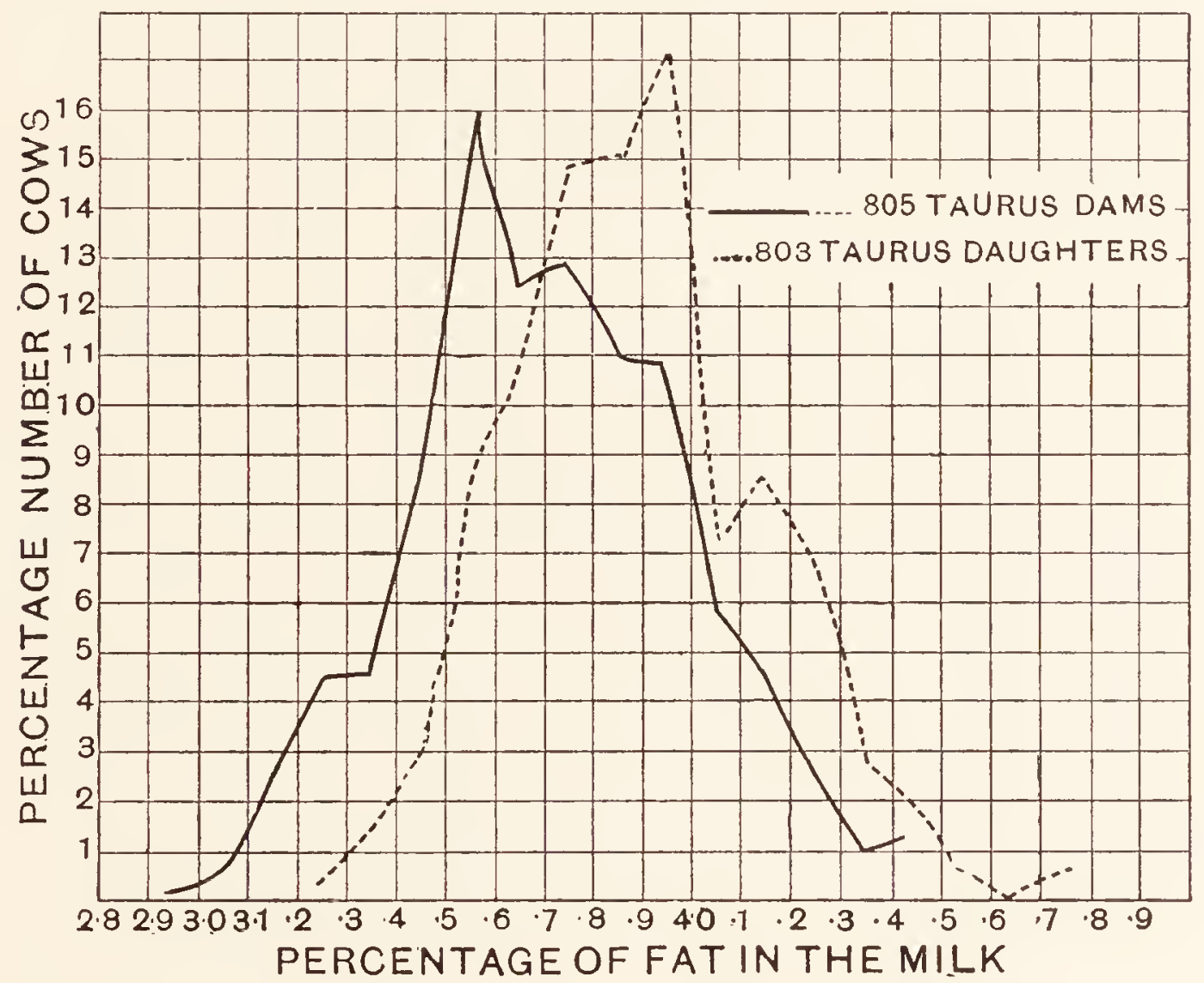

next, several in which the daughters were better and still better than the dams. In Mr. Christensen's volume on the Lombjerge sires, Lombjerge IV, the head of the line, is credited with 41 daughters; and, while the average quality of the dams' milk was 3.51 , that of the daughters was $3 \bullet 48$. The following diagram shows the quality of milk given by each cow and her daughter : the plotting being horizontal for the dams and perpen- 
dicular for the daughters. Thus the diagonal line of squares gives the dams' grades, the figures those of their daughters. If the indications of the previous diagrams be accepted, it would seem that Lombjerge carried factors which allowed his daughters to give milk down to about the $3 \cdot 2$ grade. The diagram indicates also that his daughters were better as their dams were better.

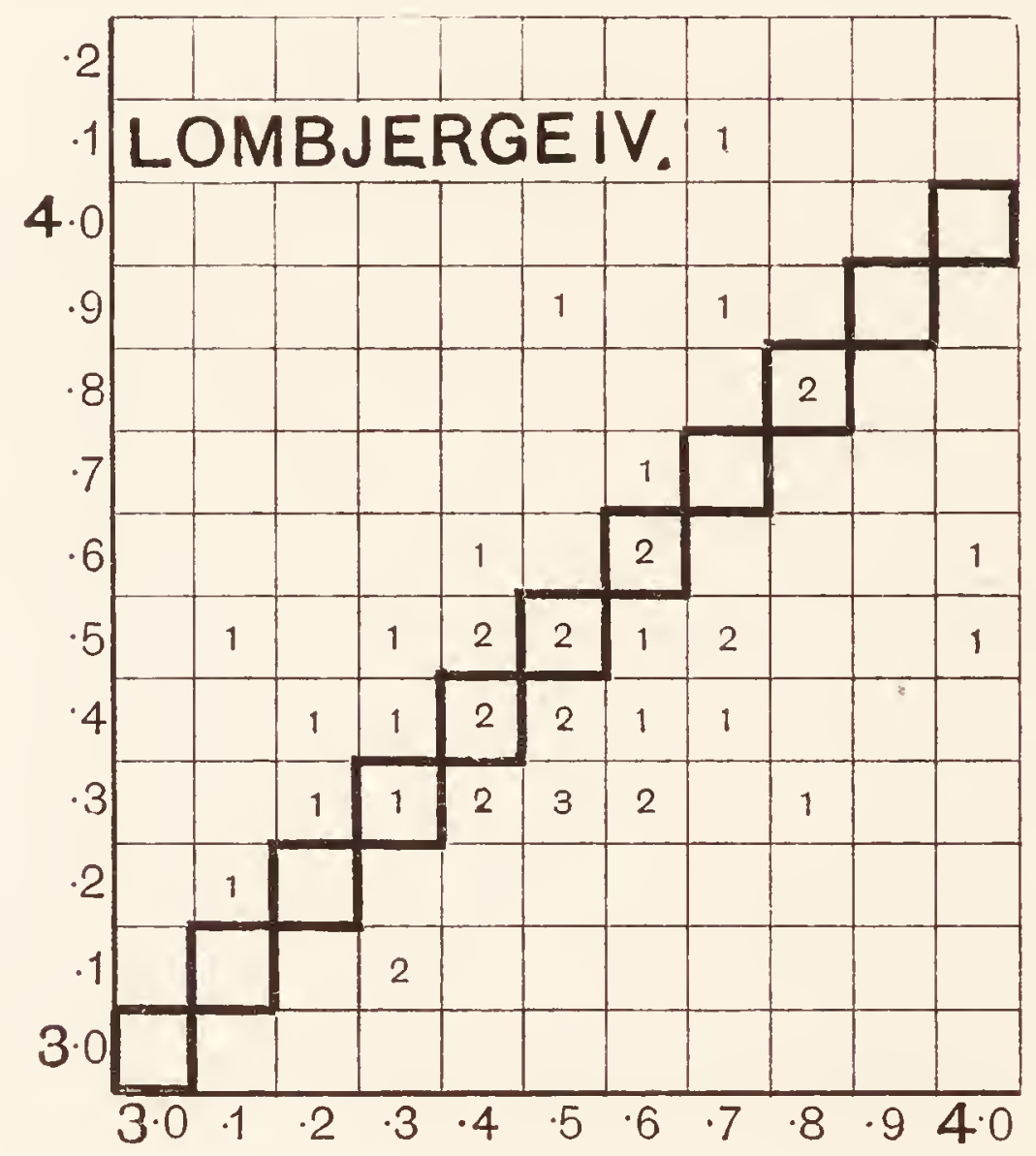

In Mr. Christensen's volume on the Taurus line of sires, Taurus IV, the head of the line, is credited with 47 daughters; and, while the average quality of their dams' milk was $3 \cdot 58$, that of the daughters was $3 \cdot 88$. In 32 cases the daughters were better than the dams; and, while several of the dams gave $3 \cdot 3$ per cent. milk and under, only one daughter fell to this point. Indeed, if the indications of the previous diagrams are to be 


\section{QUAN'TITY}

accepted, it would seem that no daughter of Taurus IV could fall below the $3 \cdot 4$ per cent. grade.

About the beginning of the present century it was observed in Denmark that the daughters of certain

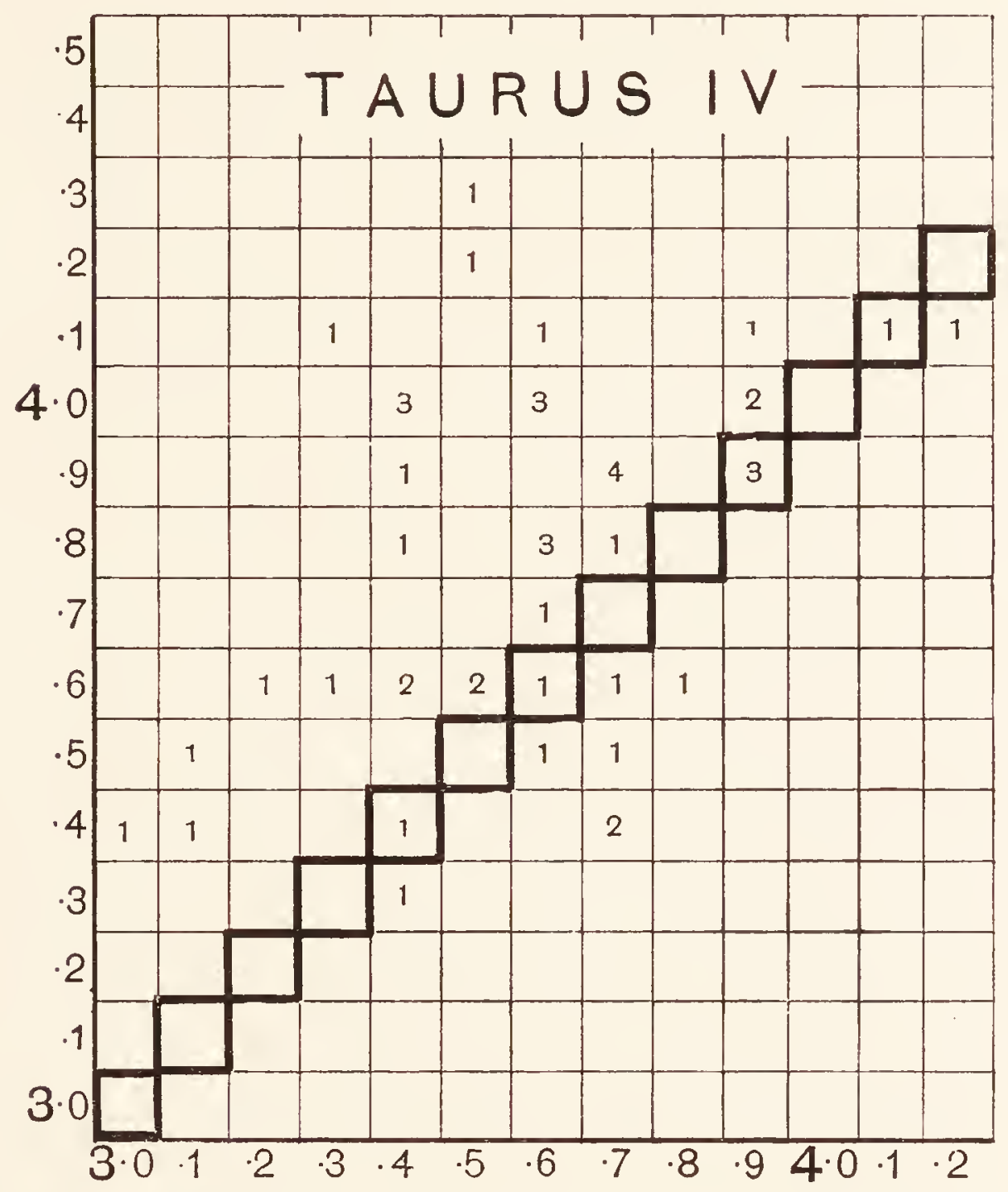

sires were an improvement upon their dams in the quality of their milk. The sires of such daughters came to be called "butter bulls." On learning this, Mr. Grut Hansen of Kollekolle near Copenhagen, who was already one of the most successful breeders of Red Danish cattle, determined to secure some of these "butter bulls" for use in his herd, and during the last ten years 
he has secured three in succession which had already been proved to be "butter bulls" by the daughters bred to them in other herds. The first of these was Dan, born in 1900, a son of Taurus IV and a cow called

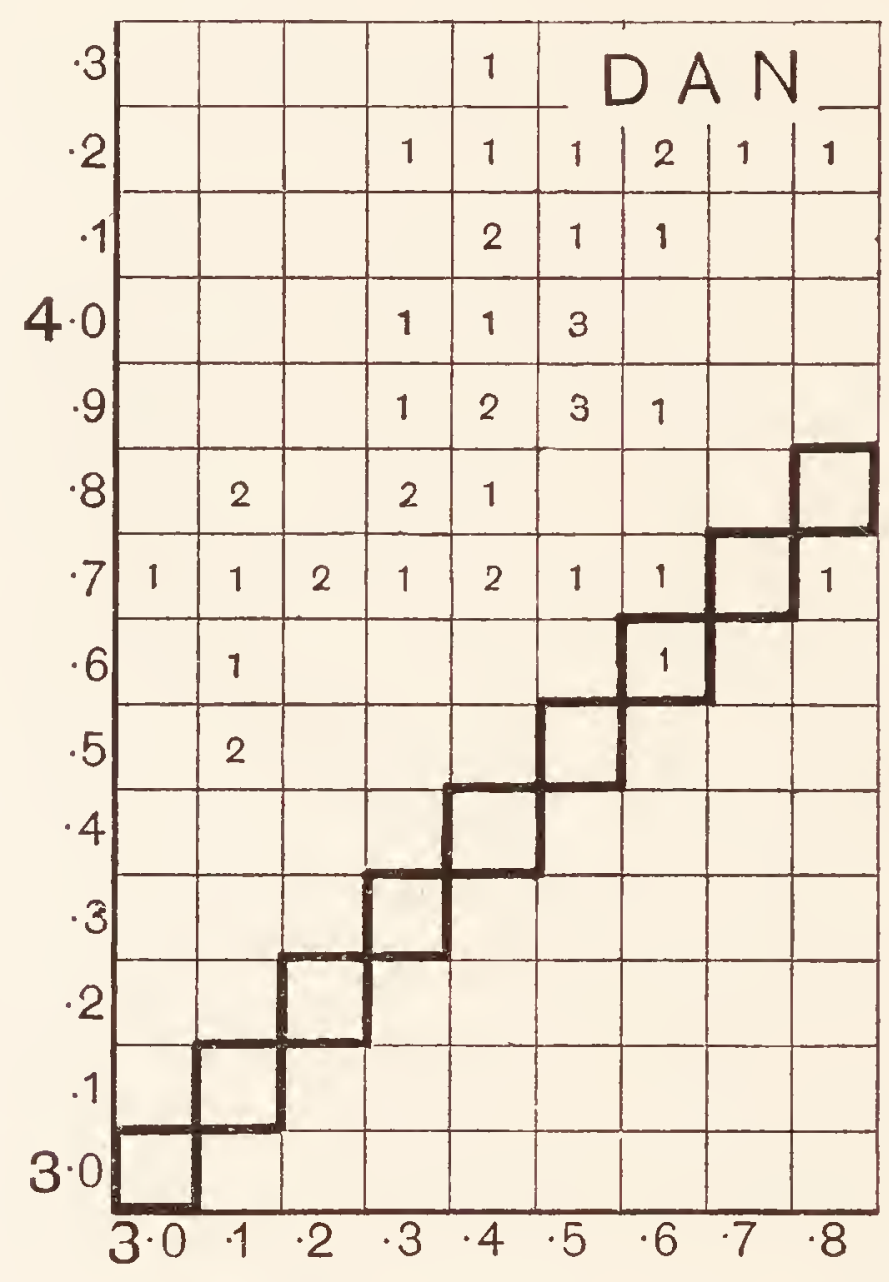

August III, whose milk over seven years was of the average quality of $4 \cdot 16$ per cent. Thus, like Professor Nilsson-Ehle's wheats, Dan was the progeny of parents which were above the average. The average quality of the milk of the cows with which Dan was mated was $3 \cdot 40$ while that of their daughters was $3 \cdot 89$. Thus Dan was even more effective than Taurus IV in getting daughters with milk of higher quality. If the indication of the previous diagrams be accepted, it would 
seem that none of Dan's daughters should fall below the $3 \cdot 6$ standard.

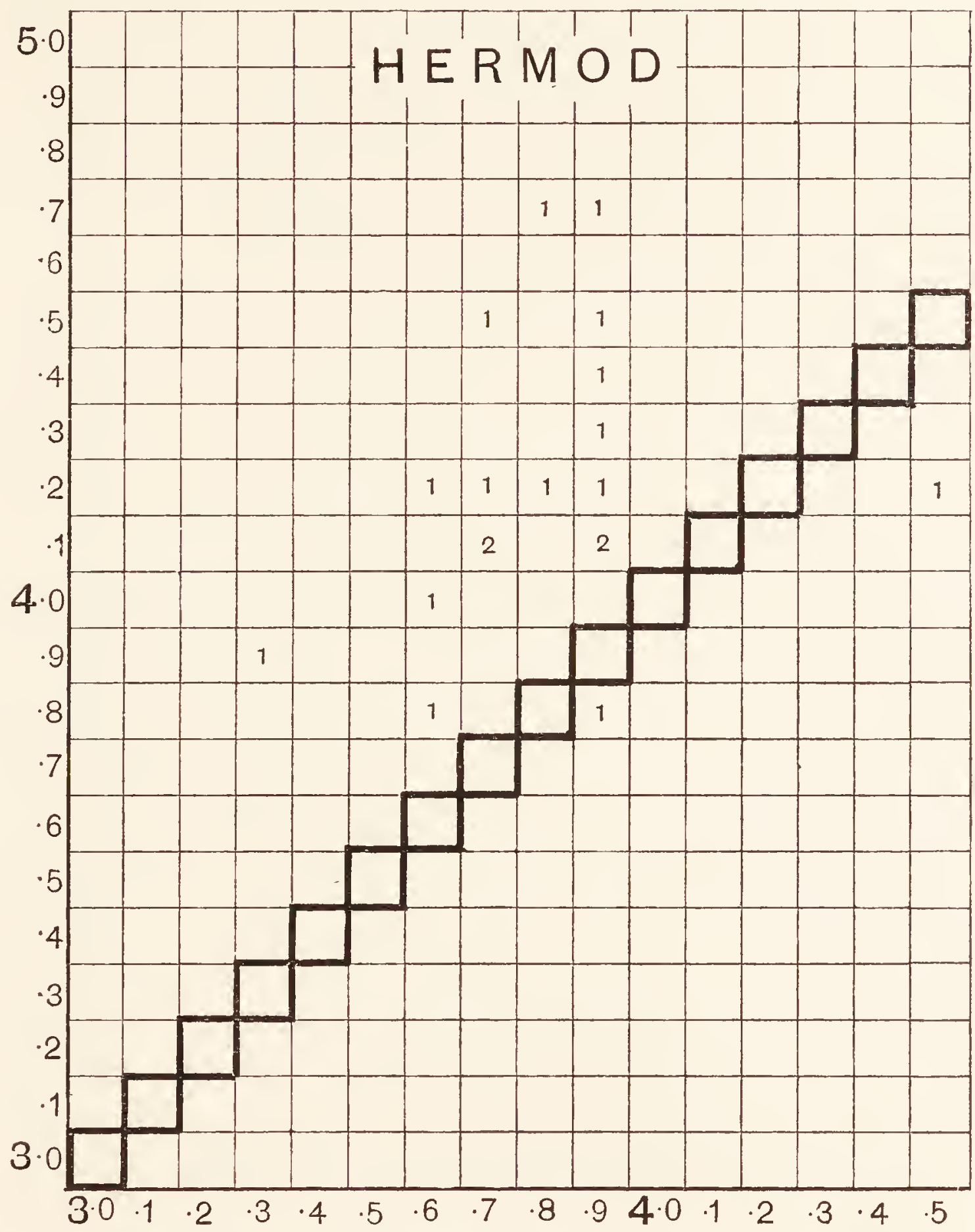

Dan's successor was Hermod, of whose daughters the records of only nineteen had been kept long enough to be quoted with confidence at the time this statement 
was written. The accompanying diagram indicates that Hermod is even a better sire than either Taurus IV or Dan, for he gets no daughters below the 3.8 grade. He was mated with better dams, of course, many of which were Dan's daughters, but very few could have been pure even for the factors for $3 \cdot 6$. The average of the dams with which Hermod was mated was $3 \cdot 80$, while the average of his daughters was $4 \cdot 21$.

After Hermod came Skjold, but, as yet, only eight of his daughters have long enough records to be relied upon with confidence. Since these confirm the previous results they may be set down, however. It will be seen that Skjold is another sire whose daughters do not fall below the 3.8 grade, although they do not rise to the grade to which Hermod's daughters rose.

Thus we have five sires, one of which threw daughters which on the average were no better while four threw daughters which were better than their dams. One feature is common to all five cases, namely, that as the parents are better the progeny are better; and not only so, but, as either parent rises in the scale of quality, the chances of their producing progeny higher in the scale increase while their chances of producing lower progeny decrease. Thus we have a phenomenon similar to that which was found occurring in Professor NilssonEhle's wheats, and it may be argued again that improvement is brought about by combining in certain individuals the different factors for high quality found in others and so expelling the factors for low quality. Whether the factors are related to each other as dominants and recessives or whether they produce intermediates is not disclosed. Most probably there are both kinds of pairs, but the fact that the four sires 
which raised so many daughters in the quality of their milk were very unlikely-judging from the run of the breed as a whole-to have carried factors as high as those carried by the best of their daughters may be

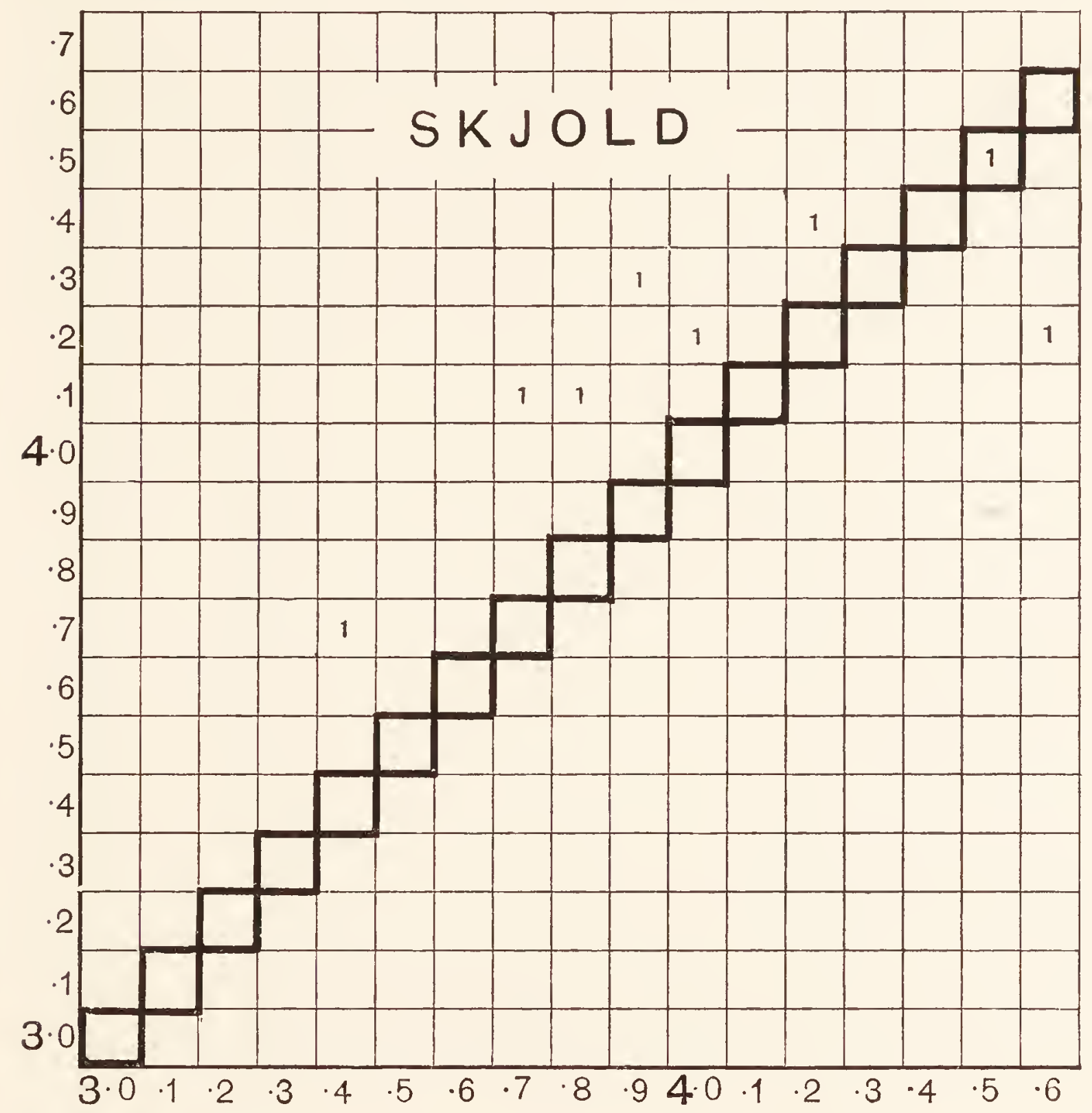

taken as evidence that some of the high quality factors at least are dominants.

In a volume published two years ago-" The Principles of Stock-breeding"-the writer of this volume expressed the opinion that there were two main factors 
having large effects with regard to the quality of milk, and probably a number of factors having smaller effects, and that the two main factors produced intermediates. In the light of the newer evidence just discussed, it is very doubtful whether this earlier opinion should stand. The earlier evidence was as follows: Count Ahlefeldt, of Tranekjaer, in the Danish island of Langeland, had a number of Red Danish cows crossed with a Jersey sire and their daughters crossed again with another Jersey sire. The qualities of milk yielded by the Red Danish cows and their half-bred daughters and three-quarter-bred granddaughters were as follows:

\begin{tabular}{|c|c|c|}
\hline Red Danish & Half-breds & Three-quarter-breds \\
\hline ? & $4 \cdot 50$ & $5 \cdot 41$ \\
\hline $3 \cdot 55$ & $4 \cdot 48$ & $4 \cdot 88$ \\
\hline $3 \cdot 58$ & $4 \cdot 63$ & $5 \cdot 15$ \\
\hline $3 \cdot 08$ & $4 \cdot 40$ & $4 \cdot 41$ \\
\hline $3 \cdot 38$ & $4 \cdot 20$ & $5 \cdot 02$ \\
\hline $3 \cdot 19$ & $4 \cdot 02$ & $4 \cdot 83$ \\
\hline $3 \cdot 41$ & $3 \cdot 85$ & $4 \cdot 52$ \\
\hline $3 \cdot 41$ & $4 \cdot 12$ & $4 \cdot 72$ \\
\hline $3 \cdot 44$ & $4 \cdot 26$ & $5 \cdot 66$ \\
\hline $3 \cdot 35$ & $3 \cdot 66$ & $4 \cdot 67$ \\
\hline $3 \cdot 15$ & $3 \cdot 85$ & $4 \cdot 55$ \\
\hline $3 \cdot 30$ & $3 \cdot 64$ & $4 \cdot 36$ \\
\hline $3 \cdot 33$ & $4 \cdot 02$ & $4 \cdot 55$ \\
\hline $3 \cdot 41$ & $4 \cdot 04$ & $4 \cdot 58$ \\
\hline $3 \cdot 07$ & $3 \cdot 52$ & $4 \cdot 66$ \\
\hline $3 \cdot 33$ & $4 \cdot 08$ & $4 \cdot 80$ \\
\hline
\end{tabular}

Average : 3.33

It was assumed that both the Jersey sires were 5 per cent. bulls, which is somewhere near the average 
of the best of the breed, and, with this assumption, it was evident that there was a high factor in the Jersey producing intermediates with a low factor in the Red Danish: the small fluctuations being attributed to the action of factors producing a much smaller rise or fall. It may be that there are two widely varying factors producing intermediates, but the evidence in support of this is less strong than that in support of factors producing the smaller differences which are clearly to be found in the Red Danish breed. Indeed it seems much more likely that Count Ahlefeldt's two Jersey sires carried several factors for high quality but did not carry them pure.

Some work has been done in connexion with milk yield in cows, but, as yet, it is little more than preliminary. Because of the economic importance of the subject, however, this preliminary work may be discussed, not without profit.

It was expected that milk should be inherited according to one or other of the Mendelian schemes, and evidence was sought in many directions. The earliest evidence of importance came from Denmark, and it indicated that there are three grades of cows giving, in round numbers, 500, 750, and 1000 gallons of milk during a normal lactation period. It also indicated that the middle grade is a Mendelian intermediate between the two extremes. At the same time considerable deviations from these yields were revealed, and it became necessary, first of all, to look into the causes of these, the chief of which were found to be $(a)$ age, $(b)$ date of calving, (c) lengths of the previous and the present lactations, $(d)$ recovery of "condition" before calving, and $(e)$ food, health, and general comfort. 
Briefly stated, the deviations due to these causes are, approximately, as follows :

(a) A cow does not come to her full yield till she has had four or five calves, that is, when she is about six years old. If the full normal yield be put at 100, then, for cows having their first calf when from 30 to 33 months old, the previous yields may be set down as : after the first calf 66 , second 80 , third 90 , fourth 97 . For cows having their first calves at an earlier age, the figures for the earlier lactations must be lowered slightly. From observations on 110 cows in Lord Rayleigh's herds, Mr. W. Gavin, of Trinity College, Cambridge, got the following figures: first calf $60^{\circ} 1$, second 80 , third 90 , fourth $95^{\circ} 6$, fifth $98 \cdot 7$, sixth 100 .

(b) A cow which calves in winter gives from 10 to 20 per cent. more milk than one which calves in summer. The extremes lie between October and February on the one hand and May and August on the other.

(c) The normal time between calves is twelve months. For one month extra between the last and the next calf, the yield for the lactation is increased from about 8 to 12 per cent., for two months extra by about 14 to 20 per cent. For a month short of the normal twelve between calves, the decrease is very variable, but may be put roughly at from 10 to 20 per cent.

(d) The yield of a cow in low condition before calving may be decreased thereby from 10 to 20 per cent. in the succeeding lactation period.

(e) The effects of poor feeding, discomfort, and illhealth cannot be stated, because of their great variation, and all data so affected must be neglected.

As with poultry, however, an observation was made by which a cow's yield can be predicted early in the 
lactation period, and, so, time can be gained and the effects of disturbing causes eliminated. The inspection of a large number of records showed that the daily yield rises to a maximum which is reached a few weeks after calving, and, if this maximum, as found on a smoothed-out yield-curve, be multiplied by 200 in the case of a cow calving in the middle of winter and by about 180 in that of another calving in the middle

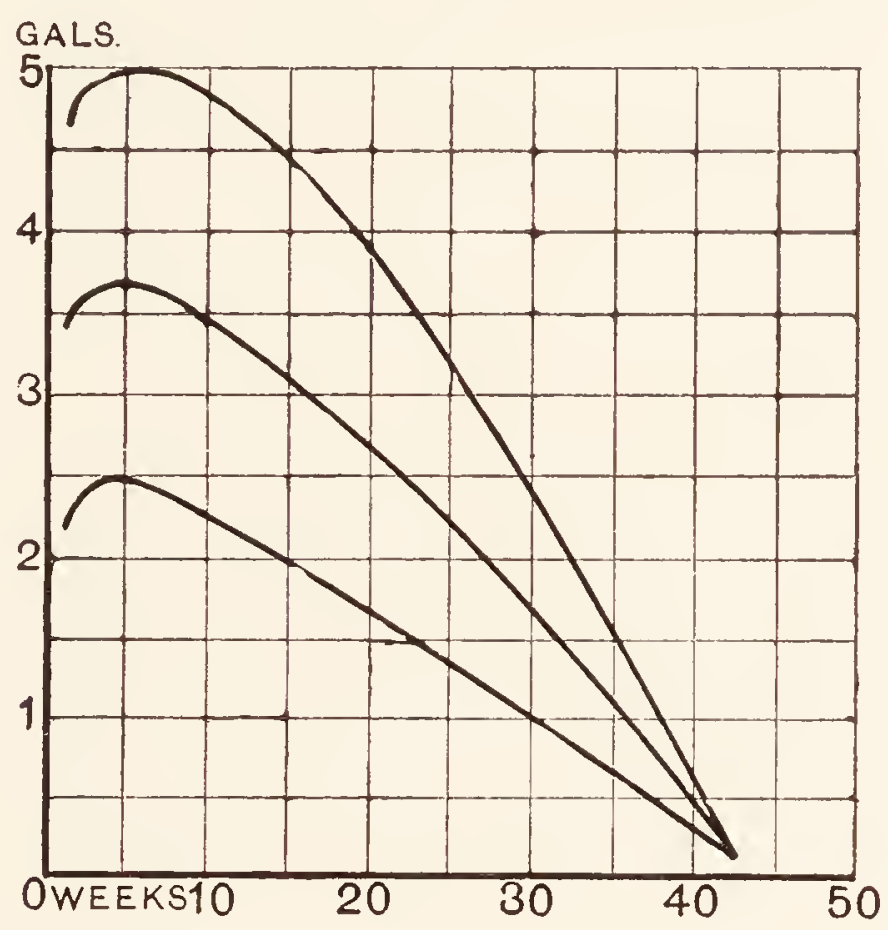

of summer, the normal yield for the lactation will be given. This result was also confirmed by Mr. Gavin, who found that what he called the "revised maximum" yield, that is the lowest yield maintained for three successive days when the cow is at her maximum-in the three cases, $50,50,50 ; 50,54,50$; and 50,52, 54; 50 is the revised maximum-should be multiplied by $\mathbf{1 9 5}$ for winter-calved cows and $\mathbf{1 8 7}$ for summer.

The above diagram consists of the smoothed-out curves of the daily yields of cows giving 1000, 750, and 500 gallons a year. 
As yet only one breeder with a herd large enough and records kept for a long enough time has been found. The records of his herd corroborate the Danish evidence. Sires were found having high-grade and medium-grade daughters, or medium and low grade, or of all three grades. The following table shows the grades which the daughters of five different sires fell into as judged by their maximum yields after their first calving :

Maximum Daily Yields 30 to $40 \mathrm{lb} .20$ to $30 \mathrm{lb} .13$ to $20 \mathrm{lb}$.

A's daughters

B's daughters

C's daughters

D's daughters

E's daughters
8
-
6
4
3
10

18

24

11

14

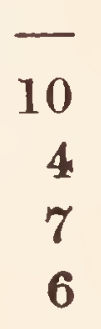

The headings " 30 to $40 \mathrm{lb}$." and so on indicate considerable fluctuations, caused no doubt by a number of factors having smaller effects which remain to be searched for in the future. 


\section{XI \\ ECONOMIC}

A generalization such as Mendel's attracts two different kinds of minds, the academic and the material. The former seeks to develop and amplify the generalization, inquires into the foundations upon which it rests, and endeavours to discover not only the very nature of the "materials" themselves but also the manner of their production and transmission. The latter is less interested in these "theoretical" problems, as he calls them, but accepts the generalization with its formulæ and asks how they can be used towards an increased production of material wealth. That the Mendelian formulie can be so used is now no longer in doubt. Pearl's and Nilsson-Ehle's results are proof sufficient. That the latter did not identify the actual factors for increased production and their individual effects may be a disappointment to the extreme academic mind, but the material mind is not to refuse Nilsson-Ehle's highly productive varieties on that account. A new and effective febrifuge or an antiseptic which acts upon the internal tissues though applied on the surface is not to be laid on one side till the physiologist or the bacteriologist discovers how it works. A child is not to be prevented reading the face of the clock till it understands the mechanism behind. 


\section{A MANUAL OF MENDELISM}

The possibilities of increasing the productivity of the vegetable world are beyond comprehension. The timbergrower; the planters of tea, coffee, and rubber; the producers of vegetable fibre; the growers of grain, roots, and forage; the raiser of sugar-bearing plants; the florist; the vegetable gardener and the pastoral farmer are all interested. The initial step is to combine in a single individual the different factors for yield already existing in other individuals. These factors may be for quicker and more energetic growth, for resistance to drought, frost, wind, or disease, for greater activity in one or more directions, as in seed, or leaf, or root production, and so on. If the hybrid is a plant reproducible by buds or shoots or suckers or in any way other than by seed, the new variety is already produced. Notable examples are the London plane which now adorns the streets of many European and American cities, the Huntingdon elm, the cricket-bat willow, the poplar of Metz, the Californian Paradox walnut, the loganberry, the Up-to-Date potato and many other recent varieties of the same species.

The present position with regard to grain crops might be taken as perhaps the most instructive. The average yield of wheat in Britain is about 32 bushels to the acre. It might be raised to 40 or even 50. For every day by which the life of a variety of wheat is shortened between seed-time and harvest, the wheatgrowing area in Canada reaches fifty or sixty miles farther northwards. A vigorous, early ripening and highly productive oat, together with a turnip having the same characters, might increase the returns from many a northern or high-lying farm in Britain and might even be the means of causing many a pasture- 
field to revert once again to the plough without the artificial and precarious stimulus of a protective duty.

But how are these new varieties to be produced? The way has been already shown by such workers as Patrick Shirreff and the staff at Svalöf in Sweden. There were other raisers of new varieties before Shirreff, but none so long persistent and none whose work illustrates better what can and what cannot be done without Mendel's law. Shirreff tells us how he began to raise new varieties on his farm in East Lothian: "When walking over a field of wheat on the farm of Mungoswells, in the county of Haddington, in the spring of 1819, a green, spreading plant attracted my notice, the crop then looking miserable from the effects of a severe winter ; and next day measures were taken to invigorate its growth by removing the surrounding vegetation and supplying manure to the roots. In the course of the summer several stalks were cut down by hares; but, notwithstanding this loss to the plant, sixty-three ears were gathered from it at harvest, yielding 2473 grains, which were dibbled in the following autumn at wide intervals. For the two succeeding seasons the accumulating produce was sown broadcast, and the fourth harvest of the original plant amounted to about $42 \mathrm{qr}$. of grain fit for seed; and proving to be $a_{\mathrm{s}}$ new variety, it was named Mungoswells wheat."

For thirty years Shirreff persisted in this work of selecting single plants in his own and his neighbours' fields and testing and accumulating stocks till he had given the world a large number of new varieties. Then came the tragedy. He began crossing, and, as we should now expect, his crosses did not breed true but were so variable that he became bewildered in the 


\section{A MANUAL OF MENDELISM}

multiplicity of their descendants. He thus inferentially refers to his lack of success with crosses and explains his success with single-ear selections: "My selections have chiefly been from natural sorts, which soon show their propensities, and often prove constant, having in all probability undergone reproduction before being selected. . . Sports may be regarded as the gift of nature to man." Shirreff was half a century too soon.

Fifty years later, Mendel's work having become known in the meantime, Nilsson-Ehle saw that the second generation, that is, the hybrids' progeny, contains all the types likely to result from the cross and that the descendants of every second-generation plant must be kept by themselves as a separate culture. Then the process of selection may begin: the most promising in yield and purity being retained, the others destroyed. The cultures retained are constantly " rogued" till the fifth generation, or later, if necessary, when the stock is usually large enough to be first tested for yield. In a year or two, field trials can be made, and a final judgment arrived at.

Nor is improvement in the animal world less necessary. The present position in the United Kingdom may be taken by way of example. She is regarded as the most successful of stock-breeding countries, for the reason that her horses for draught and speed, and her bullocks for beef, sheep for mutton, and pigs for pork are the best in the world. But, with the exception of the race-horse, which, through the three centuries of its history, has been selected upon race-course results, these animals excel in qualities which are judged by the eye and hand. With animals whose fitness for their purpose can be tested only by carefully collected 
statistics, her success has been no more than moderate. Dairy cattle are perhaps the most important example.

Breeds believed to give a large milk yield are spoken of as milk breeds, while breeds giving milk containing a large percentage of butter-fat are spoken of as butter breeds. In nearly every British breed, whether its reputation be for milk or butter or even beef, for no breed has the monopoly of any of these things, there are cows of full age capable of giving from 1000 to 1100 gallons of milk in a normal lactation; yet, even in the milk breeds, many cows give no more than 500 gallons, and it is doubtful whether, taking all ages together, the average for the whole is over this figure. In some breeds, if not in most, there are some cows giving milk containing over 5 per cent. of fat, yet the average for the country is only about $3 \cdot \%$, and even in the butter breeds the milk of many cows does not reach this average quality.

The work done in Denmark shows how this state of affairs might be altered and the wealth of the country so far as it proceeds from dairy cattle very nearly doubled. From 500 gallons at $3 \cdot 7$ per cent. to 900 gallons at 5 per cent. is a rise of 90 per cent. in milk and 150 per cent. in butter. The Danes' success starts with the careful and systematic recording of their cows' yields in both quality and quantity through every lactation. Thus their breeding stock are selected upon the actual performances of themselves or their parents instead of upon legends relating to their remote ancestors. Mr. Grut Hansen's success was made all the more easy by the fact that, in Denmark, many promising sires remain alive till their reproductive capacity can be determined. A sire's capacity can be determined as 


\section{A MANUAL OF MENDELISM}

his daughters come into profit when they are about three years old and he is about five. Few sires reach this age in Britain, and it is not a unique tragedy to discover a farmer with ten or twelve high-grade young cows and be told, on inquiring for their sire, that he has already "gone to the butcher" or "gone to the Argentine." 


\section{INDEX}

Absence of dominance, 58-69

Ahlefeldt, Count, experiments in crossing Red Danish and Jersey cattle, 140-141

Albinism, 52-53

Albino rabbits, $42-51$

Andalusian fowl, 59-62

Ayrshire cows, the quality of their milk, 129-131

Barrington, Miss, and Professor Karl Pearson on the colours of Shorthorn cattle, 65-67

data concerning Shorthorn cattle, 67

Bateson's and Punnett's cxperiments on fowls' combs, $30-32,54-57$

on Blue Andalusian fowl, 59-62

on sweet peas, 52, 107-110

Bruce, Robert, data concerning Shorthorn colours, 67

Bunsow, Robert, discovery of a pure-breeding grey Arab, 82

Butter fat in milk, 128-140

"Butter" bulls, 135

Castle, Professor W. E., experiments on rabbit colours, 38-41

colours of Barred Rock fowl, 94

Cattle colours, 53, 58-69, 70-75

Christensen, A. M., data concerning the inheritance of quality in Red Danish cows' milk, 132-135

Colours of cattle, $53,58-69,70-75$

Equidæ, 89

fowl, 53, 59-62, 91-97

horses, $58,74-89$

mice, 33-37

mules, 89

oat grains, 111-114

rabbits, 37-41, 42-51

wheat grains, 115-118

zebra hybrids, 89

Combs of fowl, 30-32, 54-57

Coupling, 90-110

Crampe, Dr., on horse colours, 75,77
Criteria for estimating annual egg yields, 99-100

milk yields, 142-143

Danish (Red) cows, the quality of their milk, 129-131, 140

farmers' efforts to improve their cattle, 128

(Red) and Jersey cattle crosses, 140-141

Darwinism and its influence on improvement of grain, 120

Donkey colours, 89

Dutch cows, the quality of their milk, 129-131

Economic considerations, 145-150

Egg laying, Dr. Pearl's experiments, 97-106

criteria for determining annual yields, 99

experience at the Maine Agricultural Experiment Station, 97

Errors in herd and stud book records, 64

Ewart, Professor Cossar, zebra hybrids, 89

Fowls' combs, 30-32, 54-57

colours, 53, 59-62, 91-97

egg yields, 97-106

Gavin, W., criteria for milk yiclds, 142,143

Hansen, Grut, experience in improving the quality of Red Danish cows' milk, 135-139, 149

Highland cattle colours, $73-74$

Horse colours, 58, 74-89

Hurst, C. C., experiments on rabbit colours, 37-38, 42-51

inheritance of colours in Thoroughbred horses, 76

Increasing production in plants and animals, 146

Inseparable effects, 30-41

Jersey cows, the quality of their milk, 140

Jersey and Red Danish crosscs, 140-141 
Jones, Rev. E. Lewis, experience with Campine fowl, 95-96

Le Couteur and the improvement of grain crops, 121

Maine Agricultural Experiment Station, experience in breeding egg-laying poultry, 97

Mass selection, 120

Mendel's experiments, 1-11 law, 12-21

work, observations and deductions from, 22-29

Mice, colours, 33-37

Milk, quality, 120-140, 149

quantity, 141-144, 149 records, 132

Murphy, Miss, criterion for estimating annual egg yields, 99-100

Nilsson-Ehle, Professor, experiments in crossing oats and wheats of different colours, 111-118

work in breeding higher yielding wheats, 121-128, 133

the bearing of his work on the application of Mendelism, 145,148

Nilsson, Professor Hjalmar and the Svalöf Seed-breeding Station, 121

Oat grains, the colours of, 111-114 Pearl, Dr. Raymond, the colours of Barred Rock and Indian Game fowl, 93

criterion for annual egg yields, 99

experiments on the inheritance of egg laying, 97-106

the bearing of his work on the application of Mendelism, $14.5,148$

Polygamous factors, 70-89

Quality in milk, 128-140

Quantity, 119-144

in milk, 141-144
Rabbit colours, 37-41, 42-51

Red Danish cows, the quality of their milk, 129-131, 140

Resistance of wheat to winter, lodging and rust, 124-126

Reversions, 58

Sex and hybridism, 90-107

Selection, methods of, 120-121

Shirreff, Patrick, selecting improved varietics of grain, 121

expericnce with crosses, 147

Shorthorn cattle colours, 63-69

Similar effects, 111-118

Single ear selections, 121

Spillman, W. J., hypothesis as to the female sex in fowl, 92

Suppressed effects, 42-57

Svalöf Seed-breeding Station, 111, 119,147

Tillering, 126

Wentworth, Professor E. N., data concerning Shorthorn colours, 67

hypothesis as to Shorthorn colours, 68

Walther, Dr., data concerning horse colours, 76, 77-79, 82

Welinder, Birger, and the Svalöf Seed Association, 119

Wheat, colours of grains, 114-118 yields, 122-128

resistance to winter, lodging and rust, 125

White cattle, 62-69

"White" cattle, 53, 63

White fowl, 53

"White" fowl, 53

Wilckens, Dr. M., on horse colours, 75

Winter "hard" and winter "soft" wheats, 123

Yields, eggs, 97-106 milk, 141-144, 149 wheat, 119-128, 146

Zebra hybrids, 89

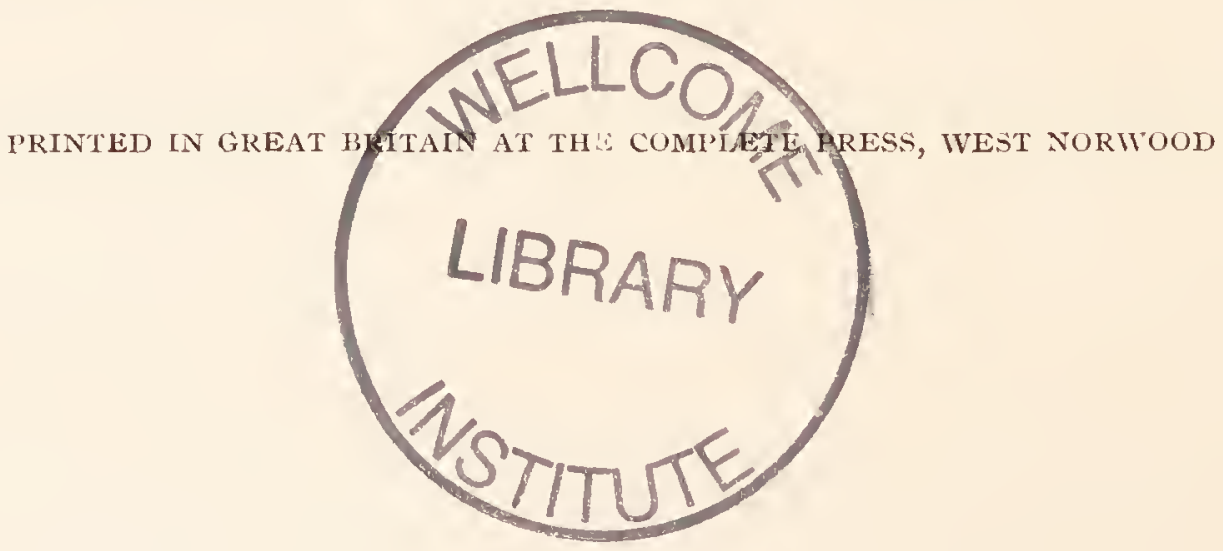





